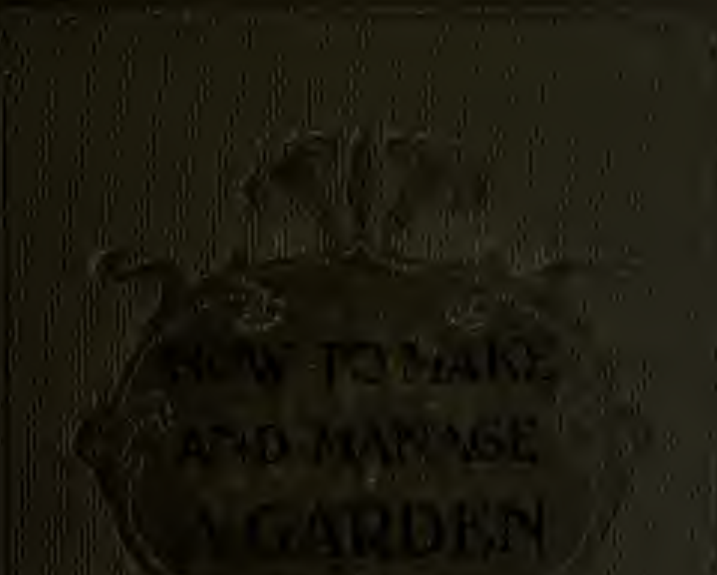

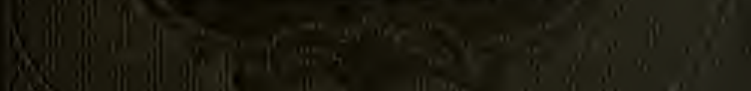
Pege

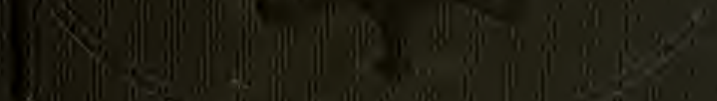

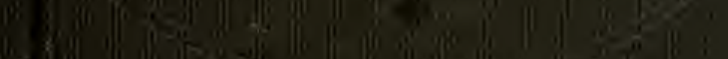

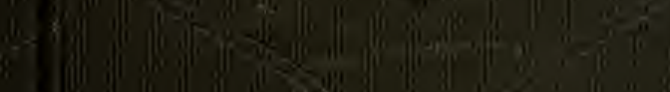

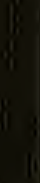

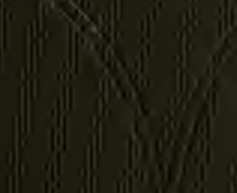

1.

1

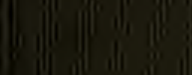

|

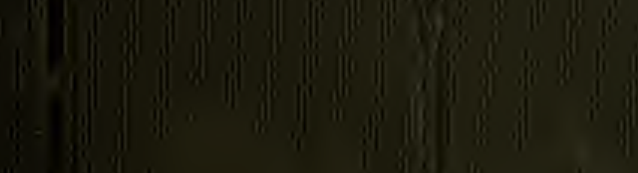

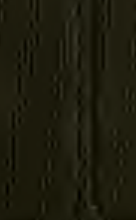

a) 

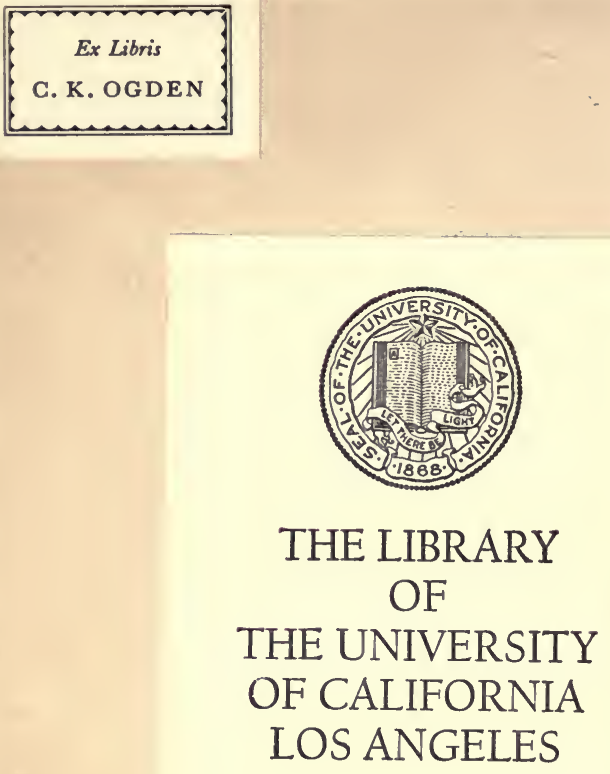


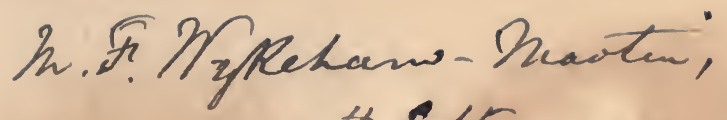

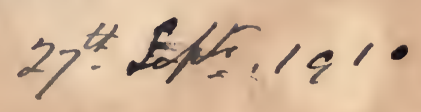

Wolming Librey 

How to make and manage a Garden 


\section{BOOKS THAT EVERY ONE WANTS}

Cloth, price Is. each, or Is. 2d. post-free

To be obtained at all

Booksellers, or from the Book Publisher,

17 Henrietta Street, W.C.

Cricket. With Contributions by K. S. Ranjitsinhji, C. B. Fry, G. L. Jessop, C. L. TOWNSEND, G. BRANN, \&c. Edited by G. L. JESSOP.

Swimming. By Montagu A. Holbein, the famous Cross-Channel Swimmer. With numerous Illustrations.

Training for Athletics and General Health. By HarRv ANDREws (Crystal Palace Trainer). The author has trained such well-known athletes as M. A. Holbein, F. Shorland, A. E. Walters, J. Butler, A. Shrubb, A. A. Chase, \&c. \&c.

How to Take and Fake Photographs. By Clive Holland, the eminent Amateur Expert in Photography. With numerous Illustrations.

Practice Strokes at Billiards. Giving examples from the actual match play of Roberts, Dawson, Peall, Mitchell, Stevenson, Spiller, and other leading Professional Players, with their method of scoring therefrom. By F. M. Hotine, Editor of Modern Billiards, \&c. With over roo Diagrams.

Etiquette for Men. By F. V. Howard. This volume gives in a simple style full and accurate directions for the due observance of Modern Etiquette for Men.

Handwriting as an Index to Char= acter. A Popular Guide to Graphology. By Prof, P. R. S. Fol1, Graphologist. With many Illustrations.

Walking. A Handbook for Pedestrians. By C. LANG NrIL. With Contributions by wellknown Pedestrians.

How Shall I Word It? A Complete Letter-writer for Men and Women on all subjects. By One of The Aristocract.

How and What to Dance. By W. LAMB, President of the British Association of Teachers of Dancing.

Small Gardens and How to Make the Most of Them. By Violet BIDDLE. This handbook teems with hints and wrinkles of the utmost importance to Amateur Gardeners.

Roses and How to Grow Them. By VIOL.BT BIDDLE, Author of "Small Gardens and How to Make the Most of Them."

Poultry Keeping, and How to Make it Pay. By F. E. WiLson, contributor to Poultry, \&c.

LONDON : C. ARTHUR PEARSON, LTD. 


\title{
How to make and manage a Garden
}

\author{
by \\ William F. Rowles \\ Author of "Greenhouses, How to Make and \\ Manage Them" \\ ,
}

With 104 Illustrations

London

C. Arthur Pearson, Ltd.

Henrietta Street

1905 
BY ROYAL WARRANT.

Manufacturers of Horticultural Machinery to His Majesty KING EDWARD VII.
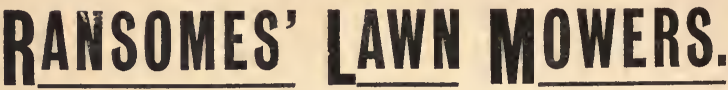

THE BEST IN THE WORLD.

Royal Botanic Soclety, 7904, Gold Medal. R.A.S.E., London, 1904, Silver Medal.

All Machines sent

Carriage Paid

on a

Month's Free Trial.

\section{s'}

With Chain or Wheel Gearing.

Elegant

and

Efrective.

\section{RANSOMES' "PATENT AUTOMATON,"}

THE BEST GENERAL PURPOSE MACHINES,

Having Important Improvements possessed by no other Machines.

8 in. to 24 in. wide.

\section{RANSOMES” "AUTOMATON MINOR."}

A new, light, Roller Machine, similar to the above but cheaper.

10,12 , and $14 \mathrm{in}$. wide.

RANSOMES" "ANGLO-PARIS" AND "LION."

The best light Machines.

Suitable for Small Gardens and for Ladies' and Amateurs' use.

"ANGLO-PARIS," 6 in. to 20 in. wide.

"LION," 9 in. to 15 in. wide.

\section{RANSOMES' "EMPIRE" AND "EMPIRE MAJOR."}

New side-wheel Machines of the highest order.

"EMPIRE," $10 \mathrm{in.}$ to $16 \mathrm{in.}$ wide.

"EMPIRE MAJOR," 17 in. to 21 in. wide.

\section{RANSOMES' "HORSE AND PONY" MOWERS.}

For large Lawns, Cricket Grounds, \&c.

New Designs, New Adjustments, and New Patent Spring Handles. $26 \mathrm{in.}$ to $48 \mathrm{in.}$ wide.

RANSOMES' MOTOR LAWN MOWERS IN VARIOUS SIZES. As supplied to H.M. The KYng, Duke of Norfolk, Duke of Westminster, \&c., \&c. 


\section{$S B$ \\ 453 \\ Rrah \\ P R E F A C E}

MANY words are not necessary in introducing this work to the public. The title itself will suggest its scope, and I leave it entirely in the hands of readers to judge of its merits.

One matter which I deem to merit reiteration, although it will be found many times in the book, is the advice to dig deeply and cultivate thoroughly. The one great thing in dealing with soil is to dig deeply. Only by this means can the full dividend be got from the outlay of labour. It may be stated as an absolute fact that no scientist and no cultivator can realise what power there is in the soil. Whereever deep digging is properly practised it invariably produces not only good but excellent results, such as will bear the strictest investigation as to finance.

It may be repeated here, for it needs to be well driven home, that there is no unfertile land. Those lands which at present are looked upon with great disfavour are rich in fertility, and it requires merely plenty of intelligent labour to be expended to improve them.

No soil that has been properly cultivated has ever yet become exhausted, for Nature works in a cycle, and as everything comes from the land, so everything must return 


\section{Preface}

to it. Man's business in cultivating the soil is to encourage, follow, and assist Nature in her infallible methods.

If in any way I shall have added to the number of amateur gardeners, or have helped them in their pursuit after pleasure and profit, then I shall take to myself the proud title of benefactor.

WILLIAM F. ROWLES. 


\section{CONTENTS}

CHAP.

I. CHOOSING THE SITE . . . . . II

II. FORMATION OF A VEGETABLE GARDEN • . 2 I

III. THE CULTURE OF VEGETABLES * * * 39

IV. FORMATION OF A FLOWER GARDEN • • 49

V. LIST OF FLOWERING PLANTS . . . . 62

VI. ARRANGEMENT OF A PLEASURE GARDEN • 66

V1I. ARRANGEMENT OF A FRUIT GARDEN • • 75

VIII. VARIETIES OF FRUIT . . . . . 80

IX. MAKING OF PATHS . . . . . . 83

X. MAKING A LAWN

XI. THE MAKING OF BEDS AND BORDERS • • 99

XII. FORMING A ROCKERY • • . • . IO3

XIII. GREENHOUSE CONSTRUCTION . . . . IIO

XIV. DRAINAGE AND WATER-SUPPLY • • • II

XV. HOW TO BRING LAND UNDER TILTH . . I27

XVI. RAISING STOCK BY PROPAGATION . . . ${ }_{3} 6$

XVII. PURCHASING STOCK . • • . $\quad$ I 45

XVIII. PLANTING AND BEDDING $\quad \cdot \quad \cdot \quad$ • $\quad$ I49 


\section{Contents}

CHAP.

PAGE

XIX. SUPPLY OF TOOLS, ETC. .

158

XX. ROTATION OF CROPS

163

XXI. ERADICATION OF WEEDS

- 165

XXII. PROTECTION FOR THE CROPS.

69

XXIII. TRAINING, PRUNING, ETC.

I 76

XXIV. CARE OF A GREENHOUSE

183

XXV. A GARDEN CALENDAR

I9I 


\section{LIST OF ILLUSTRATIONS}

Section of a Brick Wall . . . . . 23

Good and Bad Arrangement of Paths - . 30

Paths for Irregular Shaped Ground • . 3 I

Arrangement of Fruit Trees . . • . 35

Designs for Flower Beds . . . . 50, 51

Plan of Box and Gravel . . . . . 52

The Grass Plot . . . . . . . . 54

Borders and Paths . . . . . . . 55

Border with Straight Path . . . 56

Pillars and Pergolas. . . . . . 57

Plans of Rose Gardens . . . . . 59,60

Making a Terrace . . . . . . . 68

Arrangement OF SHrubs . . . . . 69

PATHS . . . . . . . . . $7 \mathbf{I}$

Rock Garden . . . . . . . 73

Fruit and Vegetables . . . . . 76

MiXed FRUit. . . . . . . . 77

Villa Garden . . . . . . . . 81

WINDING WALKS . . . . . . . 84

To Make WaLKS •.$\quad$. $\quad . \quad$. 89

LeVelling a Lawn • • • • • • 93

Tennis Courts and Croquet Lawn . . . 97

DESIGNS FOR Flower BEDS . . . . . 100 


\section{List of Illustrations}

How to Make a Rockery . . . . 105-107 GREENHOUSES . . . . . . . III Plans of Greenhouse. . . . . . . 114 Distribution of Pipes . . . . . . . II6 Plan for Draining Land . . . . . I 21 Plan for Digging Ground. . . . 129 A Trench for Cuttings . . . . . 142

A Bud Cutting . $\quad . \quad . \quad . \quad$. $\quad . \quad$. 142 Trees Grown in an Orchard . . . . ${ }^{2} 5^{2}$ Method of Planting Trees . . . . 152 Plans of Carpet Bedding . . . . . 154 Plans of Summer Bedding . . . . . . 555 Plan of Grouping . . . . . . 156 Shaping a Tree. . . . . . 177,178 


\section{How to make $\varnothing^{\circ}$ manage a Garden}

\section{CHAPTER I}

\section{CHOOSING THE SITE}

THE title of this book would seem to include the whole range of gardening, but it is not the author's intention to go into the detailed culture of the many plants rendering a garden ornamental and useful, but rather to point out the general laws which govern the making and management of a garden.

\section{Locality.}

Many readers will already own a garden, but as there are undoubtedly others who intend to take possession, and wish to start on the most advanced principles of economy, the considerations which should actuate and govern their choice had better be fully stated. Unfortunately for the imparter of knowledge, there are no rules in gardening which are not governed by an overwhelming mass of exceptions. The laws which may lead to success in one part of the country might bring failure in another; which 


\section{How to manage a Garden}

plainly shows that no principle can be laid down for all localities with unerring exactitude as in other trades. A joiner may erect a wardrobe for Penzance in precisely the same way as if it were intended for Edinburgh, but the gardener who wishes to grow grapes in both districts cannot adhere to the self-same programme, but has two separate and widely different problems to grapple with. Even in the two adjoining counties, Devon and Cornwall, the same horticultural knowledge will not suffice without modification; and cases could be pointed out where adjoining fields could not be successfully cultivated by precisely the same methods. There are in fact so many governing factors, operating with helpful or baneful influence on plants, that it is necessary to know, not so much what the plant requires, as how best to fit in those requirements with the governing elements. The fickleness of horticulture possibly has its advantages in alluring its devotees into an intense interest, and making success even more richly prized. Something of this resemblance must have been perceived by Councillor W. Coutts, of Aberdeen, who is reported to have advised unmarried ladies to take unto themselves gardeners as husbands, for "he felt that a man who loved flowers would surely love his wife."

If the amateur is able to make his choice of locality, and that choice is to be governed solely by his gardening desires, he should subject himself to a process of minute self-examination as to what feature of gardening his tastes incline to, and he will then the more easily discover where his efforts in that particular direction are most likely to prove successful. If, for instance, he is attracted by the 


\section{Choosing the Site}

beauty of hot-house plants, and desires to make them a speciality, it is evident that the cost of production would be higher in a cold district than in a warm one, owing to the larger requirement in fuel. His tastes, again, may tend towards a love of conifers, and he would then be illadvised to attempt their culture in a smoke-laden district; for if direct failure were not the outcome, his specimens would be by no means attractive, and a struggle for supremacy between a conifer and an adverse climatic environment is really a heart-rending scene.

To choose a site, then, with all due regard to making easy the path of success, and rendering the expenses as light as possible, we have to consider the climatic conditions, the proximity of large towns, the quality and character of the soil, the aspect and shelter, and the size of the holding-which latter, of course, is largely influenced by the means and tastes of the intending settler. A few words under each of these headings may perhaps lead to their being more carefully considered, and disappointment rendered the more unlikely.

\section{Environment.}

We hear so much nowadays of the powers of environment, and so much has been penned on the subject by writers taking different points of view, that the reader seeking for literary divertisement will perhaps weary of finding it mentioned in this book. If, as is now generally admitted, a man's actions are governed and his character moulded by environment, how much more so must be that of the plant; for no matter how strong the heredity of 


\section{How to manage a Garden}

the plant, it cannot grow and luxuriate in adverse surroundings. To discard the philosophical and turn to the practical side of the question, we know that the beauty of a garden (all other things being equal) increases as the distance from manufacturing towns is lengthened. Perhaps not all readers will have had opportunity for observing the force of this great truth, though all who have the faintest knowledge of plant life must admit the plausibility of the argument. The matter is, however, better explained by illustration.

For plant culture of any description the surroundings of Manchester are anything but ideal. Coniferous trees and shrubs are seldom seen, whilst even the sturdier rhododendron and accommodating laurel are painfully disfigured by the great prevalence of solid deposits of all sorts of impurities. To watch the thick black smoke issuing from the chimney, and see it wending its sooty way towards a garden is a sickening sight, but one which is only too powerfully real. All plants dread and resent this unnatural treatment, for the unchecked prevalence of which our local authorities are largely to blame; whilst some plants can make no headway at all or give up the struggle, and slowly retire into oblivion or on the rubbish heap. The Manchester district is said by many to be more injurious to plant life than the surroundings of London, and experiments made by Sir William Thistleton Dyer show that during a fog at Chelsea six tons of solid matter were deposited on a square mile, and included matters far more injurious in their chemical action than soot. By this we infer, and experience of the results teaches us, that manufacture and successful gardening 


\section{Choosing the Site}

must, in the present state of our laws and our methods, be separated by many miles. In the district of Edinburgh, which, happily for gardeners, boasts of few manufactories of the dirt-depositing type, coniferous plants grow well, as a stroll through the Royal Botanic Gardens will abundantly testify. Not a little also of the beauty of the world-famed gardens in Princes Street is due to this favourable state of affairs.

There is also to be considered the question of proximity to the coast. This has both its advantages and disadvantages, and were advice to be given explicitly, it would be, to be fairly near the coast, but yet a few miles off. Exposure to the sea often means bleakness, especially on the East Coast, a wind from which quarter is not relished by animal or plant; and the soft sea spray which is brought inland by a strong wind is inimical to the welfare of some plants. This, however, being a question to be decided on by individual tastes, will not require to be enlarged on.

What, however, is still more important with regard to the economic working of the establishment is the facilities for transit of tools, stock, manure, \&c. It is a fact well known to small growers in the country, that it is often most difficult to procure good manure in sufficient quantity and at a reasonable price. If the locality is known to be afflicted with this distress, it had better be sedulously avoided; for British land requires ample manure and thorough tillage before it will part with its fertility. The nearer, then, to the station the less will be the cost of carriage of any required material, and the greater the ease with which surplus stock can be disposed of.

Another point meriting much attention is the quantity 


\section{How to manage a Garden}

and character of the water-supply. There is at the present time much land in various parts of the country which would grow abundant crops but for shortage in the water-supply. In many cases it is but true to add that water could be procured were the necessary outlay forthcoming; but there is, nevertheless, much land which cannot be made selfsupporting in the matter of water, and unless the owner goes to great expense to obtain water from a distance, or the local authorities find, after the usual volume of correspondence, that the duty really devolves on them, the difficulty of gardening on the site will remain. If a good running stream be near at hand, the installation of a ram will be the most effective method of dealing with the difficulty. As, however, the question of water-supply will be fully dealt with in another chapter, we simply point to the necessity of including this item in the calculations whilst choosing a site.

\section{The Soil.}

Another factor, which should perhaps loom still more largely before the mind of the person choosing a site, is the character of the soil. Unless the labour of digging and trenching is intensely enjoyed, and time is of but secondary importance, I should certainly not advise that a very heavy soil be chosen. To say that a heavy soil requires twice the amount of labour to bring it into a state suitable for cropping that would be necessary for a light soil is no exaggeration. The assertion errs rather on the side of mildness. Only those who have performed the work of breaking up a clay soil, and forcing it to yield 


\section{Choosing the Site}

to the plant an abundance of nutrition, can thoroughly appreciate the enormity of the task. The reward, however, of seeing a splendid crop gained against fearful odds is highly prized, for it reflects at once the ability, the intelligence, and the patient perseverance with which British workmen will strive towards their ideal of perfection.

My remarks should not lead readers to think that I incline to the belief that a light soil is an ideal one. Nothing is further from my opinion. I wish, however, to emphasise the fact that a heavy soil means an increased expenditure in time and labour, and as those not fully acquainted with the cost of successful tillage are inclined, through want of knowledge, to treat the land in a manner opposed to good culture, it is far better for them to choose a light soil, where the possibility of error is considerably diminished. Personally I should choose a land, when possible, that was midway between the extremes, with a leaning rather towards heaviness. A strong soil, I am fully aware, is more richly endowed with plant food, and if thoroughly tilled, and all waste matter returned to it, will grow splendid crops for years without the addition of animal manures. But, would the amateur treat it properly? There's the rub. I do not accuse him of culpable ignorance, for the necessary knowledge and practical demonstration is not always within his grasp. At the present moment I can view a plot of land which has on it some useful specimens of vegetables, some of which will in due course grace the exhibition table; but notwithstanding that no animal manure has been put there for quite six years, the tiller has gained many prizes 


\section{How to manage a Garden}

in open competition, and, after catering for his own wants, has had a useful surplus for sale. The secret to all this is deep and thorough digging, and returning to the soil all those parts of the produce not required for food. Well would it be for Britain were such an example multiplied ten thousand times.

It may seem a curious statement, but it is nevertheless a fact, that the best time to view land which you propose to buy or lease is on a wet day, for then you can the better discover its true character. On a fine day the land may, to a superficial observer, appear crumbling, mellow, and in every way desirable, whereas a few hours' rain would convert it into a mud-pool. In wet weather its good qualities cannot be so easily exaggerated. Better still, however, is it to view the spot on both a wet and a fine day, and to take with you a skilful judge of the growing capacities of land, and let him view a spit of the soil and of the subsoil, not in one, but in various parts. An experienced man will also base his judgment of what is approximately the standard of productiveness on the character of the crops, herbage, or weeds. Further on in this work will be found practical information, founded on experience, of the method of treating different soils in bringing them into preparation for lawns, shrubs, fruit, flowers, and vegetables, for each of which the preliminaries are somewhat different.

\section{Aspect and Shelter.}

The aspect of a plot often makes a great difference in the results obtained. On an exposed hillside facing east 


\section{Choosing the Site}

we can hardly expect success equal to that which would obtain were the exposure to the south, whilst a slope from the south, or to the south, though less noticeable, does make a difference to the growth in that each plant casts a longer shadow, and each receives the rays of the sun more obliquely when the slope is to the north. The best position that could be obtained for gardening in general is a gentle slope towards the south, with sufficient shelter, especially from the north and the east. As, however, this ideal position is not often easily procured, it is evident that the nearest approach to it should be sought for. The amount of shelter may be said to practically make the spot, and as there are few instances where Nature is so kind as to leave a hill to keep off the adverse winds, or a wood to effectively break them, it often becomes a necessity for us to make our own shelter. In this respect likewise we have to consider the size of the place, for it would obviously be unwise to plant tall trees such as larches or poplars round a small garden, and thus take away not only the adverse winds, but likewise a considerable amount of the best morning sunshine. In a small garden a good hedge will often keep off sufficient of the wind, and the shadow cast will not be too great. A privet hedge is about the quickest in growth, but for general purposes it is not the best. What may probably be considered the best for appearances, usefulness, and rarity, is the common holly; but it is likewise very slow in growth. Where the garden is large and some higher shelter is required, larch, poplar, and spruce will be found useful if planted some distance off, so that their shadow will not interfere with the growth of other subjects. It will, of course, be generally admitted 


\section{How to manage a Garden}

that where shelter of any kind already exists, the expense of putting any up is thereby saved to the ingoer; and before it is decided to plant shelter trees, it is better to look well ahead and see that you do not plant what will probably, owing to the terms of your lease or other circumstances, be of little use to you. This remark should apply also to the planting of fruit-trees. Unless previous arrangements with the landlord are arrived at it is quite likely that, when you quit the holding, you will find yourself insufficiently recompensed for the expenditure and labour. We have unfortunately to take our land laws as they stand; and obviously they are largely in favour of the landowner, which makes a real agreement, free from compulsion on either side, a moral impossibility. 


\section{CHAPTER II}

\section{FORMATION OF A VEGETABLE GARDEN}

\section{The Question of Boundary.}

IT would greatly benefit the country in general, and cottagers in particular, if every workman had the means of cultivating his own vegetables. The sad fact remains that under present circumstances it cannot be. A great good could, however, be done by those who have the opportunity of doing so, yet neglect it ; for we cannot be blind to the fact that many of our cottagers need to be wakened to the knowledge that it would be better for them, both from a pecuniary and from a health point of view, to spend their spare hours in raising good wholesome food for the support of their families.

For several reasons it is necessary that a vegetable garden should be enclosed. Chief among these are the exclusion of cattle, large and small, and the breaking of the wind; in a word, for shelter. Since I am speaking also to those who can afford to devote an acre or two to vegetables, as well as to those who can boast only of a plot a few yards in area, it will be necessary for me to allude to the advantages to be derived from enclosing the allotted area within walls. The advantages of having the ground bounded by walls are that safety from cattle, rabbits, fowls, \&c., is thereby assured, a good shelter is obtained, 


\section{How to manage a Garden}

prying individuals of the meddling type are restrained, an impassable barrier is placed to the force of the wind, the exclusiveness of the place is secured, and many fruit-trees may be grown on the walls.

Presuming that a wall is to be built, it should be made of sufficient height and sufficiently solid; and to be in any way useful for fruit-trees should not be less than ten feet. Small low walls may be good for growing tomatoes and rose trees on, but are of little use for the more serviceable crops of apples, pears, plums, apricots, peaches, \&c. Even walls six feet high afford no chance for fruit-trees to give us the best that is in them. If the walls can be made higher than ten feet it would be greatly to the advantage of the trees trained thereon, but as the cost would be great and the size of the garden may be too small, we will fix the standard height at ten feet. There is also to be considered the solidity of the masonry. To put up walls which the first September wind will blow over, or the first fall below $32^{\circ}$ will crack up, and cause to crumble away, is useless. Whether we have stone walls or brick walls does not matter much, if they are well pointed; but they must be well pointed. Certainly, however, brick walls are much better for training fruit-trees on. They present a more even face, are, if anything, warmer, and offer greater facilities for nailing. It is generally necessary, where stone walls are used, to attach wire to the walls; and galvanised wire in the vicinity of large towns is known to have a bad effect on the trees. At one time, as we read in the old books, and as we can often see now in large gardens, hollow walls were built and fires made to heat them, to grow thereon peaches, nectarines, \&c. I doubt if they are 


\section{Formation of a Vegetable Garden}

ever so employed now. The custom has become obsolete. Solid walls are now required.

The foundations should be deep and the ground on which they are built firm, so that the amount of trenching necessary for bringing the garden into good tilth will not imperil the stability of the wall. Such advice may seem superfluous, but I can assure my readers that it certainly is not so, for there have come under my own observation cases where it was looked upon as a crime to dig deeply near a wall, and this for the very simple reason that it would cause it to quickly topple over or sink. Two and a half feet below the surface is the right depth for a foundation. To have it less is to be guilty of the "penny-wise pound-foolish" species of economy, or to compel the forgoing of that thoroughness of cultivation which is so necessary for all crops, but more especially so for fruit-trees.

A wall, also, of the given height of ten feet should not be less than one brick and a half thick, that is fourteen inches; and should be built in the form shown in Fig. I. The foundations should be twice the width of the wall, and should gradually diminish as shown in the illustration. In a considerable length of wall it is better to have piers about twenty feet apart. Some sort of coping will also be found necessary to keep out the wet, and should be so formed as to obviate the

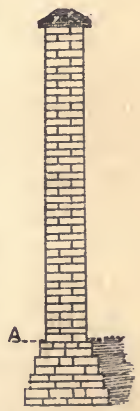

F1G. 1.-Section of brick wall. dripping of the rain on to the fruit-trees. A-Earth line. It may be either sloping one way or both ways. In cases where, for some reason, the outer side of the wall is not 


\section{How to manage a Garden}

used for fruit or other trees, it is far better to have the slope all towards that side, but when both sides are used, the burden should be divided between them. The coping should project out quite three inches so that the fruit-trees will not be made to suffer unduly. Hollow walls are sometimes advised as being a great saving in bricks. That is true, and they may be all right as long as they are in good repair, but when the mortar wears away and the bricks become loose, as they will in course of time, it is then that the mischief begins; and once the wall becomes the abode of those insect pests which are so prejudicial to the life of the trees, it is well-nigh beyond the power of mortals to eradicate them. It should be seen during the course of erection that good substantial mortar is used, for it will be especially necessary in this case, where the amount of nailing will give it a sore trial. The jerry-builder's type of mortar could not here be tolerated.

The information here given relative to the construction of garden walls is not offered in the hope of inducing every one to be his own builder, but rather in order to impart an intelligent interest in the work. The more a person knows of the principles of building, the more readily will he perceive flaws, and the more vigilant will the builder be to avoid them. If a more intelligent interest were taken in building, the number of jerry builders would be considerably reduced. Having now dealt at some length with the subject of walls as a boundary for a kitchen garden, it behoves us to turn to others.

Board fences or wooden railings are sometimes used for dividing the vegetable garden from other parts, but they 


\section{Formation of a Vegetable Garden}

do not equal walls in general utility. They have, however, their uses, and do not deserve contempt. For general solidity a board fence can hardly be compared to a wall, but if properly treated they will last for a considerable time. To be made somewhat substantial, thick posts should be sunk deep into the ground at certain distances apart. Cross pieces are in turn nailed to these, and then upright boarding is fixed. For those parts which are to be under ground plenty of tar should be used, as it keeps them from rotting, or the same purpose may be served by having them charred. The other portion should also be tarred, or first of all coated over with good red lead, and then painted any desired colour. This latter course is certainly preferable. Fruit-trees may be tried on these fences, but they are not usually found to succeed well. Rose trees and miscellaneous climbers, however, are suitable for covering them, and when well covered with trailing subjects they form without doubt a very pleasing feature of the garden. Wood railings are in themselves less unsightly than bare board fences, but they have the disadvantage of being less useful as a wind-break. On the score of cheapness they are certainly preferable, and without sacrificing strength an appearance of rusticity may be given by leaving the bark on them. The pieces need also to be pretty close if rabbits are to be kept back. Common iron railings have nothing further to recommend them than that they keep back cattle. In each of the two lastmentioned cases it would be impossible to grow anything close to the fence, if there were stock on the other side, or it would surely be damaged.

There are other means of fencing open to us which, 


\section{How to manage a Garden}

perhaps, all things considered, come next in point of general desirability to brick walls, and these are hedges. Here we have a fairly large variety of choice, for if we resent the common and ubiquitous privet, we may like the holly, or if the yew is too sombre and deathlike, we have the quickthorn and the myrobalan plum; whilst if utility forms a large part of our composition, we can fall back on the common gooseberry, which forms a thick impenetrable hedge, and may also afford us a few small fruits. Of course we can hardly expect to have large berries and also a maximum of utility in the way of impenetrability.

Whilst on the subject of hedges, a few words will probably be in place as to the way of forming them and their general upkeep. Hedges are not formed in a day, and if they are eventually to be used to fence against stock, some temporary method of fencing should be put down until they are of sufficient size and thickness to perform that work themselves. For this purpose of protection for the hedge iron railings are eminently suitable; or posts driven about fifteen feet apart and strand wire stretched tightly between will also act splendidly. Protection of this kind having been provided, a trench should be taken out two feet wide and two feet deep. The bottom should be well forked over, then a layer of half-rotten manure spread over. Next put in about a foot of soil, and procure then some good turfy loam to mix with the top spit. When sufficient soil has been put in to fill the trench, slightly tread it over. The soil that remains should be used to form a small bank, as it were, on each side of the hedge, so that it can be watered immediately after planting and at subsequent periods; for it will surely want some assistance in that 26 


\section{Formation of a Vegetable Garden}

way until new roots are thrown out and the older ones induced to perform their proper functions. Plant in a straight line at about six inches apart, taking care not to crumple the roots, and make the soil firm. This is essential. About six months after the time of planting, the hedge, as we will even now venture to call it, should be cut back to within six inches from the soil. This may appear to some to be a species of backward progress, but we must recognise that the chief essential of a hedge in this case is impenetrability, and this can only be gained by encouraging a strong, vigorous, and multiplied growth from the bottom. The many hedges we see by our country roadsides are a sad evidence of this impatience to procure quickly a large high hedge at the expense of a sparse bottom. Give a thorough foundation in the beginning, and you then have something to build upon. During the second year the hedge should be cut back to one foot, and from that time onward it should be allowed to grow and retain about one foot each year. For forming a clean, shapely hedge there is no method of cutting it better than that of clipping with the shears. It may take longer, but the work is much neater; and for a hedge in the position we are discussing it is necessary to preserve a neat appearance. The trimmings from the hedge, no matter what its composition, should be burnt, and the ashes resulting carefully stored away for use in the regetable garden. Any attempt at making topnots and whatnots in the way of topiary work is to be discouraged, for it is a barbarous and hideous custom, besides being a great waste of much valuable time, which could be better applied to the production of vegetables and flowers. It 


\section{How to manage a Garden}

is also a difficult work, and rarely is it seen performed successfully. When the hedge has attained to a sufficient height the railings, or protecting fence, may of course be removed. There is this disadvantage in a hedge, which does not exist when the boundary is a wall or wooden fence-viz., it is inadvisable to have a border immediately against it, as the roots are apt to make towards the border, which will of course be better cultivated, and the flowers or vegetables contained therein are likely to become impoverished; for hedges as a rule are gross feeders. In view of this it is usually better to have a walk immediately against the hedge, and the border next the path, where it is extremely improbable that the crops will be robbed.

\section{The Arrangement of Paths and Walks.}

The subject of boundaries has been treated at great length, but as having an important bearing on the welfare of the crops within, the information afforded will not, I think, be considered unnecessary. The number of paths and the size of them depends solely on the size of the plot, for it would obviously be unwise to lay down paths six and eight feet wide in an area of half an acre. In a small plot the pathway must of necessity be reduced to the minimum necessary for getting about with the necessary manure, \&c. ; for good land is extremely valuable to the small holder, who does not believe in putting down gravel where he can grow cabbages. Moreover, the needs of a small garden are obviously less than those of a large one, and where a cart would be required in the latter case a wheelbarrow would do in the former. For any garden up 


\section{Formation of a Vegetable Garden}

to an acre paths four feet will be sufficiently wide for all purposes, and in many cases three feet of width will be ample, but for laid down paths this should be the minimum. There are many cases where a plot of ground is laid out and crossed here and there by paths, but with no gravel laid down, or any proper edging. Such paths, it will be contended, serve their purpose, and this cannot be denied; but wherever appearances and comfort of working count for anything, paths formed of good gravel well laid down are always to be advised. In the garden which is intended merely as a piece of ground for profit, it can hardly be said with accuracy that the laying down of good paths would beneficially affect the revenue; but in cases of small plots I am certainly of opinion that the outlay would be very small, for most of the labour could be done at a time when operations among the crops were fewer, and the gravel may perhaps be procured locally, or a path be made of the clinkers, ashes, \&c., on hand. The making of a path will not here be given in detail, for the formation of paths, whether for pleasure grounds or for vegetable gardens, is much the same, and will be found treated of on page 87 .

Now, the arrangement of the paths cannot be well divorced in treatment from the arrangement of the plots, for by the very act of laying out the one we mark off likewise the other. They will therefore be dealt with together. As has been previously pointed out, the land is, or should be, regarded as a valuable asset, and should not be unduly cut up into paths, which besides being a great waste of space is a great waste of time, for many short rows take longer to put in than a few long ones, even when the number of plants in each case is identical. Any one who 


\section{How to manage a Garden}

is so rash as to doubt this may experiment for himself. Whenever possible, except as before mentioned in the case of having a hedge for a boundary, there should be a border under the wall. In some cases this is only four feet, whilst in large gardens I have known it to be thirty feet wide. A very useful width, however, is ten feet. By having a border in this way, we not only afford root room for the fruit trees trained to the walls, but also get protection for early vegetables; for it is on borders of this

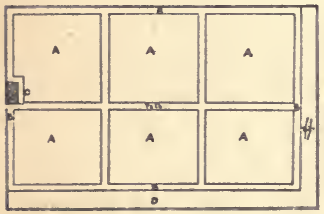

FIG. 2.

Bad arrangement.

A-Plots. B-Path.

C-Tools. D-Border.

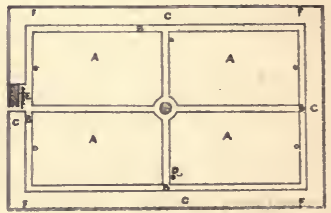

FIG. 3 .

Paths.

Right arrangement.

A-Plots. B-Path. C-Borders. D-Water. E-Tools. F-Walls.

class that the best vegetables and the earliest can be more easily produced. Having arranged for a border of the said dimensions along each of the four walls, a path four feet wide is marked out. Then commences the subdivision of the patches remaining. More information will be procured by glancing at the arrangements shown in the accompanying illustrations, Figs. 2 and 3 , than could with sufficient clearness be conveyed in words. I would recommend a careful study of these, and some examples of mistakes which are likely to be committed will be gleaned from a comparison of the right and the wrong methods of arrange- 


\section{Formation of a Vegetable Garden}

ment. Particular attention is called to the method of laying out shown in Fig. 4, where a hedge forms the outline of the vegetable area, and where it does not conform to a straight line in any of its sides. If the outline of the hedge is followed in laying down the walks, it is certain that the plots will be anything but rectangular, and cropping will thereby be rendered difficult. The proper way of

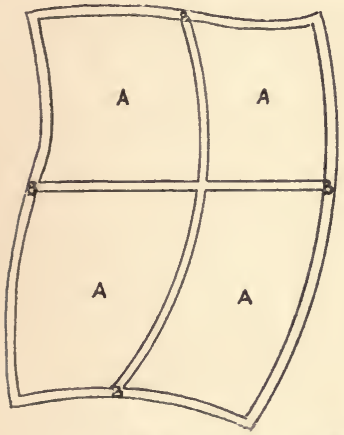

FIG. 4.
Paths.

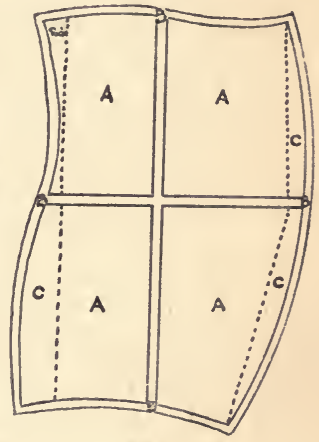

FIG, 5 .

Right arrangement.

Wrong arrangement.

A-Plots. B-Paths. C-Borders.

meeting such a state of affairs is shown in Fig. 5, where a straight path runs across the garden and is bisected by another one, the lines for cropping being measured from these. A curved line in a kitchen garden is a violation of all the best principles of utility, and should, unless absolutely unavoidable, never be tolerated. It may be mentioned in passing that the best form for a vegetable garden is an oblong, with its broad sides to the south. 


\section{How to manage a Garden}

This gives large opportunities in the way of cultivating wall trees of the more delicious species of fruit, such as peaches, nectarines, and apricots; or if the taste does not incline towards these, pears and apples may be brought thereon to earlier maturity, not to mention the increased amount of south border, which means earlier vegetables. When the outline of the garden is not already made, it should certainly be made rectangular, that is, of an oblong or square shape. Rarely, but very rarely, we find a round kitchen garden; but no person having the crudest notion of the arrangement of the crops within would think now of planning in that form.

\section{The Edging of the Paths.}

There must be in a well-regulated garden some manner of frontier-line dividing the path from the plot. Usually this may be made a matter of choice, ungoverned by any other factor. The first process is to choose between a live or a dead edging; that is, whether some edging plants such as box be used, or whether boards, tiles, stones, \&c., be preferred. Among the former, common box is preferable to all others, because it effectually keeps up the separation between path and plot, and also because it can easily be kept within bounds, is neat in appearance, and succeeds well in the position. Two objections are commonly urged against it, viz., that it harbours slugs and insects, and that weed-killer cannot be applied to the walks withoutal so killing it. These views are, however, untenable. In the first case, only a system of neglect will allow box to grow so dense as to make the harbouring of 


\section{Formation of a Vegetable Garden}

insects possible. Box should be clipped yearly, and should never be more than four to six inches high. If allowed to exceed this limit, slugs will certainly find a habitation therein, but six inches is a sufficient height for all practical purposes. The objection with regard to the inability to use weed-killer would be serious were it true, but fortunately it lacks this quality, for boards can be laid against the box in a slanting direction on each side, and the weedkiller is thus kept off the box and away from its roots, the only danger being that the person using the mixture may carelessly let it be sprinkled beyond the boards. The weeds immediately against the box could surely be pulled by hand.

If, however, the overthrow of these arguments is not sufficient to induce one to have box there are several other means of edging, so as to prevent the trespass of the soil on to the walks. Among these may be mentioned, boards, stones, and tiles. Boards when used should not be less than one foot wide and one inch thick and should be secured by posts two or three inches square driven well into the ground. Both boards and posts should be coated with tar for their longer preservation, and when fitted down should be about four inches above the path level. If the posts are placed at a reasonable distance apart the warping of the boards will not be very great. Stones are preferable as being more lasting, but they are in few cases obtainable without a great expense. Where they can be procured by all means use them, for if they are well chosen (those of a very shelly nature being discarded) they are practically imperishable. They should be as far as possible of an even thickness, and sunk well into the 


\section{How to manage a Garden}

soil, so that they are not loosened by digging near them. We next come to consider tiles, and it is very easy to make a mistake in these, for what may be a handsome pattern viewed in a shop and likewise inexpensive, may prove a very bad investment after a hard frost, when they will be seen to have broken up under the strain. Glazed tiles though dearer are not so subject to this defect. Rough cobble stones are not to be recommended as edging to a regetable plot, for they are so easily displaced and do not serve the real purpose of an edging, viz., in keeping the soil away from the path. An edging which for neatness and appearance I can recommend beyond all others is to lay down a verge of turfs one foot wide. By simply running the machine over and clipping it occasionally it can be made to look a model of neatness. A piece of board should be used when running a wheelbarrow on to the plot.

\section{The Position of Trees.}

In a vegetable garden it is strongly urged that fruittrees be planted where they will not interfere with the orderly cropping of the ground. The introduction of a few trees into even the smallest gardens is greatly to be desired, and I would certainly advise every cottager who has any more than a rod of land to make a point of having at least one fruit-tree. In the garden extending to an acre enclosed within walls the fruit-trees should be disposed as shown in Fig. 6. On the walls they would be planted about twelve feet apart with red or white currants trained to the pillars. Six feet from the main walk and 


\section{Formation of a Vegetable Garden}

on both sides would be trained espaliers. Three feet from the inner portion of the other walks would be planted pyramids at a distance of six or eight feet apart. Whilst young the space between these would be occupied by gooseberry trees, and a row of strawberries would be grown where the closely dotted lines appear. Fig. 7 gives an erroneous method of cropping and is intended to display the error

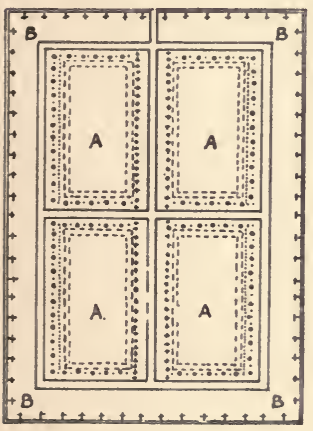

FIG. 6.

Right arrangement. A-Plots. B-Borders.

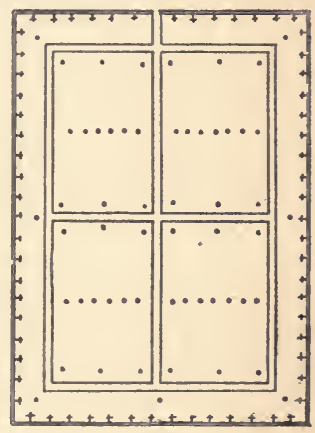

FIG. 7.

Fruit.

\section{Wrong arrangement.}




\section{How to manage a Garden}

\section{Flowers in a Vegetable Garden.}

There are some folks as well within as without the pale of professional gardening who like to separate gardening by nicely divided lines, and who would no more think of planting flowers in a vegetable garden than of planting pyramid pears on a croquet lawn. Such sharply-cut divisions have no parallel in nature, and although I would not advise fruit-trees to be planted in a pleasure ground, it is chiefly because they would not receive such good treatment as if they were in a properly formed vegetable or fruit ground. To bar flowers from a vegetable garden is, however, nothing more nor less than a foolish whim. It remains as a sad fact which I have frequently observed, that visitors, no matter of what class, are rarely shown over the vegetable portion of an estate. The first visit is to the glass houses, then to the flower and pleasure ground, whose every walk is religiously traversed, but a mere glance or bird's eye view is considered sufficient for the vegetables. "Those are only vegetables. You do not want to see them," says the head gardener as he sweeps his hand contemptuously towards the most necessary part of the garden. Such is unfortunately the case, but we all know that a familiarity with the growth of vegetables would make happier the lives of thousands. Are we to educate them by means similar to those quoted above? Now I contend that the very fact that a person is brought through the vegetable ground to see the flowers may also cause him to observe, question, and perchance eventually practise some of the kitchen garden operations. Now the most suitable places in the garden for flowers are in the borders 


\section{Formation of a Vegetable Garden}

skirting the main walks, and I have purposely advised that espaliers should be grown to give a background to the flowers. It is not my intention here to tell minutely how this space is best to be utilised for the attainment of the object in view. That will be dealt with in its proper place. I may merely say that such borders are often made to look glaringly brilliant and quite as attractive as any portion of the ground. I well remember when first going to work at a large place how, on emerging from the gardener's cottage, I was particularly struck by the beauty of a border of annuals skirting the kitchen garden area, and I always have that picture in mind when commending the adoption of the feature or condemning its absence. Though pyramids are sometimes used as a background they are inferior to espaliers for the purpose.

\section{Water-Supply.}

The question of water-supply to a garden must in all cases be settled locally, for it is governed solely by local circumstances. The stubborn fact, however, remains, that it is well-nigh impossible to produce vegetables up to any great standard of merit without copious supplies of water during periods of drought. A great saving of labour is effected by having the water so laid on that a length of hose-piping may be made to reach all parts. The first cost may seem to be heavy, but any one conversant with the true canons of economy, and aware also of the need for water and the labour its application involves, will readily concede that it is a sound speculation. I speak now of the ideal method of distributing the water, and inasmuch 


\section{How to manage a Garden}

as the system approaches this will it be perfect. An illustration, Fig. 3, will doubtless show my meaning plainer than words. Here is shown one large tank in the centre, and several small tanks or barrels disposed along the side walks. Each of these is fed from the main pipe, and is provided with a tap on which can be screwed a length of hose-piping by means of which the water can be distributed to all parts. Of course, the more numerous and the larger the barrels the more perfect the system. There is still much to be learnt as to the value of water, if we may judge of the amount that is allowed to go to waste during heavy storms. A large supply of water could be obtained by making full use of all that comes from cottages, greenhouses, and other buildings. At present we usually find one tub to catch this water; but this in a heavy storm is soon filled, and perhaps four or five times the quantity is wasted. Now, I would like to see a system worked out by which the overflow of one tub would go to fill up another; the overflow from that passing to another, and so on. With a fall in the direction of the garden, and a few drainpipes, this could easily and cheaply be brought about, and the garden would materially benefit. 


\section{CHAPTER III}

THE CULTURE OF VEGETABLES

\section{ROOT CROPS.}

Artichokes.-We have among these the Jerusalem and the Chinese artichoke. The former especially will grow on almost any ground, but gives better results when well treated with good soil and a dressing of manure. The tubers should be planted early in March, in rows two or three feet apart, and eighteen inches between the tubers. The smaller Chinese may be planted closer. Both may be dug up in the autumn, and put in some cool, dry place, or left in the ground till required.

The globe artichoke is altogether a different plant, and is grown for its head. A stock may be got together by division, the plants being set out about four feet by three. The plants should be freely mulched and dug amongst. In some places they need protection during winter.

Beetroot.-Like all root crops these require a free soil into which they can readily plunge. Sow early in May in rows twelve or fifteen inches apart, using ground which has not been manured since the last crop was taken off. Thin early to a distance of nine or ten inches, and keep free from weeds. Carefully lift the roots without bruising, and stack together under cover.

Carrots.-For success with carrots it is necessary to 


\section{How to manage a Garden}

grow in a light soil. In a heavy soil they can seldom be relied on, and are very likely to crack. Sow thinly, thin out early, and keep the hoe freely at work between the rows. Both carrots and parsnips may be grown to a large size by making holes two to two-and-a-half feet deep with a crowbar, and filling up with fine soil. This is only advisable for exhibition. Dig up the roots with a fork and store in dry sand.

Leeks need to be sown in drills in March, and when of a fair size planted in shallow trenches in a way similar to celery, though the trenches need not be so deep. Some growers nip off the points of the leaves, but there is no real advantage in this. The plants should be set out from nine inches to one foot apart, and if large produce is required they should be frequently watered with liquid manure. Earth them up in early autumn, and when blanched use them as required. The Musselburgh leek is by far the best.

Onions.-To get onions out early they should be sown in boxes early in the year, and kept in a warm frame. Thin the plants in the boxes early, and put in a cold frame to harden off before being put outside. Plant out in April in rows fifteen inches apart, but do not bury deeply. Whether for planting or sowing the ground should be deeply dug and afterwards made firm. Furthermore, good varieties should be chosen, such as Ailsa Craig, Giant Rocca, and James' Keeping. Keep down weeds during summer, and pull the bulbs when well ripened. For keeping up a continuous supply sow also in August.

Parsnips.-Like the carrot and beet the parsnip also resents fresh manure, which tends to make forky roots. 


\section{The Culture of Vegetables}

They may be sown in drills made with the hoe, about one inch deep, and thinned out afterwards to one foot apart ; or holes may be made for them, as before mentioned, dropping two or three seeds on the top of the soil, filling each hole, and eventually thinning out to one. They may be taken up in the autumn, or left in the ground to be used as required. Varieties: The Student and Improved Hollow Crown.

Potatoes.-Only a few words need be said on these tubers, as the mode of culture is known to every one. Secure good, sound, well-shaped tubers for seed; plant in well-prepared soil ; earth up when four to five inches high; keep free from weeds, and dig up when ripe, an indication being the dying down of the tops. Store in favourable weather in a dry shed and cover with straw. In the case of seed sets leave them open to the light.

Turnips may be sown from February to August to keep up a succession. Choose a time when the ground is moist, so that they may grow sharply and thus escape to a great extent the attacks of the turnip fly which riddles the leaves with small holes. Let the rows be a foot apart and thin out as soon as the plants are large enough to handle. With a good season and freedom from the fly there is little fear of going astray in turnip culture.

\section{GREEN CROPS.}

Broccoli.-These may be said to be really hardy forms of cauliflowers, for that represents the whole of the difference between them. Sowings may take place from March to May in the open ground, choosing varieties 


\section{How to manage a Garden}

which will keep up a supply from the time cauliflowers are done with until the following May. Seed beds should be protected by stretching netting over them. Plant out in fine weather in richly manured ground. During frost the leaves may be bent over the flowers to preserve the heads.

Sprouting Broccoli.-These form a very useful dish during spring. There may be the purple or the white sprouting Broccoli. Small heads are grown in profusion on the stem of the plant, and may be plucked off to make a very acceptable dish. Sowing may take place in April, and the growth throughout may be worked in accord with that of the Broccoli.

Brussels Sprouts. - If an early sowing of these is required it should be made in boxes in February, the boxes standing in a warm frame; or a sowing may be made outside in mid-April. When large enough to handle prick out the seedlings to a distance of three or four inches apart. In June plant out at a distance of two feet apart, or if space can be spared let the rows be two-and-a-half feet asunder. Brussels Sprouts seem to relish a firm soil, which tends also to give firmness to the sprouts.

Cabbages.-For spring use, sow seeds in July and plant out in September or October. They may be planted at a distance of fifteen to eighteen inches apart, as there is little fear of their becoming overcrowded. In the spring keep the ground open by hoeing to encourage them to come away quickly. An early sowing of cabbages may be got along in greenhouse or frame in January or February. Cabbages of all kinds relish a deep rooting soil rich in 


\section{The Culture of Vegetables}

manure. Where club-root attacks them gas-lime the land, and refrain from putting cabbages thereon for several years.

Cauliflowers.- These partake of the same species of culture. The two best varieties for general purposes are Early London and Autumn Giant. Much is gained in point of earliness if sown in autumn and the plants pricked off into frames and protected during winter. When planted out in the spring there is a possibility of their "buttoning," but if they have been well cared for in the frame the danger is diminished. Seed may likewise be sown in boxes in January and in the open in April. Constant hoeing between the plants will keep the moisture in the ground during a drought. If early frosts ensue cauliflowers may be taken up with a ball of soil and planted in a shed or cellar, where they will keep for some time.

Curly Kale.-For winter and early spring use this vegetable is especially serviceable, for after the head has been cut off it will continue to throw out side growths for a considerable time, which if pulled when young form a very appetising dish during a time of few fresh vegetables. The culture is precisely the same as that recommended for the Savoy.

Savoys.-Sow in mid-April, and prick off in beds, planting towards the end of June or beginning of July. Let the distance between the plants be eighteen to twentyfour inches. Leave a small basin round each plant so that they can be watered; and keep the hoe well going between them as long as there is room enough to work. Savoys are generally supposed to be improved by frost. 


\section{How to manage a Garden}

\section{SALADS, \&c.}

Celery and Celeriac. - This useful vegetable is well worth growing in every garden. Seed should be sown in pans or boxes, filled with sandy soil, early in March and submitted to gentle heat either in a greenhouse or over a hot-bed. When large enough to handle, prick out three or four inches apart. Celery should be planted in trenches specially prepared so that the plants may be easily earthed up. Plant in May or June in single rows, and if necessary protect from late frosts. Water plentifully throughout their stay in the ground, this being their chief requirement. Earthing should be done some eight to ten weeks before they are needed, but not to such an extent as to bury the heart. Suitable varieties are Standard Bearer and Daniel's Exhibition Pink.

Celeriac does not need to be planted in trenches nor earthed up, for it is the roots that are required. These should be dug up and stored.

Cucumbers. - Plants need to be raised in a temperature of not less than $60^{\circ}$, and are better afterwards grown in frames where there is some heat either from hot-water pipes or a hot-bed. Make up a heap or ridge of soil and plant the cucumbers thereon when eight or nine inches high. Stop the main shoot when it has nearly reached the limit, and stop fruiting shoots at one or two leaves beyond the fruit. Do not allow the fruit to hang too long or the flavour will be spoiled and the produce curtailed. Water freely and syringe to keep down red spider.

Endive and Lettuce.-Endive is not greatly in use in cottage households, but could with advantage be grown 


\section{The Culture of Vegetables}

as a change. Sow in a frame during March and later on out-of-doors. Plant out in lines one foot apart and water well during dry weather. As these plants are needed to be blanched for use, pots may be set over them when dry to exclude air and light. Lettuces should be grown in well-prepared soil which has been trenched, so that it will well retain moisture. Seeds may be sown from the beginning of the year up to September to keep up a succession. Like endive they should be planted one foot apart ; and if they do not readily "heart in," tie the top with raffia grass. If allowed to become dry, lettuces will soon run to seed.

Mustard and Cress. - These are grown together, though it is better to sow cress a few days in advance of the mustard. Sow thickly, and do not cover the seed. A week or ten days is usually sufficiently long for it to remain before cutting. Cut when about an inch high before it gets into rough leaf.

Radishes.-These may be sown either broadcast or in drills one foot apart. They need to be on well-worked soil and be kept free from slugs, \&c., by putting a ring of lime around the bed. Thin out as required and before they lose their crispness. Frequent sowings should be made to keep up a succession.

Tomatoes.-The great secret in growing tomatoes well out-of-doors is to get plants well forward, so that they may be bearing green fruit when planted out. Sow in late February or early March, and prick off into boxes. As growth proceeds, pot off into five-inch pots and stake until the end of May, when they may be planted out and trained to a south wall or fence. Train on the single 


\section{How to manage a Garden}

stem system, pinching out all side shoots as they appear. Feed well with liquid manure, and let them never want for water. When about four feet high stop them and let the fruit ripen. All unripened fruit should be pulled before frost and put on greenhouse shelves to colour.

Mint may be propagated from cuttings or by division of roots, or it may be boxed up and forced for use with early potatoes. Parsley may be sown in rows under walls or by the borders of paths. Thyme may be increased by seed or division. Sage may also be increased by cuttings.

\section{MISCELLANEOUS CROPS.}

Asparagus.-For the raising of asparagus, seed should be sown in March and the seedlings thinned out. For forming a permanent plot it is better to buy one-year-old plants and plant in rows four feet apart and two-and-a-half feet between the plants, or in beds five feet wide, with three rows at eighteen inches apart. Thoroughly trench the ground before planting. Give yearly a dressing of manure and a sprinkling of salt. Do not cut from the plants during the first year, and sparingly during the second. In other years cut the strong shoots until the middle of June and leave the weak ones to grow. When there is sufficient space between the plants dig the ground yearly.

Beans.-Among these we have runner, dwarf, and broad beans. To grow runner beans well, take out a trench in autumn; dig up bottom. Fill in with weeds, \&c., and, just before planting, with soil. Plant beans in double rows eighteen inches apart, or in single rows, with 46 


\section{The Culture of Vegetables}

the beans nine to twelve inches asunder. Stout poles should be used for the beans to climb up. Pick the pods before they become too large, and do not allow too many to hang for seed, or others following will not set. Plant early in May. Dwarf beans may be put in single rows nine inches apart and two-and-a-half inches deep. They need no stakes. Broad beans should be planted at the same distance, and may be kept up by driving in several stakes along each side of the row and connecting them with cord.

Marpows.-Seeds of marrows may be sown singly in pots during March. As they grow shift them into 6-inch pots and plant out at the end of May. Marrows pay well for having the ground thoroughly trenched and plenty of manure incorporated. Water well after planting, and cover for a few days with yew or laurel boughs. Marrows need little other attention than watering the plants and cutting the produce.

Mushrooms.-In growing mushrooms the chief thing is to get the manure in the right condition. All large straw should be taken from the horse manure, and the small thrown up in a heap. Turn it well over every other day until the rank smell has gone. Then put it up into a bed which may be flat or conical-shaped. Tread firmly and let it stay for a few days before spawning. Break each cake into eight pieces and bury about one inch deep in the manure. Put soil over a few days after. Keep well watered and covered with straw and mats. Mushrooms may be expected about eight or nine weeks after spawning.

Peas may be sown from December to May or even June. 


\section{How to manage a Garden}

Sow thinly, but not too much so, in drills two inches deep. Earth up when a few inches high and put small stakes to the peas before they topple over. Larger stakes may be afterwards placed. Water well to keep down mildew, and mulch during hot weather. Smaller varieties may be chosen which do not need staking. Among varieties may be mentioned William I., Chelsea Gem, Duke of Albany, Telegraph, Telephone, and Gradus.

Rhubarb. - This is usually increased by division. Cut off from the old stock pieces having one or two eyes or crowns, and plant three to four feet apart. Once established on good soil rhubarb needs little attention other than dressing annually with manure. It may be got along early by covering with boxes or tubs and putting litter or leaves over these, or pieces may be taken up and forced beneath the staging of the greenhouse or anywhere where there is warmth. Needless to say the crowns are of little use afterwards.

Seakale.-This may, in most respects, be treated similar to rhubarb. It is propagated by division of the crowns and may be planted in spring from two to two-and-a-half feet apart. It is necessary that the stems be blanched, and for this purpose boxes or pots may be placed over them and covered with leaves or litter.

Spinach.-This is often used as a catch crop, since it may be sown and used within two months. It may well be grown among peas or in rows twelve to fifteen inches apart. Sow when the soil is moist and thin out as required. A sowing may take place in September to last over the winter. 


\section{CHAPTER IV}

\section{FORMATION OF A FLOWER GARDEN}

\section{What we mean by a Flower Garden.}

THE formation of the vegetable garden having been dealt with, we turn to treat of the flower garden in like manner. For the purposes of treatment only have I divorced the flower garden from the pleasure ground. In practice there can be no such separation without marring the beauty of either, and lending colour to the idea, that the person to whom was entrusted the laying out of the grounds was not gifted with a right sense of proportion, and deficient in a true conception of the picturesque. I intend in this chapter to treat merely of the arrangement of beds and borders for flowers, and will leave out of my calculations such matters as the grouping and arrangement of shrubs whether flowering or otherwise. The subject of bedding or the arrangement of plants within the beds and borders will be treated of later.

\section{Design in the Flower Garden.}

Most philosophers agree that there is evidence of design in the universe, but if their powers of research had to be concentrated on a search for the evidence of design in some flower gardens they would find none. This is of 


\section{How to manage a Garden}

course a defect. A flower garden should conform to some design, though by this is not meant that the design should

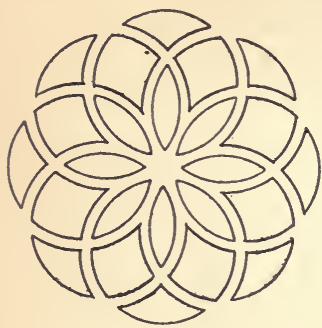

Fig. 8.

Design not practical.

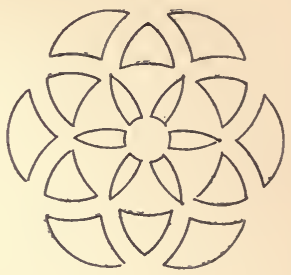

Fig. 9.

A better design.

be regular and geometrical. The design in some cases is too evidently regular. I will endeavour to prove this by

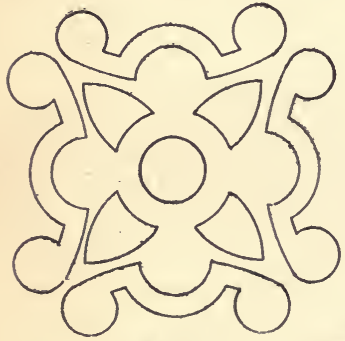

Fig. Io.

Square.

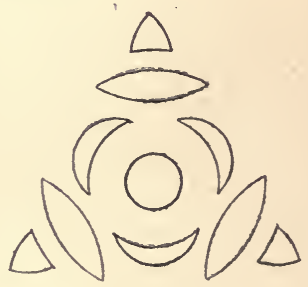

Fig. 11 .

Triangular.

illustration. Fig. 8 shows a very pretty design, very regular, well conceived, and one which on paper must do credit 


\section{Formation of a Flower Garden}

to the person conceiving it. When I had a cruder idea of what qualities should go towards the make-up of a flower garden, I spent several hours in forming this plan, but I tremble to think of the ridicule which would be hurled at me were I ever to put the design into practice. Personally
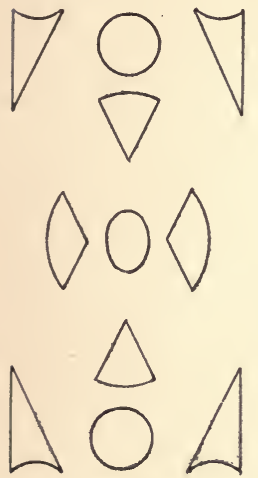

Fig. 12,

Oblong.

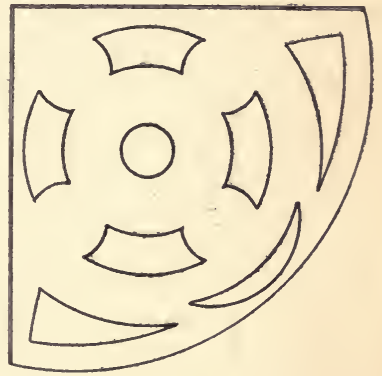

FIG. 13.

Irregular.

I should be inclined to call on some neighbouring mountain to cover me. There is too much symmetry, too much regularity, and altogether such a plan is an outrage on Nature. In the garden especially, Nature must be supreme. Art may enter and beautify, but it must not usurp the Queendom. The beds themselves may conform to the run of the line or the sweep of the compass, but the geometrical relations of one bed to another should not be so obvious as in the case under discussion. A better 


\section{How to manage a Garden}

design is given in Fig. 9. Here the beds are according to the scale of a useful size and a regular shape, and the space between them varies, unlike the first plan, where the paths are of the same width throughout. Some other designs are given to suit a square, an oblong, a triangular,

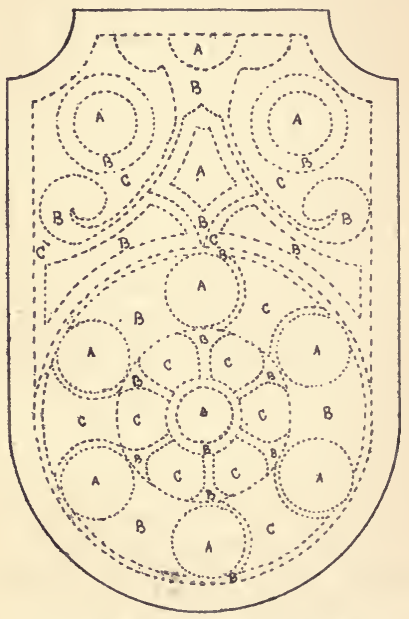

Fig. 14. - Plan of box and gravel.

A-Beds. B-Box. C-Gravel.

and an irregular, piece of ground. These beds are usually worked out on grass which is kept closely cut, but at times we find them bounded by box edgings and separated by gravel walks. When the box needs renewing every other piece is taken out one year and fresh pieces planted. 


\section{Formation of a Flower Garden}

Next year those pieces which were left are pulled up and some fresh pieces put in their place, so that it thus takes two years to renew the edging. In some cases also we find coloured gravel put between and some very fantastic designs worked out with the box. This system is now however old fashioned, and is rarely seen in up-to-date gardens, Some idea is given of what is meant in Fig. 14. I certainly advise that in all cases the beds be cut out in the grass. and the edges kept cleanly cut. Of course it will be necessary to see that the lawn is either level or slopes or undulates regularly. There can be no more pitiful sight in a flower garden than to see some part of the lawn, or probably one or two of the beds, under water after an autumnal shower. This, however, is sometimes seen where better conditions are naturally looked for. Want of drainage and an irregular surface is responsible for this.

\section{The Size of Flower Beds.}

It is clearly very difficult to say precisely how large or how small a flower bed should be, but some idea can be given of the size which can be conveniently worked. Of course the size of the flower garden itself must depend on the size of the estate or holding, and also on the tastes of the occupier. It often happens that a person fond of flowers will be tempted to put on his ground a large number of beds when the beauty of the garden as a whole could be obtained with half the space. In such cases it is far better for the flowers to be grown in borders, and not dotted about the lawn in beds. A simple and pretty design is shown where flowers are grown in borders with a plot of lawn containing but one bed (Figs. 15 and 16 ). 


\section{How to manage a Garden}

A glance at the corresponding plan will show the hideous effect of breaking up the plot. It will be found difficult to plant beds which are more than eight feet wide, so that if we give in a little and say that a bed for ordinary flowers should not exceed ten feet in width it will be pretty safe to follow the rule throughout. For producing effect this

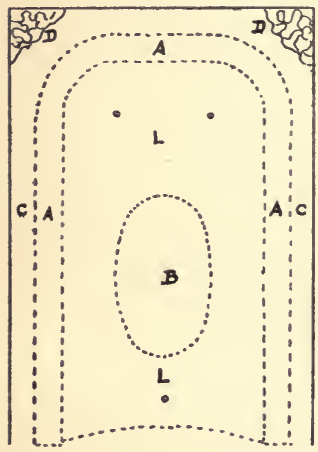

F1G. 15.

Good arrangement.

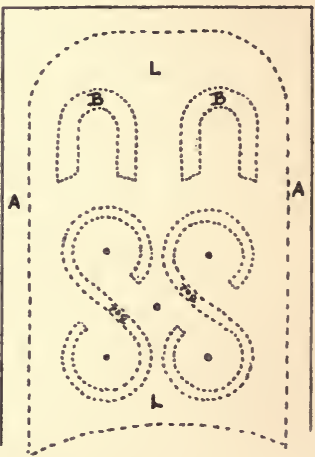

FIG. I6.

The grass plot.

Faulty arrangement.

A-Border. B-Bed. C-Path. D-Rockeries. L-Lawn,

width will also be found to be sufficient. In the case of borders the width may be extended to fifteen feet, but I am afraid few of my readers will be able to spare even that. To show off a good border of annuals arranged after the "massing system" this space could be advantageously utilised, for the plan cannot well be carried out on a small scale. 


\section{Formation of a Flower Garden}

\section{Borders.}

I have already hinted that borders are sometimes more useful than beds worked out on a design. They are planted with less likelihood of error, and are in many ways more conducive to good culture. Not that I wish to disparage the making or employment of beds, but I con-
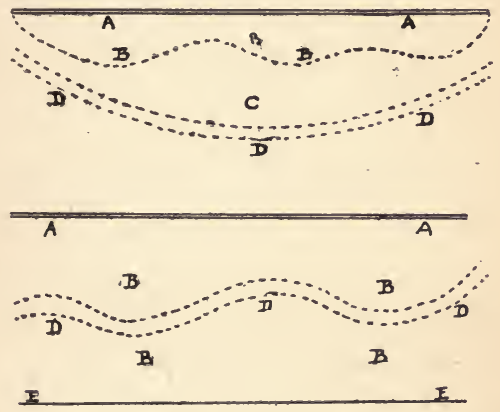

FIGS. 17 and 18.-Borders and paths.

A-Wall. B-Border. C-Grass. D-Path. E-Hedge.

sider that as a general rule the amateur will find the ends he has in view more fully realised by the use of borders, which, as it happens, are often despised and considered common. A few very palpable errors are often mixed up with the idea of borders. It is conceived that they can only exist against a house or under a wall, and that they must conform in all cases to some straight line. These flimsy arguments can be very easily disposed of. 


\section{How to manage a Garden}

We find borders certainly under walls, a position eminently suited to them, but we find them also skirting belts of shrubs, and on either side of walks, or with an artificial background of pillars, \&c., in almost any position. Nor is it essential that their outline should be perfectly straight, or their width in all cases uniform. This would prove monotonous and would be a blemish on the laying out. It should, in fact, be contrived to have a curved outline

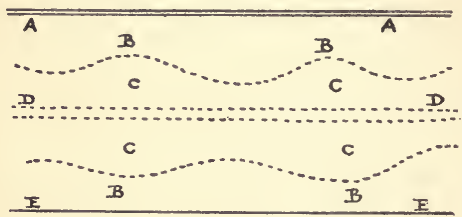

FIG. 19.-Border with straight path.

A-Wall. B-Border. C-Grass. D-Path. E-Hedge.

such as is shown in Fig. 17. If against a walk the walk may either conform to the outline of the bed, as is shown in Fig. 18, or it may run straight, the space between the edges of the border and of the walk being lawn, as in Fig. 19. A grass verge of at least a foot wide should in all cases be left when the border skirts the walk, as it is a very pleasing feature, and a lawn-mower can be very quickly run over it once a week to keep it in ideal condition. 


\section{Formation of a Flower Garden}

\section{Pillars, Pergolas, \&c.}

These are very pleasing features in a garden when they are not too numerous; but it unfortunately often happens that in his praiseworthy ambition to make his garden look well the owner oversteps the mark, and tries really to include too many features, with the unhappy result that none of them looks well. A ground plan is here given where this is only too apparent (Fig. 20). Pillars may

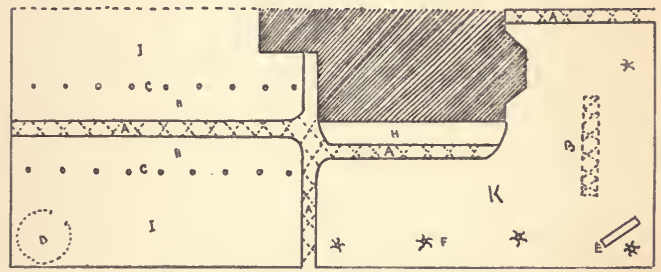

FIG. 20.- Too many pillars and pergolas.

A-Pergolas. B-Arch. C-Pillars, D-Summer-house. E-Seat. F-Trees. H-Borders. I-Vegetable plots.

be of iron or wood. For better preservation they should be iron, but for appearance wood is to be preferred. Strong posts can be procured, and well coated with tar in that portion which will be beneath ground. The bark should be kept on if possible, as it increases the ornamentation. Chains are sometimes slung from one pole to the other, but wire will serve the purpose equally well, for it will not be discerned when well clothed with climbers. These pillars may be placed about eight feet apart, and form a useful background to the border. Roses 


\section{How to manage a Garden}

of the crimson rambler type may be employed to cover them, or the well-known canary creeper, clematis, ampelopsis, and many other subjects. Arches reaching from one border to the other, and spanning the walk, also form a pleasing feature in the garden. During their period of flowering I can imagine no sight more beautiful than that of several arches spanning a broad walk, and being well clothed at sides as well as at the top with large clusters of the well-known crimson rambler. These arches may be bought ready made in two sections, or they may be formed of rough pieces of wood intended to give a rustic appearance. For the person of small means this latter method is certainly the better.

Pergolas are formed somewhat in the same way. A pergola is not to be advised for a small garden. It takes up valuable space, breaks the view, and gives rather more shadow than in a small area is conducive to general success. Therefore I strongly advise amateurs to leave pergolas severely alone, and occupy their space with something which will surely give them pleasure. This advice is, however, not intended to apply to those whose garden area is more spacious.

\section{The Rose Garden.}

The position of the rose garden should, unless uncontrollable circumstances conspire to make it otherwise, be out of view of the house, for although it is a picture of beauty during the summer months, even the most ardent devotee to the "queen of flowers" must acknowledge that a mass of rose trees possesses no beauty in the winter time. It should then be away from view of the house, 


\section{Formation of a Flower Garden}

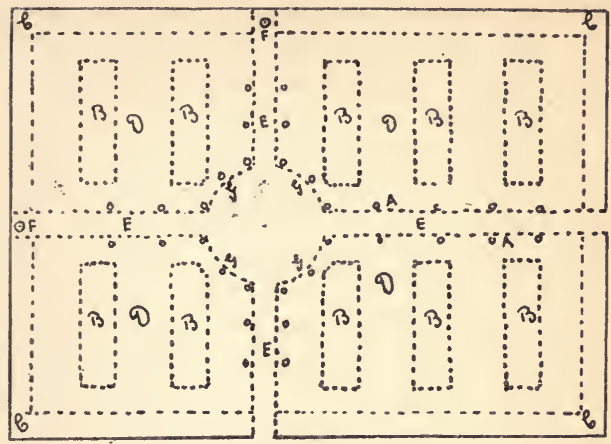

FIG. 2r.-Plan of Rose Garden.

A-Pillars. B-Beds. C-Borders. D-Grass. E-Gravel walks. F-Statue. G-Seats.

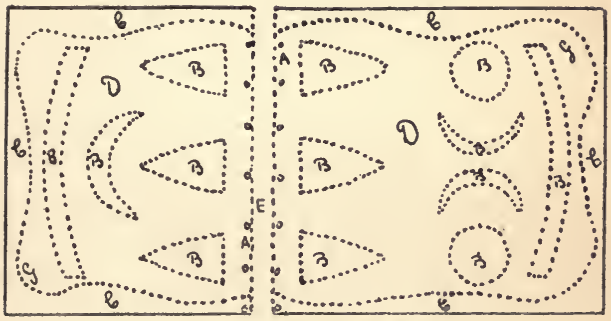

F1G. 22.-Plan of Rose Garden.

A-Pillars, B-Beds. C-Rhododendrons. D-Grass.

E-Gravel walk. G-Seats. 


\section{How to manage a Garden}

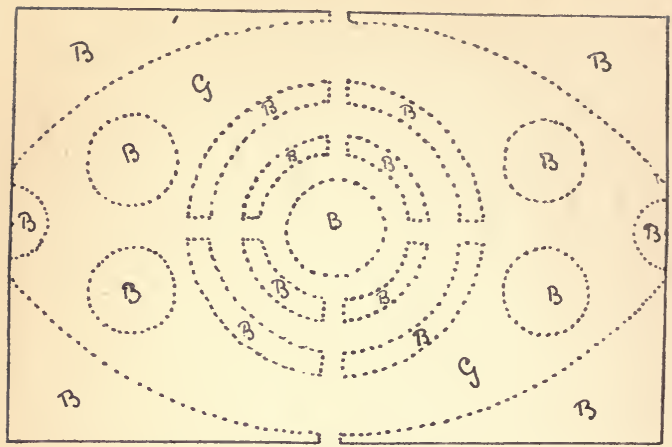

FIG. 23.-Plan of Rose Garden.

B-Beds. G-Grass.

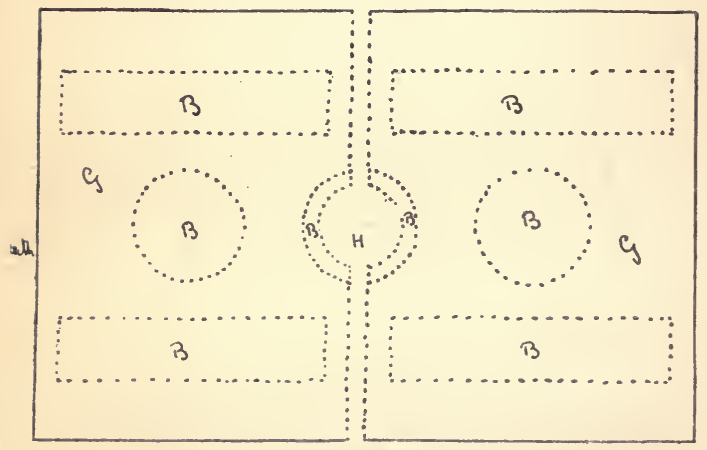

Fig. 24.-Plan of Rose Garden.

B-Beds. G-Grass. H-Gravel path.

60 


\section{Formation of a Flower Garden}

but not far from the house itself. It should be sheltered on all sides, and yet in such a way as to afford a maximum of sunlight. Such attributes belong to the rose garden shown in Fig. 21 . That figured in Fig. 22 is sheltered by a tall belt of rhododendrons, which being of different varieties give quite a picture when in flower. One or two other designs of rose gardens are given (Figs. 23, 24). There need be nothing very elaborate about any of these. In fact a rose garden must possess a keynote of simplicity if it is going to be useful, and to appeal to those possessing good taste. Provision should be made to grow roses as standards, as bush trees, as pillar, and wall plants, and let not the beautiful briars be forgotten. 


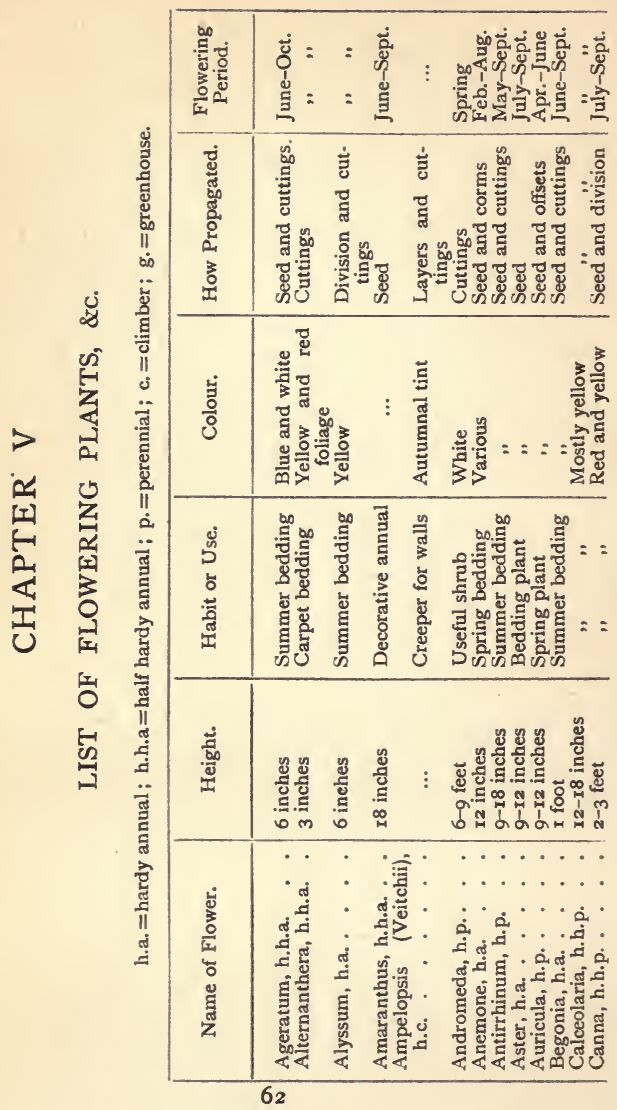




\section{List of Flowering Plants, etc.}

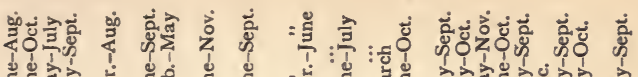

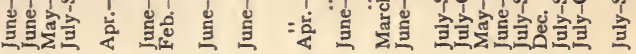

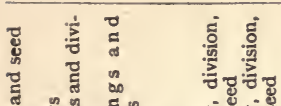

क

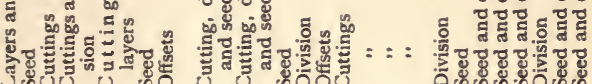

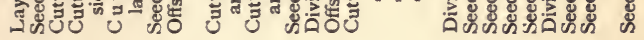

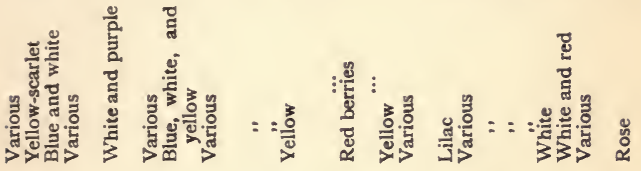

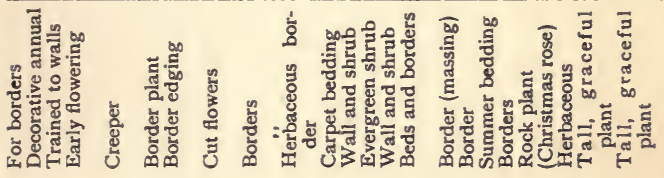

ธะฐ

鄫 काmon

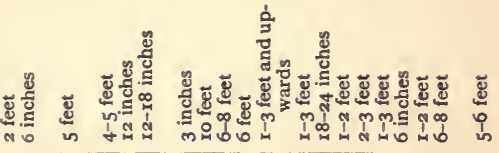

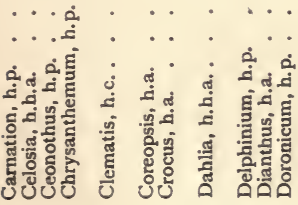

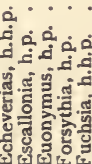

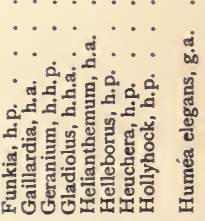




\section{How to manage a Garden}

\begin{tabular}{|c|c|}
\hline 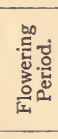 & 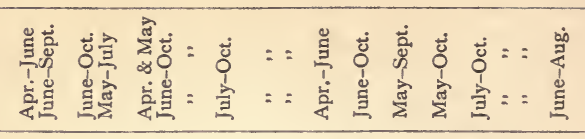 \\
\hline 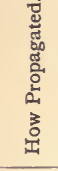 & 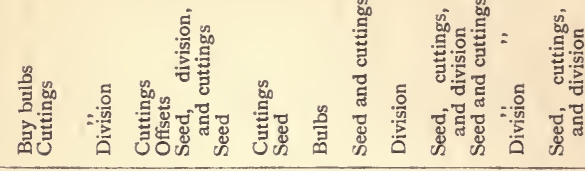 \\
\hline$\frac{5}{3}$ & 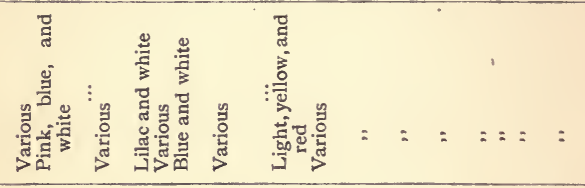 \\
\hline مّ & 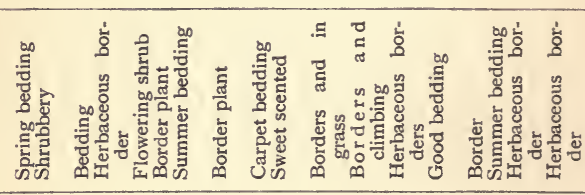 \\
\hline $\begin{array}{l}\text { 总 } \\
\text { 总 }\end{array}$ & 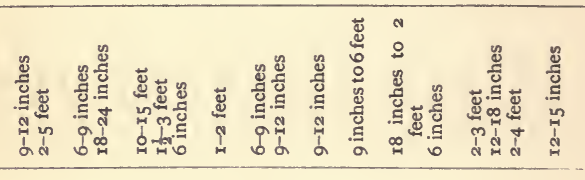 \\
\hline 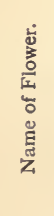 & 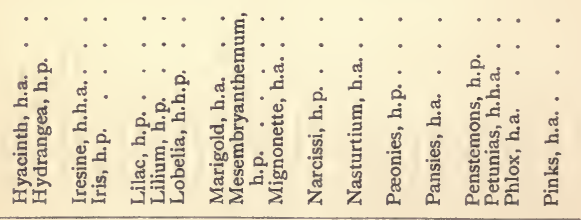 \\
\hline
\end{tabular}




\section{List of Flowering Plants, etc.}

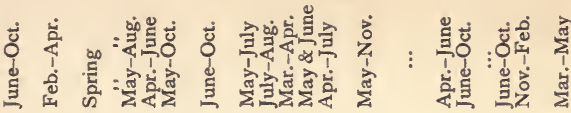

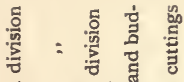

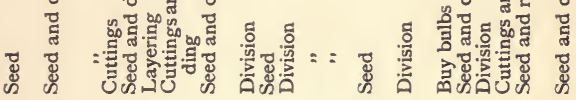

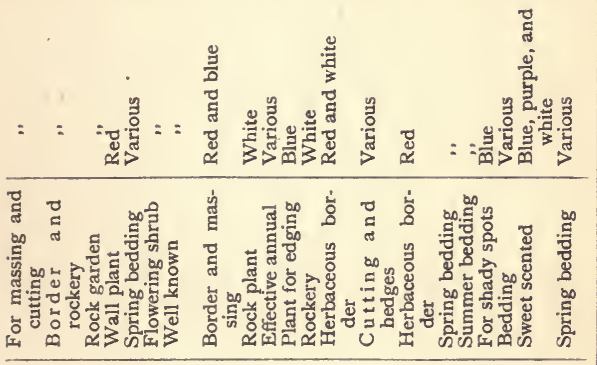

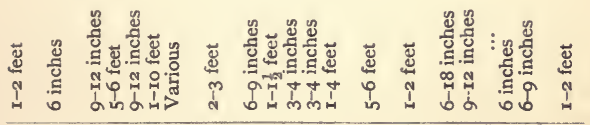

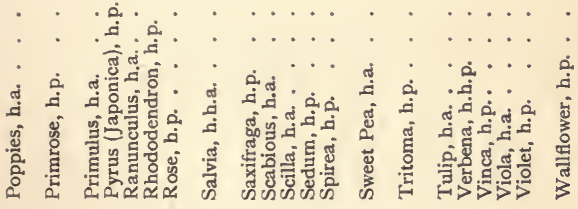




\section{CHAPTER VI}

\section{THE ARRANGEMENT OF A PLEASURE GARDEN}

\section{The Ground Work.}

IT may be well to preface the remarks under this heading with a few words which should apply throughout this work. The author has no particular garden or class of garden in view, and since it is his earnest desire to aid all those who are ambitious to make use of their facilities for gardening to the fullest extent, he cannot confine himself to the treatment of a small garden, nor of a large garden, but must deal separately with the main features which are likely to be incorporated in either. When the general arrangement of the pleasure, the fruit, and the mixed garden have been shown, the detailed construction of paths, lawns, flower-beds, \&c., will be dealt with, and the remarks will then apply equally to all. Meanwhile let all draw from this and the foregoing chapters whatever suits their own individual case, and endeavour to put it into practice. In laying out a pleasure garden, the aim should be to interfere as little as possible with the general nature of the ground. It is often possible to make a beautiful pleasure ground without altering the form of the surface. Certain it is that an undulating surface invariably commands admiration, but where this does not naturally exist 


\section{Arrangement of a Pleasure Garden}

there is grave danger that in endeavouring to form it, the result will be a revolting lack of harmony and want of proportion, to say nothing of the expense incurred. In small gardens I should lay it down as a general rule to take the surface as we find it, and make the best of it under the conditions.

In the case of a retentive soil especially, or even in that of a light one, it will often be found necessary to take out a certain depth of soil to have a good foundation for a path. It is also a good plan, when means afford, to take off the top spit from that part of the ground where shrubs or flowers will be grown, and to make up with fresh soil. In such cases much soil will be on the hands, so to speak, of the garden maker. This can, in most cases, be readily disposed of for filling up sunk places where it is feared the water might lie, in forming a mound in some appropriate spot, or in the making of a terrace. It will rarely be found that the surface is uniformly even, and in such cases it is always better to make it so, unless the mounds and dells are sufficiently marked to be really picturesque. In distributing soil in the manner indicated, take care to keep the best at the top, that of the worse kind being put at the bottom. The reverse of this is very often done, and it is found to be especially the case when a building is going on. The builders take out the foundations, putting the soil down anywhere just as it is taken out, with the result that the gardener is put to great trouble in reversing the position of the soil, or is called upon to bring into cultivation soil lying previously two or three feet below the surface. In the case of a garden sloping well from the house, a terrace is often a pleasing feature, when well 


\section{How to manage a Garden}

made. A sectional view of a garden before and after the terrace is made is given in Figs. 25 and 26. The question of

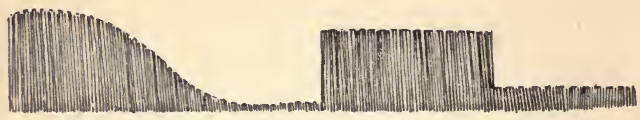

FIG. 25. Making a Terrace.

The soil before.
Fig. 26.

The soil after.

draining land, which should of course precede all operations, will be found fully dealt with elsewhere.

\section{The Arrangement of Shrubs.}

The proper and proportionate arrangement of shrubs is a matter in which many amateurs fail. In their eager desire to include a little of everything, they end up by making their garden into an intricate maze, the face of which might resemble an unbeautiful mosaic. We cannot really blame them for this, for it is a fault begotten of a virtue; but at least the fault can be pointed out, a remedy suggested, and much time, money, and labour saved, to be expended in some more serviceable manner. Shrubs seldom look well when profusely dotted about, but are generally appreciated when formed into groups and belts. An endeavour is made to show the difference in the two methods in Figs. 27,28 . If a pleasure-ground is really to deserve its appellation, it should be composed, not only of shrubs which grace the landscape with the beauty of their foliage, but should likewise have several specimens of good flowering shrubs 


\section{Arrangement of a Pleasure Garden}

which will flower in their turn almost throughout the year. Further, they should be well arranged and well cultivated. A good belt of shrubs around the outskirts of a garden, and a broad expanse of lawn within, often gives a much more pleasing effect than if several groups of shrubs were used to break up the lawn. When planting shrubs some idea of the size and form they will eventually take will be absolutely essential, in order that they be not overcrowded. There is really no harm in planting shrubs fairly close at

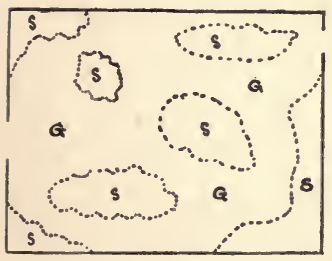

FIG. 27.

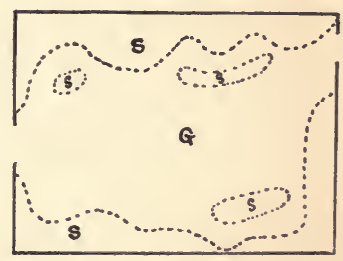

Faulty arrangement.

FIG. 28.

Shrubs.

Pleasing arrangement.

G-Grass. S-Shrubs.

first, if a firm resolution is made to thin them out as required, but experience shows us that it is easier to make the resolution than to keep it. In view of this it is perhaps better to advise planting thinly at first, and if the ground seems bare to plant the vacant spaces with flowering plants, which will latterly have to be removed. Whenever it is possible a margin should be left for flowers, either annuals or perennials. There is a large variety of plants especially suited to this position, and the intending grower should make a point of viewing some garden where they are known 


\section{How to manage a Garden}

to be well done, and take his lessons of what he would like, and what would suit his circumstances therefrom.

There is a wealthy range of choice among ornamental trees for purposes of small, as well as large gardens, not only among deciduous trees, but also among conifers. Before planting coniferous trees it should be ascertained whether they are known to do well in the district, for nothing will spoil a pleasure garden more completely than the appearance of ragged specimens of choice varieties of this class. As hinted in preceding pages, conifers are known to be averse to the smoke-laden atmosphere of large manufacturing towns, and should be avoided in such cases. Where it is intended to grow specimen trees, particular attention should be given that they are afforded a position where they will have every opportunity of growing symmetrically. In the selection of trees it is necessary to ensure harmony in the tint of foliage alike in the autumn, spring, and winter, and to see that from the walks, and the windows, the best view is obtained, and one beauty does not hide another. To label all trees is to make the place of some educational interest, and the trouble and expense of doing so is small.

\section{Paths, Drives, and Walks.}

If there is one thing more than another which is taught among gardeners it is that paths in pleasure grounds should, with few exceptions, take a wavy outline. This is splendid advice, but unless qualified it is likely to lead into errors such as are found in Fig. 29, where the curving is carried to extremes. If anything this is a worse fault than 


\section{Arrangement of a Pleasure Garden}

having all straight walks, for in the latter case there is the internal evidence of method; but in the other a vain and presumptuous imitation of the artistic, and failure to secure it, are seen. Two other illustrations are shown which will explain on sight how much better it is to have a few curves in place of so many angles. (See Figs. 30, 3I.)

The width of the walks and their position in the ground must be governed solely by the prevailing circumstances.

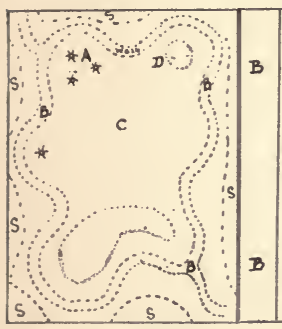

FiG. 29.

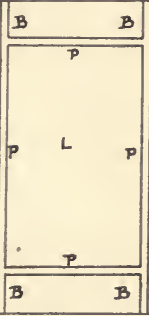

Fig. 30 .

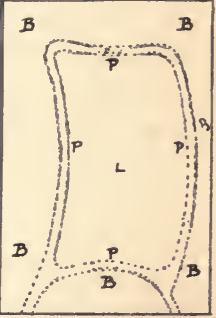

Fig. 3r.

Paths.
A-Trees. B-Walks.
C-Lawn. D-Beds.
B-Border.
B-Border.
P-Path.
P-Path.
S-Shrubs.
L-Lawn.

Broad walks in a small garden are entirely out of place; for they betoken a wanton waste of space, while narrow walks are not suitable to a large garden. When less than four feet wide paths seldom look well, so that I would advise that in the large majority of cases this be regarded as the minimum. As to the material of which they are composed, gravel is generally in favour, but if stern utility is to be considered, asphalt or cement will be used, such 


\section{How to manage a Garden}

as is found in some of our parks. By the use of some of our patent weed-killers, weeds can easily be kept from the paths. Personally, I think a firm walk far more comfortable to traverse than one covered with loose gravel. Certain it is, that if a walk is to rightly serve its purpose, it must be comfortable to walk upon in all weather; must be free from weeds and rubbish, and have a clearly defined outline. The approach walk or drive must of course be fairly wide if it be entitled to be called a carriage drive. It should never be less than ten, and in most cases fifteen feet.

\section{A Rock Garden.}

We are all aware that a few stones put together with spaces between for the culture of flowers will be styled by the amateur his "rock garden." In this he is no doubt somewhat soaring, but it cannot be considered blameworthy. Here, however, the meaning is a piece of ground set apart especially for the formation of several rockeries intersected by paths. To be suitable for the majority of rock plants, it will need to be sheltered and slightly shaded, and should in most cases be hidden from view of the windows by belts of shrubs. A dip in the surface would (all other things being equal) admirably fulfil the purposes of a rock garden. There should be no formality of any kind about it. The position of rocks and stones in nature should be considered, and intelligently followed. To put stratified stones in an upright position, with peaks jutting rudely above the others, is to violate one of the main principles learnt in the for- 


\section{Arrangement of a Pleasure Garden}

mation of rocks; for in nature we seldom, if ever, see rocks so placed. It is also a great fault to endeavour to imitate nature in her more remarkable performances, in poising one rock on another; for it only illustrates how puny are the works of man compared with the colossal products of the universal laws. Let us endeavour in our dealing with nature to admire the wonderful, but in all cases to confine our imitation to the beautiful. In this way we may perhaps succeed in pleasing the eye of man without annoying his sense of proportion.

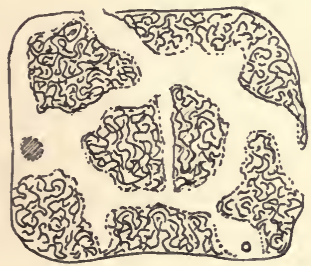

FIG. 32.

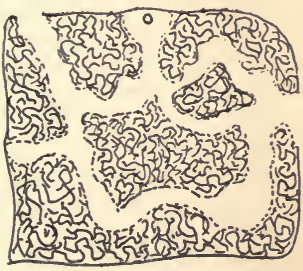

FIG. 33.

Rock Gardens.

To any one taking a deep interest in this phase of gardening, and who has the time and opportunity, I would advise a visit to the rockery of the Royal Botanic Gardens, Edinburgh, which is splendidly conceived, fully furnished, and well cultivated. He may again learn something from $\mathrm{Kew}$, or if he be more centrally situated, he might view the rockery of Messrs. Backhouse of York, where a speciality is made of the feature, and where innumerable hints in formation and furniture could be gained. If, again, it should be the 


\section{How to manage a Garden}

reader's good fortune to be within easy distance of the world-famed Clifton Suspension Bridge, I should certainly advise a visit, from which may be seen some highly instructive examples of rock formation as well as some artificially formed rockeries. Many facts may be learnt in an old disused quarry. Note especially those places where the vegetation succeeds, and study the position of the rocks, so that the necessities of the plants may be learnt and duly catered for in your own modest endeavour. Plans of rockeries are here given which will render the irregular form which a rockery should take easily understood. The method of constructing a rockery will be given in due course (Figs. 32 and 33 ). 


\section{CHAPTER VII}

\section{ARRANGEMENT OF A FRUIT GARDEN}

\section{The Cottager's Fruit Garden.}

IT may hardly be supposed that the cottager or the amateur is likely to devote the whole of his ground to fruit culture, although a large number could do this with benefit to the community and to themselves. It must be stated that the extent to which fruit growing is carried out in this country by the working classes is considerably less than it might be. It is most unfortunate (and is chronicled here in order to draw public attention to the matter) that where houses are being built in rural districts the amount of garden allotted to each cottage is indeed very small, and in some cases is no larger than that enjoyed by the town dweller. This happens where land for agricultural purposes is very cheap. It must be said, with all due deference to the opinions of others, that this action on the part of landowners, tending to restrict, or altogether annul, the cultivating power of the cottager is highly reprehensible, and is nothing short of a national danger. The present condition of our laws does not empower interference, but our land laws, be it remembered, are by no means immutable. This being no place for politics, the matter had better be left for the reader's own meditation. Meanwhile we 


\section{How to manage a Garden}

will consider what can be done by a cottager having at his command land which might well be used for fruit culture. Supposing the space at disposal to be half an acre, I have prepared a plan (Fig. 34) which is arranged with a view to affording a variety of fruit, and that without

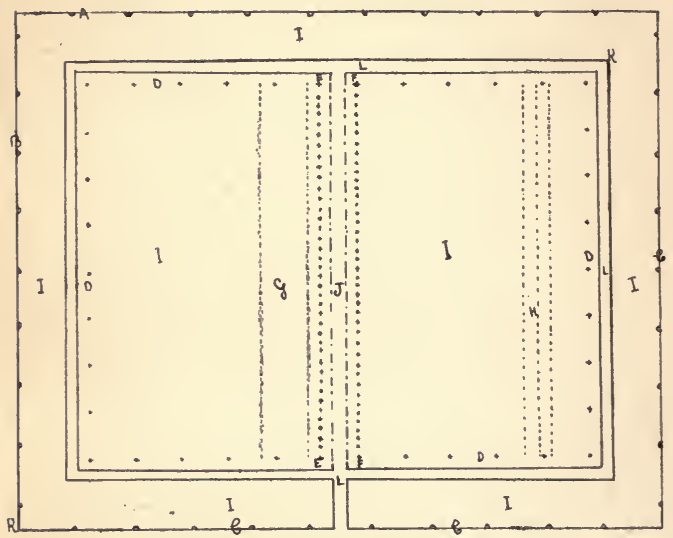

FIG. 34.-Half an acre of fruit and vegetables.

A-Damsons, B-Plums. C-Apples. D-Pyramids, E-Currants.

F-Gooseberries. G-Strawberries. H-Raspberries. I-Vegetables. I-Ground walk. K-Hedge. L-Path.

altogether excluding the culture of vegetables. Vegetables, giving a quicker and more bulky return, are usually given first place; but there can be no solid reason why the two should not go together. It is of course necessary to point out that, especially in the case of the larger fruit, there must be some solid ground for believing that 76 


\section{Arrangement of a Fruit Garden}

he who plants shall also pluck the fruit, and this can only be where there is some security of tenure, or where arrangements have been made for suitable compensation in the event of the planter quitting the holding.

\section{A Variety of Fruit.}

The greater the variety of fruit the more enthusiastic should be the interest taken in the fruit ground. A plan

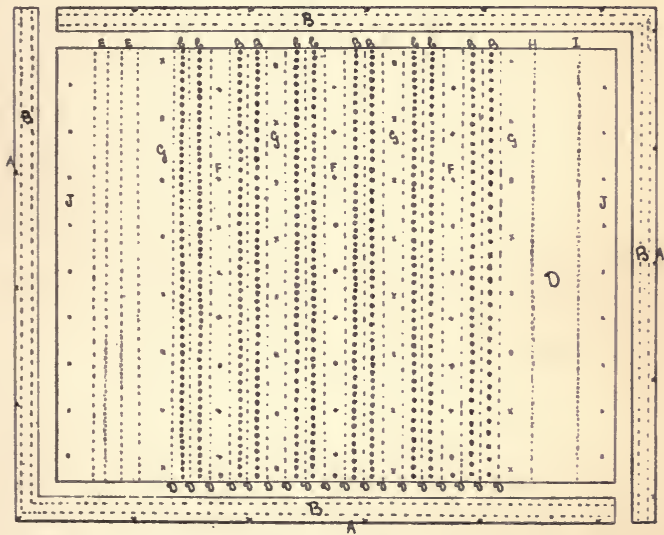

Fig. 35. - Half an acre of mixed fruit.

A-Damsons. B-Gooseberries. C-Currants. D-Strawberries.

E-Raspberries. F-Pyramids. G-Standards. H-Blackberries. I-Logan berries. J-Espaliers.

has been prepared for the purpose of showing how a plot of ground (Fig. 35) can include a large variety of 


\section{How to manage a Garden}

different fruits, and yet each have all the conditions necessary for complete success. It would be tedious and unnecessary to go through the plan, for the references will clearly show what is meant. It might be added that, apart from the money profit which would in most cases follow an extension of fruit culture, we have the opinion of eminent doctors that ripe fruit is highly nutritious, and is far more wholesome than many of the patent foods so freely advertised, and as we venture to suppose so freely bought. Then, again, there is the possibility of making jam, which in the case of a growing family cannot fail to be beneficial to the children, and a great saving to the parents. It is greatly feared that many of the jams at present on the market have not those wholesome and nutritive qualities which should accompany whatever is formed from fruit. In view of this the making of jam, by cottagers and others, should by all means be encouraged.

\section{Distances to Plant.}

Although it is not intended to go into the question of planting, which will be fully dealt with in a succeeding chapter, it will be well to point out that overcrowding is an economic evil. At the same time economy of the true type demands that there should be no waste of room. To strike the happy medium is not difficult.

It often happens that trees are planted thickly at first, with the laudable intention of thinning out later on, but in many instances this is neglected, much to the detriment of the trees, and, if he could but recognise it, to the dis- 


\section{Arrangement of a Fruit Garden}

advantage of the grower's interest also. If the promise to thin can be relied on, there should be no reason to militate against the practice of planting closely at first, but in view of this difficulty it will be well to plant more permanent trees, such as apples, pears, \&c., remotely, and crop the intervening spaces with small fruit and vegetables, eliminating these gradually as the spread of the trees and their need of the land extends. To overcrowd trees-that is to deprive them of the freedom of growth, of light, and of sunshine-is wrong and wasteful, but it is quite as wasteful to allow them more land than they can use, and it is a most economic practice to cultivate every spare foot which does not endanger in any way the fruitfulness of the trees. The real distance apart can only be measured by an approximate estimate of the size they will become on the system on which they are grown. Figures are but a guide, and are given simply with that view. Pyramids may be planted 6 to 8 feet apart; wall trees, 10 to 20 feet; bush trees, 10 to 30 ; small fruit (gooseberries and currants), 5 to 8 feet, raspberries, blackberries and loganberries, 2 to 3 feet; strawberries, 2 to $2 \frac{1}{2}$ feet; tomatoes, I to 2 feet. 


\section{CHAPTER VIII \\ VARIETIES OF FRUIT \\ Apples.}

Devonshire Quarrenden, Irish Peach, Duchess of Oldenburgh, Cox's Orange Pippin, Ribston Pippin, Lady Sudeley, Blenheim Orange, Keswick Codlin, Emperor Alexander, Lord Derby, Betty Geeson, Bramley's Seedling.

\section{Pears.}

Doyenne du Comice, Louise Bonne of Jersey, William's Bon Chrêtien, Jargonelle, Pitmaston Duchess, Marie Louise, Beurré Diel, Souvenir du Congrès.

\section{Plums.}

Coe's Golden Drop, Czar, Victoria, Late Rivers, Green Gage, Early Prolific.

\section{Peaches and Nectarines.}

Lord Napier, The Cardinal, Stanwick Elruge, Early Rivers, Bellegarde, Princess of Wales.

\section{Apricots.}

Frogmore Early, Moor Park, Large Early. 


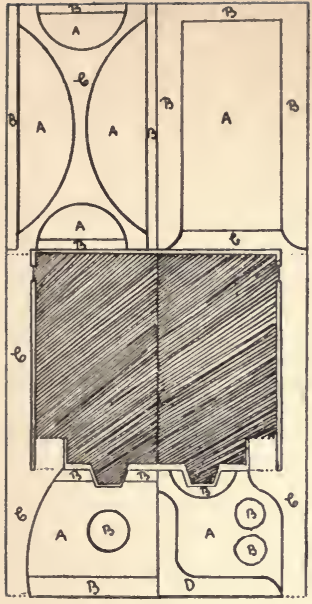

Fig. 36 .

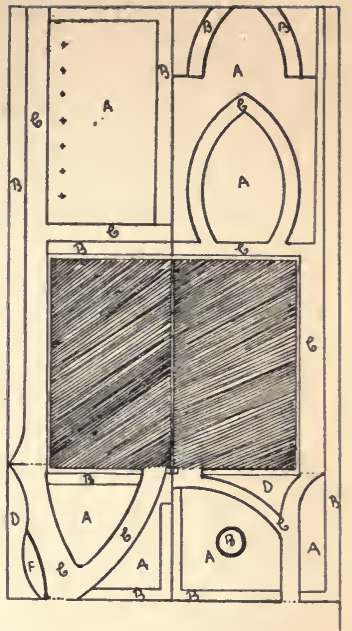

FIG, 37 .

Semi-detached Villa Garden.

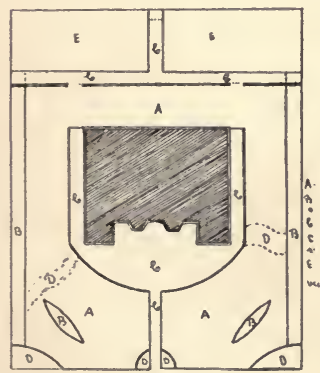

FiG. 38.

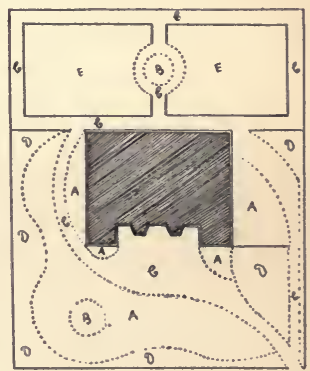

FIG. 39 .

Detached Villa Garden.

A-Lawn, B-Beds. C-Paths, D-Shrubberies. E-Vegetables. 


\section{How to manage a Garden}

Cherries.

Black Eagle, Early Rivers, Noble.

Currants.

Black_Black Naples, Lee's Prolific; Red-Raby Castle ; White-White Grape.

Gooseberries.

Lancashire Lad, Ironmonger, Winham's Industry, Red Warrington.

\section{Grapes.}

Muscat of Alexandria, Foster's Seedling, Buckland Sweetwater, Black Hamburgh, Gros Colmar, Alicante.

\section{Strawberries.}

Royal Sovereign, Black Prince, Dr. Hogg, The Leader, The Laxton, Sir J. Paxton.

\section{Raspberries.}

Superlative, Carter's Prolific. 


\section{CHAPTER IX}

\section{THE MAKING OF PATHS}

\section{Qualities of a Path.}

THERE are some special qualities which all paths should possess before they can be considered to have fulfilled their purpose. A path should at all times be firm and dry, giving comfort to the tread in all weathers, clean, of sufficient width, and built of material which, in construction and upkeep, have due regard for economy. Unless all walks possess these attributes, they are in some way wanting. We will now examine the means of securing a good walk, and the keeping of it in that condition. Previous mention has been made as to the width of a walk, which should, whilst being sufficient for all practical purposes, be proportionate to the size of the place. In a pleasure ground the walks should be winding, but there must be some apparent reason for this wandering from the straight line. To make a path take a zigzag course without some apparent reason, gives an idea of stupidity to the whole concern. A tree, a bank, a belt of shrubs, a rockery, an arm of water, and many other devices may be put in the ground for the purpose of lending colour to the necessity of giving the walk a serpentine outline. Two illustrations (Figs. 40 and $4 \mathrm{r}$ ) are given to show where these conditions are absent, and how they may be put in, the 


\section{How to manage a Garden}

general effect of both systems being thus clearly seen. Where the strong cause of utility must have supreme sway -as in the vegetable garden where much carting and barrow work must be done-curving paths would be altogether out of place.

\section{The Composition of a Walk.}

It is known to most people that marking out the walks is one of the first operations in the making of a garden;

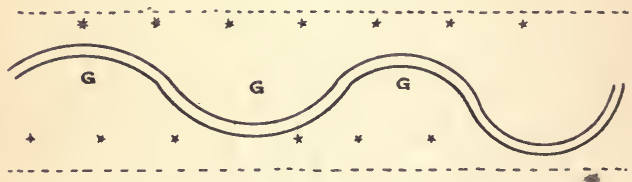

FIG. 40.-Walk winding without reason.

G-Grass.

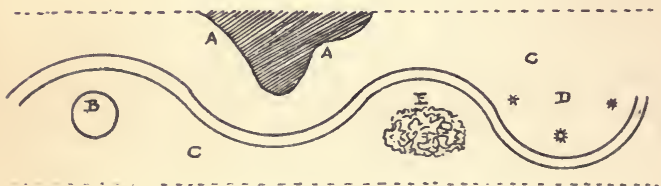

FIG. 4I, - Reasons for winding a walk.

A-Water. B-Beds. C-Grass. D-Trees. E.-Shrubs.

and for this reason there can be no excuse if they are not properly arranged and formed. Now we have a fairly large range of choice before us in the material of which our paths are to be made. The walk may be composed of 84 


\section{The Making of Paths}

hard gravel, loose gravel, ashes, concrete, or asphalt. We will endeavour to lay down impartially the special advantages possessed by each. Hard gravel is formed by the judicious admixture of sand to the stone, and as long as the right proportion is used all is well, but it often happens that there is more sand than is necessary to bind it, with the disastrous result that during wet weather the walk becomes one layer of thick, sticky mud, which is trampled throughout the house, over the lawns, and makes a large increase of work for every one on the place, besides in time rotting the path. This is, of course, wrong, and must be speedily remedied. The fault, however, does not always lie directly with the one responsible for the making of the path, for the gravel is often sold with a far too liberal proportion of sand. Now a hard, firm walk, such as is in most cases the ideal one, must have just sufficient sand with which to bind it, and not lose its firmness on the first shower. That such a path is within the range of practicability is beyond all dispute, as is abundantly testified by the many well-formed walks found in private gardens and public parks. As to the pleasure of walking upon such a path, I think there can be no two opinions on the matter; and if we except the grass walk, which does not here concern us, I think that a thoroughly well-formed and well-kept firm gravel path must bear the palm for perfection when compared with others. Loose gravel walks are often seen, not only around large mansions, but even around the villa residences now springing up about our towns. They usually look pretty. They are easily hoed. But are they easily swept? Are not the stones likely to be kicked on to the grass to come into contact with the mower 


\section{How to manage a Garden}

or the scythe? Are they easy to walk upon for old and young; those with tender and those with sound feet? Do they not more quickly destroy the boots? These things must be considered. If a strong liking is entertained for this form of walk, and these objections can be overruled, then by all means have a loose gravel walk. In this case it is essential that the gravel be clean, that there lurks no sand among it, and that the drainage is sufficiently sound. To look well, all the gravel should be able to be passed through an inch sieve, but very little should be small enough to pass the meshes of a quarter-inch one.

Ashes, pure and simple, are never used for the making of a walk in any part of the grounds where a good walk is really needed, and since it is only employed in cases where the need for a good walk is not sufficient to warrant much expense, it need not here engage our attention. We will pass on to the consideration of the merits of asphalt and concrete walks. There is undoubtedly a great prejudice against these walks, mainly on account of their artificiality as it is termed. All roads are artificial, only with a longer acquaintance with macadamised roads we fail to so clearly notice the fact. The artificiality itself should not militate against the adoption of asphalt and concrete walks if they are useful, and do not too glaringly destroy the naturalness of the scenery. In some public parks which I could mention, such walks having been well formed are thoroughly appreciated, since they are always clean and dry even immediately after a shower, and by such tests should the value of a path be judged. When there is a deep slope it is well-nigh absolutely essential that such a form of walk should exist; for during a heavy storm the gravel will be 86 


\section{The Making of Paths}

washed down, and thereby entail endless unnecessary labour. Beneath trees also it is often noticed, not only in gardens but also along country road-sides, that the road or walk does not dry up quickly after a shower, and the gravel is there likely to rot, or the walk at that point be objectionable. Such arguments cannot be used against asphalt and concrete walks. The additional expense would not, I think, outweigh the increased advantages; but on this subject I much prefer that readers should judge for themselves; and having now pointed out the advantages and disadvantages of the various forms of walks, I will address myself practically to a description of their formation.

\section{The Construction of a Walk.}

Knowing, as we now do, what qualities should go towards the make-up of a good walk, it behoves us to see how these ends are to be attained. The class of soil to be dealt with has much to do with the method of construction. In a dry soil it will not be necessary to take out so much soil to form the foundation as in a wet soil, where drainage would be impossible without it. Now, the limits and outline of the walk being clearly marked out, excavation should be made to the depth of eighteen inches to two feet. When there is plenty of material, and the expense of labour is not a serious item, I should certainly advise that quite two feet of soil be - taken out; for besides thoroughly draining the path, it has also the advantage of keeping drier some at least of the soil skirting the path. When the bottom has been 


\section{How to manage a Garden}

beaten hard and made of a concave or convex shape, according to the position the pipes will take, these should be laid in. Pipes may or may not be necessary, but when they are, a row should be put down the centre of the walk, or at each side, the bottom of the walk sloping towards the pipes. Brickbats, stones, mortar rubbish, clinkers, glass, and all hard substances, such as broken crockery, \&c., may be thrown in. These should be broken to about the size of a cricket ball, and well rammed down. When the former level has been nearly reached, the work may with advantage be left for a week or two to let it pitch, although there is no downright necessity for this. Some good gravel should then be obtained-not such as is found at the top of a path, but of a coarser sort, almost like that used on the public highways. About six inches of this should be put down, and among it may be scattered some lime rubble, if there be any about. This also should be well rammed, and it then remains to put on the final dressing of gravel, which should be neither too coarse nor too fine, but all capable of passing through the meshes of an inch sieve. With this may be put some sand, either before it is put down or afterwards. The face of the walk should present a slightly convex appearance, just sufficient to adequately throw off the water, but no more. Of course the wider the walk, the greater must be the height of the centre compared with that of the sides; but in no case, and certainly not in a small walk, should the curvature be so pronounced as to make walking uncomfortable. In the sectional plan given (Figs. $42-44$ ) is shown what is really meant. When the form of the face is made, water should be poured over if dry, and the roller put on. 


\section{The Making of Paths}

This should be daily repeated until a good firm surface results.

The like process is necessary in making an asphalt and concrete walk, with the exception that these materials are put on at the top instead of the small gravel. A good walk can be made by procuring clean-sifted coal ashes, one part, slaked lime, two parts, and adding sufficient boiling
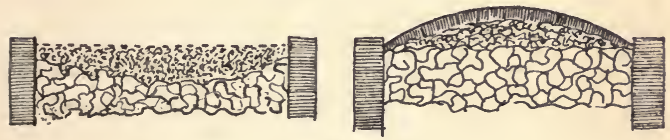

FIG. 42. Badly made paths. FIG. 43.

Too flat. Too curved.

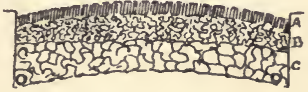

FiG. 44.-A well-made walk.

A-Fine gravel. B-Coarse gravel.

C-Brickbats.

tar to make the whole into a mortar. This should then be spread over the walk, beaten down, some sand strewn over, and then rolled. Three inches of this should make a good walk. Or small gravel may be obtained and mixed with a due proportion of cement and lime to be formed into a concrete. Drain-pipes will have to be put down along the side of the path to take the water to the drainage below. To cut sidings and holes in the turf 89 


\section{How to manage a Garden}

always appears to me a very primitive form of drainage, and one which is by no means entirely satisfactory.

\section{The Upkeep of Paths.}

Once the paths are well formed, there is little to learn regarding their upkeep. They certainly will wear, and should be repaired before they are so far gone as to become a nuisance. When new gravel is put down, the old should be loosened with a pick, and if found to be rotten, carted away. The autumn and winter afford good opportunities for attending to the making and repairing of roads, not because of the nature of the season, but because of there being then less work about. To keep a walk free from weeds there is no better, and more economic, plan than making frequent use of the weed-killers now on the market. 


\section{CHAPTER X}

\section{MAKING A LAWN}

\section{Making a Lawn.}

THERE are two different ways of forming a lawn-by laying down turfs and by sowing seed. Which of these two methods is the better depends entirely on the requirements. If a lawn is wanted quickly, it can be got by using turfs; but if a good lawn is required at small expense, and there is sufficient patience to wait for it, then by all means let seed be sown. The disadvantage in laying down turf is, that the defects of an old lawn are thus implanted, and gain renewed vigour on a new. With seed-sowing we have, so to speak, a carte blanche to work upon. The first thing to consider is whether the ground is drained. If not, then that work should at once be performed. In heavy soils the drains will need to be nearer the surface, and nearer to each other, than in a lighter soil. In no case should they be less than eighteen inches from the surface. Let us, however, presume that drainage is completed; there is still another important work to perform, and that is to dig and trench the ground to the depth of eighteen inches if possible, and in any case not less than one foot. In this work an eye should be kept to making the soil level, by freeing the surface from lumps and hollows. It is a good plan to work among the 


\section{How to manage a Garden}

soil some well-decayed manure and some leaf soil, and if heavy, some lime. With a heavy soil should be incorporated, when possible, some good loam, free from weeds; and an opportunity here presents itself of disposing of a good quantity of sifted coal ashes. The digging must be to a uniform depth, whatever that may be.

When the digging has been completed the surface should further be made level by means of the rake, for no matter how good the digging may be, it is impossible to make the ground sufficiently even with a spade. When levelled in this way let it be trodden down and then raked again. When making a croquet lawn, it is especially desirable that the ground be made perfectly level. To ascertain whether this is so can be done only by use of the borning rods (which are so simple as scarcely to need explanation) and a spirit-level. On a large scale other expensive instruments would be used, but in ordinary cases a careful use of the spirit-level will give equally good results. A piece of board one inch thick, four inches wide, and ten feet long, is procured (commonly called a straight-edge). A thick peg is driven in at one end of the lawn, leaving perhaps six or nine inches out of the ground. The straight-edge is then stood, thin edge upward, on this; and at its other end is driven another stake which is approximately supposed to equal the level of the first. With the ends of the board on the pegs, we place the spirit-level in the middle, and drive the second peg down to such a depth that the bubble of the spirit level is in the centre of the tube. These two pegs now being level, we let the board rest on the second and a third peg and do in like manner, until there are sufficient pegs to 


\section{Making a Lawn}

guide us. The level of the lawn is then taken as one, two, four, or six inches below the top of the peg. When completed and satisfaction is assured as to the levelness of the lawn, the pegs may be withdrawn or driven deeply down. (See Fig. 45).

We now come to the dividing line. Up to this point the work is the same whether turf be laid or seed be sown. Let us first of all consider the question of turf-laying. Turf is usually procured cut into pieces, three feet long, one foot wide, and two inches deep. This is rolled up. If the lawn is made thoroughly level and the turf has been well cut, there is not likely to be any great difficulty in

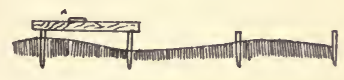

FIG. 45--Levelling a lawn.

A-Spirit-level.

laying it down. It has already been mentioned that the surface should be firmed and raked, and the next work is to lay some turf along the outside, allowing it to overlap so as to afterwards render it possible to cut a clean verge. This should then be beaten. Proceed afterwards to lay down the inner part, taking care to keep the turfs close together, and when they may be wanting in thickness, some soil (in a barrow close by) should be put beneath, to avoid even the smallest inequalities. This also should be beaten in as work proceeds. It should incidentally be mentioned that during very dry, very wet, or frosty weather, the work should not be undertaken, or it can 


\section{How to manage a Garden}

hardly be expected to prove successful. When all the turfs have been laid down it is a good plan to get some soil, composed of fine loam and leaf soil both passed through a half-inch sieve, and scatter over the surface, dispersing it well with a rake, so that besides filling in the spaces between the turfs, it may also act as a topdressing to help forward the reinvigoration of the grass.

An important piece of advice to be given is that good seed be sown. It is essential also that the seed, besides being good in itself, should also be peculiarly adapted for the particular purpose and the particular soil. For this reason it is strongly urged that application be made to a seedsman who makes a speciality of grass seeds, explaining to him clearly what is required, the nature of the soil, and the computed area to be sown. He will then forward what is estimated to be suitable and sufficient. From one to two pounds per rod is the quantity usually found necessary. It should be sown broadcast on a mild day and be afterwards rolled in, taking precautions, such as are deemed necessary, for warding off birds. The best time for sowing is in the spring-about the end of March. When the grass has grown to a height of three or four inches, it should be cut with a sharp scythe, and throughout the first season it is advisable to use the scythe in preference to the lawn-mower, which is apt to tear the grass before it has gained sufficient root-hold. After each mowing the roller should be put over if the weather is at all suitable, and should dry weather ensue some means should be made for watering it. 


\section{Making a Lawn}

\section{Mowing and Rolling.}

For the perfection of a lawn, mowing with a good machine is absolutely necessary, and should be done frequently. I use the epithet "good machine" advisedly, for it is patent to all whose experience is in any way extended that a bad machine will tear up a lawn and quickly destroy its beauty and its utility. It is not so often the fault of the manufacturer that a machine becomes bad, as it is the fault of the owner in not keeping it in a proper condition. If a machine is put away when wet, is seldom oiled, is not properly set, and is run over stones, sticks, and all sorts of rubbish, it is not at all likely that it will bear the strain, and under such conditions the strongest machine will quickly be broken up. To cut the grass fairly low down without danger of biting and pulling it up by the roots, its knives should be made to pass so closely to the shoe-plate that they will cut paper at any point, and until the proper method of setting it higher and lower, according to the exigencies of the moment, be thoroughly understood, it will be impossible to have any guarantee that it will work satisfactorily. Sticks and stones should be swept off the grass before the mower is put upon it; and when being put away at night the machine should be cleaned and oiled, so that it may not rust. During the winter season when the machine is not in use it should be taken apart, each piece well oiled, and stored away separately, taking particular care not to lose the bolts and screws.

Mowing should be started early in the year, and kept on well into the autumn. Avoid also cutting the grass 


\section{How to manage a Garden}

when it is wet. It is all very well to cut the grass with a scythe when the dew is upon it, but it would not act with a machine, as any one working it would speedily discover. To work it well it is better to cut at least once a week in the height of the season, but less often in the beginning and end, as the grass does not then grow so rapidly. There is often an argument as to whether the cut grass should be left on the lawn or taken away in the box. It may be answered that it depends primarily on individual taste, for there is no very decided advantage either way. If the grass is left on the lawn it will afford some measure of manure, whilst when allowed to become long before being cut, and then left, it will disfigure the lawn. Hence we may adduce the safe principle that if the lawn is regularly mown there is no reason why the grass should not be left, but if neglected for a fortnight or more the grass should certainly be collected. At each mowing the verges, whether skirting walks, beds, or borders, should be clipped. If allowed to become overgrown the verge is very quickly spoilt, and weeds will the more abound in the path or border. The verges require also to be cut straight at least once during the year, and the soil resulting may be used for potting purposes. Rolling should be done after every mowing and every shower.

\section{Cleaning a Lawn.}

Next in importance to making a good lawn is keeping it in that condition which it enjoyed on completion. This is not so difficult as the work of cleaning a bad lawn, which by the ordinary means of weed eradication 


\section{Making a Lawn}

is a work almost superhuman. The moss is the most difficult to get rid of. It should be raked off as far as possible with an iron rake whose teeth are closely set. The idea after most of the moss has been removed is to get the grass to outgrow the moss, and this is effected by top-dressing liberally with prepared soil or with woodashes. Moss, however, is usually an indication of want of drainage, and in such cases the proper remedy should be applied if the expense can in any way be spared.

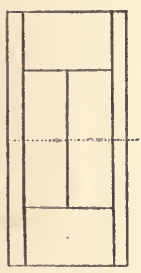

FIG. 46.

Lawn Tennis Courts.

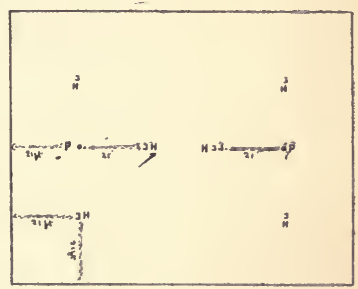

Fig. 47.

Croquet Lawn.

Otherwise there will always be a battle between the labour of the gardener and the growth of moss. Among other weeds difficult to destroy are daisies, plantains, thistles, \&c. There exist some patent contrivances for pulling up these weeds, but it means much labour and by no means proportionate success. Perhaps the safest of all plans is to go over the lawn armed with a knife and a bottle of carbolic acid. Cut off the top of the plantain or other weed, and then drop a little of the carbolic acid into the roots. Usually this will have the effect of 


\section{How to manage a Garden}

completely destroying them without leaving on the lawn any unpleasant reminder. When the lawn is almost wholly covered with undesirable weeds, it is far better to take off the turf and remake the lawn entirely, or such part of it as is thus infested. With a new lawn there is every possibility for a painstaking owner to keep it clean, if he will only be watchful to keep the grass in good growth and destroy weeds at first appearance.

Diagrams are here given showing the method of making a lawn for tennis and for croquet, and it is even more important in these cases to have the lawn in an ideally even condition, and free from moss and other weeds. (Figs. 46 and 47.)

A word of advice on the subject of lawn mowers may not be out of place. Avoid cheap makes, they are always dear in the end; get one by a good maker, and with fair usage and proper attention it will last indefinitely. My own experience is that for durability and effective work Ransome's lawn mowers cannot be beaten. 


\section{CHAPTER XI}

THE MAKING OF́ BEDS AND BORDERS

The Shape of the Beds.

WE have already seen (page 49) that although the flower beds should bear some relation to each other, yet that relation should not be the direct outcome of any geometric conception, or so apparent as to show that more pains have been taken to set down the plan on paper than to furnish one to suit the special exigencies of the case. Let us now address ourselves to the question of the special shape which beds should take. Obviously no hard and fast rule can be laid down, but it is desirable to guide the taste of the amateur grower into the right channels, for there is abundant opportunity for error. Let it then be asserted that an easy simple outline is invariably more pleasing than ingeniously conceived and skilfully workedout plans, which have a multitude of angles or of so intricate a nature that it would occupy more time in committing it to paper than it would take to work an easier one on the ground. Some idea of what is meant to be avoided may be gleaned from the three Figs. 48, 49, and 50. It might be well also to give in figure the method employed for forming beds of different shapes. (See Figs. 5 I to 62.)

There is perhaps no more pleasing shape for a bed than 


\section{How to manage a Garden}

the oval. It has the full grace of the circle, but gives a larger area without taking away the ease of planting. The

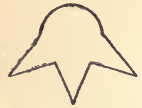

FIG. 48.

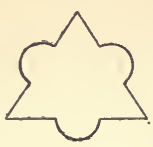

Fig. 49.

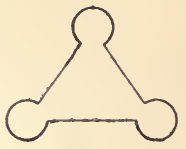

FIG. 50 .

Bad designs.

difficulties of planting a bed of irregular outline must be known to some readers, who will appreciate one that has in
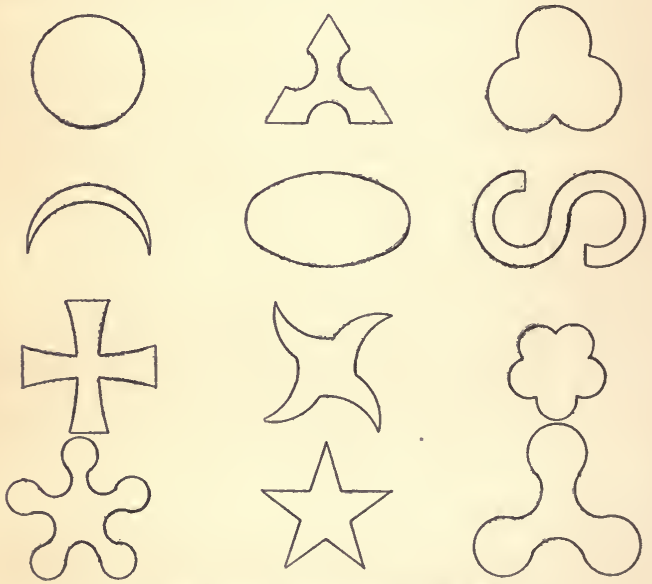

FiGs. 51-62,-Good designs for beds.

it all necessary beauty and a good deal of common-sense utility. That utility and beauty are antagonistic is an I00 


\section{The Making of Beds and Borders}

exploded theory, and can be no longer maintained as relating to any department of the garden. The famous scroll beds are of yesterday. We admire therein the genius of man saturated as it was with all the conceptions of an ornamental education, but we cannot admire their ideas of Nature in the imitation of which they were so sadly lacking. Even to-day, when we gaze on carpet-bedding in our parks, we fail to admire the beauty of the plants themselves, for that is absorbed by the regularity of their combination. This is as it should not be.

\section{The Practical Part of Formation.}

Having seen that the shape of the bed should be at once graceful and useful, we turn to the question of formation itself. If the soil is of good quality, and suited to the necessities of its future occupants, it will need simply to be dug over, and sufficient manure or other soil incorporated to raise it above the surrounding level; but if it is of a cold, damp, uncongenial nature, and in its very essence unsuitable for flower culture, it should be taken out to a depth of not less than eighteen inches, and, after the bottom has been dug, filled up with good soil composed of broken turf, half-decayed leaves, horse manure, and plenty of gritty material. Some may urge that by thus digging a hole we invite, as it were, the drainage water from the surrounding land. With the depth of soil taken out and that dug, amounting to quite two-and-a-half feet, there should be no fear of such a quantity of water flowing in as to render the soil which will contain the roots so wet as will 


\section{How to manage a Garden}

engender disease and death; and certain it is that the plants will thrive better in a loose than in a sticky soil.

If the lawn and the flower bed have both to be made it is necessary to mark out roughly the shape of the beds after the whole piece has been dug over, and then to lay down the turf so that it will overlap the edge of the bed, and enable a clean verge to be cut. This work of verge cutting should not be undertaken until the grass has begun again to grow. It is usually better to have beds raised somewhat beyond the surrounding level, as it tends to show off its occupants to greater advantage. There is of course a limit which we sometimes find exceeded, so that the bed is of such a slope as to make it very difficult to water it satisfactorily, or even to easily plant it. Carpet-bedding cannot be well exhibited unless the surface of the bed is eventhat is, either flat or at a suitable angle without being rounded.

Borders require the same process in making as do beds. The boundary must be marked out first, and a good trenching given or soil taken out, and fresh put in. As to the edging, where there is not grass it may be stones, tiles, box, or whatever suits the individual taste. Whatever it may be it should be so set down that deep and close digging will not loosen it. 


\section{CHAPTER XII \\ FORMING A ROCKERY}

\section{What a Rockery is.}

JUDGing by what people say, and more especially by what they do, it is very evident that a great misapprehension exists as to what a rockery should be. Many think it merely a mass of stones with soil thrown between, whilst others think it a mass of soil topped by large stones. Neither of these views is correct, but it often happens that they are acted upon, and wonder is expressed that the plants do not flourish, the end being disgust. A little reading, a little advice sought for in the right direction, would have transformed many a man that is now a scorner of the "purest of human pleasures" into an enthusiastic gardener. We must however bear these losses, and strengthen our forces and extend our empire by propagation of the right kind of knowledge. A rockery, if we may attempt to define it, is put up in imitation of nature, and is intended for the more perfect growth of those plants which in their natural habitat are found to do well among rocks and stones; and whilst endeavouring to give a pleasing picturesque informal style to the rockery, the needs of the plants must be kept in view and must not be sacrificed on any other consideration. Obviously a mere pile of stones, the work of man in mimicry of nature, is little to be admired unless we admit 


\section{How to manage a Garden}

the beauties of nature by giving every opportunity for the plants to succeed. Now it is quite possible to combine the utmost ruggedness with great usefulness, but rather than argue the point as an abstract question I would direct readers to those places I have mentioned on page 73 , where they will see the possibilities and variations of rock-work in all forms, and, moreover, observe the remarkable success of the plants.

\section{How to Make It.}

The remarks which are now given are intended to apply to small as well as to large rockeries. Now it is a pleasing feature-often, I am glad to say, seen in our suburban gardens-to have a small form of rockery skirting some of the walks, especially when for some reasons the path is lower than the surrounding ground. When built without any regard to formality, and with the true interests of the plants in view, there is every chance of it looking well, but we sometimes see the stones piled up one on top of the other without sufficient space being left for the plants, and the general appearance is then not pleasing. Only recently I saw bricks and stones piled up in this way and forming a regular outline with the idea of making an ornamental feature to the carriage drive; but whoever admires such an inartistic and useless arrangement must have small powers of observation, or spare opportunities of exercising them. This remark applies likewise to the making of rockeries properly so called. We often see stones piled up so as to give a globular appearance, and are like a heap of stones by the wayside for the repair of the highway rather than a rockery. Of course there can be the other extreme, viz., 


\section{Forming a Rockery}

stones set out at the most absurd angles, and wholly incapable of retaining soil between them, or perhaps they are formed of fancy stones of all kinds which are not in their nature suitable. It behoves us, however, to point out rather how a good rockery should be made, and we will proceed forthwith. Figs. $6_{3}$ and $6_{4}$ are given showing the faults recently complained of.

As in most operations connected with garden making, the first essential is that the land be properly drained. In some cases the nature of the soil does away with any work in this

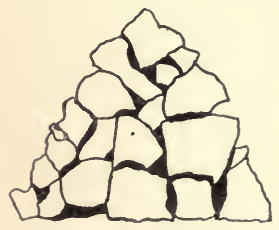

Fig. 63 .

Not enough soil.

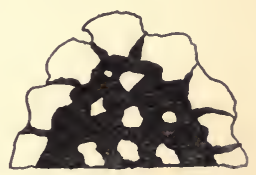

- Fig. 64.

Too much soil.

connection; but when it is heavy it is better to drain it at first than to suffer from the neglect later on, when it can only be remedied at greater expense. To drain it, take out the soil for a depth of quite eighteen inches, and put in drain-pipes to carry the water away to the lowest point, then lay in quite six inches of stones, brick rubble, \&c., putting the soil again on the top. Procure then the necessary stones of all sizes and get them near at hand. Stones sufficiently suitable for the purpose may usually be procured locally. Igneous stones are not the best, for they do not absorb and retain the moisture to the extent of a 


\section{How to manage a Garden}

sandstone, and though a little more picturesque in themselves are in most localities difficult to obtain. Sandstone which is not of too free a nature is very suitable for forming a rockery in which plants will grow. In cases where it is especially difficult to obtain stone, composition may be employed, but it should only be done as a last resource.

Having selected the stone and got it all in readiness, we must procure also the soil. Of this there had better be two classes. One may consist of any of the old soil from pots and boxes, vine borders, \&c., which has been put aside as not valuable enough for further use in that direction, and of yet sufficient worth to preserve it from being entirely thrown away. This will be found useful for filling in those parts where the roots are not so likely to reach. If wanting in quantity, procure turf to mix with it, chopped to about the size of a cricket ball. The other sort should be some well-prepared compost made up of loam, leaf soil, mortar rubble, and gravel. The plants being mostly of an alpine character, the gravel should enable them to find some of the conditions which accompany them in their native habitat. The larger stones are then placed in the form which the rockery will take. The stones are not set to touch one another, so that a space is left to be filled with good soil and form the free rooting medium for the plants. It is most essential that the stones, wherever they be placed, are firm and immovable, and for this purpose the larger portion of the stone should act as a base, and should be sufficiently buried to provide anchorage and ensure stability. The middle is filled with large stones also, but soil is worked among them all as the I06 


\section{Forming a Rockery}

work proceeds. Stones must be so placed that there are plenty of ledges on which soil can be put and plants grown, and arrangement should be made to prevent the soil from being washed from the upper to the lower parts. It is far more difficult to explain by writing what is meant than to figure it, so I have here given two diagrams which will, I hope, explain my meaning more clearly (see Figs. 65 and 66 ). The pockets or spaces for plants should vary in size, but should not be too numerous; and by all means avoid a patchwork

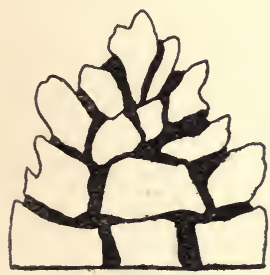

FIG. 65.

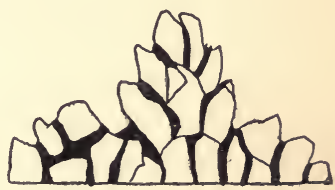

FIG. 66 .

Good rock formation.

appearance. The best advice that can possibly be given is to visit some neighbouring park where there is almost sure to be some small example of rock-work properly constructed. Large stratified stones stood with their tops sloping inward, and placed one over another with a space of three or four inches between, made by being propped up with smaller stones, will not only form a massive appearance, but will be most suitable for the growth of numerous varieties of plants. The great idea is to have plenty of root space, and the surface soil may 


\section{How to manage a Garden}

with advantage have smaller stones strewn over it for the purpose of diminishing the evaporation. By judicious placing of the stones it should be possible to cater for all varieties of alpine plants-those which like sunshine, those loving shade, those which like to grow upwards, and those which droop down. It will be understood that an artificial construction such as a rockery will in dry weather need copious supplies of water, and should therefore be placed in close proximity to that important element.

\section{Wall Gardens.}

It is not my intention to spend any great space on this subject, although it is one of great interest, but I should like to call the attention of amateurs to the fact that they have here a grand opportunity of adding a very pleasing feature to their garden without much fear of going wrong, and without any great expense in money or labour. Wall gardens could of course be made very elaborate, but that is not here intended. It will have been noticed by many in their country travels that in some old walls we find some very interesting specimens of plants growing in the dry mortar. Wallflowers figure prominently in this category. Now if these plants find sufficient nourishment in the dry mortar, not only to maintain their existence, but in many cases to flower profusely, surely they would increase their vigour and their floriferousness if better nourishment were afforded them. Most. readers also will in the course of their rural rambles have seen what we might call stone hedges. 


\section{Forming a Rockery}

They exist in many parts of England where stone is plentiful, but perhaps the county most noted for them is Cornwall. Here we find them in all parts, and often not only strongly but picturesquely built. In some districts prizes are offered for the best hedge built. Now in these stone fences no mortar is used to bind the stones, but merely soil worked between. In some cases the stones are stood upright, but this would not suit our purpose. Almost any kind of stone would do provided they are large enough to be well bedded in ; and a fair amount of soil should be left between them so that ferns and other plants may be grown. For the purpose of keeping it fresh, and giving every opportunity for the plants to do well, it will need to be watered or syringed frequently during dry weather. 


\section{CHAPTER XIII}

\section{GREENHOUSE CONSTRUCTION}

\section{The Value of a Greenhouse.}

THERE are, perhaps, a few people who would not recognise the value of a conservatory or greenhouse; but they are, I believe, very few indeed. In fact, from the largest garden down to the smallest, the complaint is always that there is not enough glass. The great advantage in having glass is that it greatly assists operations outside, inasmuch as things can be got along early and brought out after danger of frost has passed. Thus without glass it would be almost impossible to get tomatoes, but with it they can be grown along, and have fruit set by the time they are planted out. Without glass it would be impossible to have bedding plants, such as we so often admire, unless they were dearly paid for; whilst even a frame would lessen our dependence on other growers. This point, however, need not be laboured. We will presume that all who have a garden would like also a greenhouse, no matter whether their chief interest were centred in the vegetable or the flower garden.

\section{The Question of Form and Size.}

Obviously, the size of a greenhouse depends solely on the means and requirements of the owner. Beyond 


\section{Greenhouse Construction}

that we cannot go, for the intending possessor will know these governing circumstances better than any one else. Now, as to the form there is a large range of choice. There are three principal types, known as the

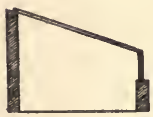

FIG. 67.

Lean to.

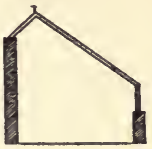

FIG. 68.

Hip-roofed.

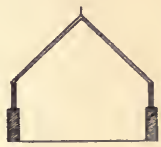

Fig. 69.

Span-roofed.

Greenhouses.

"lean-to," the "hip-roofed" or three-quarter span, and the "span-roofed," which are here shown (Figs. 67-69); but there are also many modified forms, some of which take fantastic and useless shapes, such as are figured in

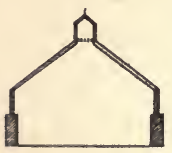

FiG. 70.

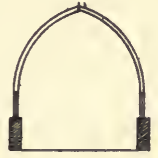

Fig, 7r.

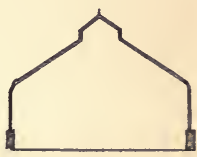

FIG. 72.

Undesirable forms of houses.

Figs. 70-72. Any of these latter shapes should be sedulously avoided, no matter how much they may appeal to architectural tastes; for it is demonstrated by experience that curvilinear roofs are not so favourable to the proper development of plants as in the case of a plain 


\section{How to manage a Garden}

even roof. Since, then, the choice is thus narrowed down to the three forms first named, it behoves us to consider their relative value for general purposes of cultivation. The lean-to has an advantage which is also enjoyed by the hip-roofed shape in that it can be built against any existing wall, when the cost is thus much lessened. It is also on this account, and if it does not face a windy quarter, much warmer; but there is not the same amount of light, and the back being merely a blank wall, the plants grow in a very one-sided way, their balance and perfect symmetry of form being thus destroyed. In consideration of this, the choice of a span-roofed structure is about the best for general purposes; for we have more light, more opportunity for ventilation, more sunshine, and greater advantage in showing off the beauty of the plants.

\section{Some Remarks on Construction.}

It is not of course expected that the amateur should build his own greenhouse, nor would it be advised that he should do so, unless he were by trade thoroughly qualified to undertake the work; but he should certainly be acquainted with the details so as to supervise in some manner and take an intelligent interest in what is going on. It is not suggested that builders are dishonest, but it is certainly more reasonable to suppose that better work will be put in when the one for whom it is being done shows himself to be quite capable of fair and intelligent criticism, and who is anxious to know whether he is getting a full pound's worth for every 


\section{Greenhouse Construction}

twenty shillings expended. We must all recognise that it is necessary for a greenhouse to be dry in itself, and able also to keep out the wet in the interest of its occupants, that it is sufficiently strong to withstand the wind, and sufficiently tight to keep out a great deal of it; that, moreover, it admits a large quantity of light and has ventilators so fixed as to arrange a large influx of air from either quarter. If, then, the material is durable and useful, and means can be taken by hot-water heating, or otherwise, to keep out the frost, we have all the essential qualities of a greenhouse. A man holding premises as a tenant has not the same opportunity as a person possessing a freehold, for it is certain that men are so built up that they object to erecting greenhouses, \&c., for the ultimate use of people probably better circumstanced than themselves. A man deserves to reap what he sows, and hence in this matter he must seek some method of constructing a greenhouse without prejudice to his own interest. In such a case he will have to content himself with what is known as a "tenant's fixture." These need to be so fixed that they can be taken away at expiration of the lease without injury to the ground. Before erecting a house of this sort it is better to become somewhat acquainted with the law in that respect.

In happier circumstances, the amateur would probably have put in brick foundations and brick walls. The foundation should be twice the width of the wall. Now, presuming the wall is to be nine inches wide (and it should certainly be no less), the foundation would be eighteen inches. Over the wall should be glass and wood-work for quite 


\section{How to manage a Garden}

two feet, and from the top of this should spring the roof, which in its angle should be neither too sharp nor too flat. Shutters should be made in the wall to be used for ventilation, when it would not be discreet to use the side ventilators. There is also provision for ventilation at the top. We are now referring to Figs. 73 and 74 , sectional and ground plans. A staging four feet wide runs round the house, also a path three feet in width, whilst there is a central staging six feet wide, and somewhat higher than the side ones. Beneath the staging are the hot-water pipes. The

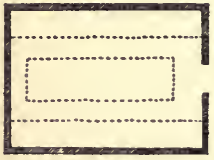

Fig. 73.

Ground plan of plant house.

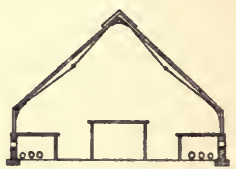

FIG. 74.

Span-roofed house showing stages.

staging should be made sufficiently strong, and may be formed of wood, over which may be spread fine shingle, intended to absorb and retain much moisture, and thereby save labour in syringing and watering. Sifted coal ashes will serve the same purpose. The walks may be of gravel, or made of cement, tiles, bricks, or trellising. The latter is, in my opinion, at once the cheapest and cleanest, and is made of strips of wood, set slightly apart, and nailed to stout cross-pieces, these being in turn fixed on bricks. For the greater safety of the structure tie rods are put in, which greatly help to support the roof. 


\section{Greenhouse Construction}

\section{Heating a Greenhouse.}

Over the question of heating a greenhouse much valuable ink has been spilled. Yet the matter when resolved into its elementary principles is very simple indeed. It is understood that a certain figure on the thermometer must represent the minimum and another the maximum degree of heat, and it is necessary to keep well within these bounds, so that by what means this is accomplished matters little, provided those means are not antagonistic to the growth of the plants, nor extravagantly dear. With gas and oil lamps the great thing is to get reliable apparatus, and to understand properly their use and regulation. At this point the great mistake is made. If, however, the fumes from the oil or gas cannot be kept out of the house, then by all means abandon entirely the idea of this form of heating, for in such circumstances it will not act. Personally, however, I strongly advise heating by the hotwater system.

Here likewise we must jot down a few rudimentary principles, and obviously the first thing to do is to see to the selection of a suitable boiler. There are so many on the market which receive from their makers a host of laudations that it is not surprising that the amateur should feel puzzled, and should be torn by conflicting testimony. Now, if he will take my advice, he will choose what is known as an upright boiler. It is very easy to work, and, if suitably regulated by a damper, a steady heat can be maintained. There are, moreover, no intricate flues, which are often not understood, and the setting is very simple. In fact, I cannot conceive a more suitable form of boiler 


\section{How to manage a Garden}

for small structures. The fuel should be coke, broken small, and mixed with dusty coal. Some amount of experience will be needed with this as well as with other boilers, to ascertain precisely how to regulate the damper and ash box door, and how much coke to put on at night to maintain a steady heat, and yet have a bright fire in the morning. The ashes resulting from the fire should not be thrown aside as useless, but if put out in the open for some time to become well weathered and free from sulphur,

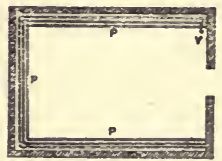

FiG. 75 .

Distribution of pipes.

P-Pipes. V-Valve.

they will be found useful for a variety of purposes, such as plunging pots, putting on stagings, \&c.

The hot-water pipes should be not less than four inches in diameter, if efficient working is to be guaranteed. It is essential that the supply tank (which should if possible be fed automatically) be higher than the boiler and pipes, that the pipes should rise gradually from the boiler to the air pipe; that the air pipe (which is better than a tap) should be carried to a greater height than the supply tank; that the flow pipe be at the top, and the return at the bottom of the boiler. With these essential conditions, we have every possibility of an effective service. 


\section{Greenhouse Construction}

It is also not only useful but necessary to flush out the boiler twice or thrice a year, and see also that the chimney is kept clean. With the method of joining the pipes, \&c., we need not here be concerned, but a simple diagram has been prepared to show how the pipes should be distributed through a house. (Fig. 75.)

\section{Cold Frames.}

Many a man who is unable to afford a greenhouse can put up some cold frames, and he will find them most useful for growing and preserving plants which would otherwise be killed by frost. Even those who have greenhouses will quickly discover that many of their choicest plants will, during the summer months, do much better in a cold frame where they can be readily supplied with all the attention they need in the way of water, air, shading, \&c., and are not then dependent on the conditions deemed necessary for the proper culture of plants valued above them, but with whose system of culture they do not agree. Although frames can be cheaply bought and then put together, there can be no reason why any handy workman who thinks himself capable should not put one together for himself. I should advise then that some good stout wood be procured, and when set down should be placed on a row of bricks, and in a dry spot, so that the frame will not quickly rot. To further prevent this a yearly coat of paint will go a long way. The bottom over which the frame is stood should be covered with coal ashes for the better preservation of moisture, and the lights covering it should be made up of large pieces of glass, not innumerable 


\section{How to manage a Garden}

small pieces. These frames may be ventilated in several ways. In the most simple form the lights may be drawn off entirely. They may also be slid alternately up and down, but obviously these ways can apply only during the prevalence of fine weather. The other methods are to tilt the frames alternately at back and front by means of pieces of wood or stones, or to tilt them by putting these same pieces at one side, and in such a way that the opening is, so to speak, facing the leeward quarter. There is yet another word to be said in reference to frames, and that is to indicate the means by which the danger of frost may be lessened, if not altogether averted. The wooden sides of a frame are not sufficient guarantee against its entrance, so these must be reinforced by having earth, ashes, or stable manure banked up against them, putting in posts and boards to support these if deemed necessary. This system of protection from frost is termed "lining"; but even yet we are not secure. There is the top to be considered, and this may well be covered with quite one foot of straw, and mats and boards put over to keep all safe in the event of strong wind. To further aid in the exclusion of frost, it is not altogether a bad plan to put in some fresh horse manure which has been turned over several times to allay its rapid fermentation. A need will then exist for occasional ventilation to let off foul air even in the coldest weather. 


\section{CHAPTER \XIV}

\section{DRAINAGE AND WATER-SUPPLY}

\section{A Question of Soil.}

THE question of drainage is more often a question of soil, for we always find that a clay soil has too much moisture, whilst a light soil often has too little. The taking off of surplus moisture warms the soil, makes it more amenable to tillage operations, and enables the plant to grow more rapidly, and use more plant food in building up a strong constitution. Drainage is needed in most lands in England, although its need is much more apparent in clay soils. We may judge of the ill effects of want of drainage by indulging in a little experiment with two pot plants. Put some stiff clay over the hole in the bottom of a flower-pot, and then pot a plant with the best soil obtainable. Procure another pot and put therein an equal plant, substituting the orthodox draining material-crocks-for the clay. Water both plants. You will find that the water will soak away from the properly drained pot, whilst it will be retained in the one which is stopped up. If you can summon sufficient patience to continue the experiment for several weeks, treating each plant in like manner, it will be found that the well-drained plant will make headway, while the other will be making proportionate retrogression. It might be pointed out in passing that there 


\section{How to manage a Garden}

is but one main difference in draining a heavy or a light land, and that has reference to the depth and distance of the drains. In a heavy land they will need to be nearer to the surface and near to each other.

\section{Methods of Draining.}

We understand then that the object in draining is to get the soil in a condition which will render it capable of being brought by tillage into a suitable state of cultivation, not only during dry periods, but also during very wet seasons. Being convinced then that it is necessary in the vast majority of cases, we must now apply ourselves diligently to the question of ways and means. Several systems of drainage now appeal to us, but before adopting any of them it will be necessary to take stock of our land, and note which is the lowest point, so that we may take our drains in that direction. We must seek to take our main drain down the line of the lowest lying ground, and let other drains feed this as tributaries, or we might have two main drains, according to the exigencies of the relative levels and slopes. Something of the idea intended to be conveyed may be gathered from the accompanying diagram, Fig. 76. The double lines are the main drains, and the single ones tributaries to feed them, and the surplus water from the whole plot is thus conveyed to a large pond or ditch. Of course the main drain will need to be at least twice the size of its tributaries, and preferably three times as large, or its work will be greatly impeded during heavy rains.

We can choose between open ditches, brick drains, 


\section{Drainage and Water-Supply}

stone drains, rubble drains, horse-shoe tiles, or drain pipes, properly so called. Sectional views of each of these are given, and the reader will be able to gather which, in his estimation, is likely to prove the least costly and most useful (Figs. 77-82). Open drains we still sometimes see in our old orchards, and they are religiously cleaned out

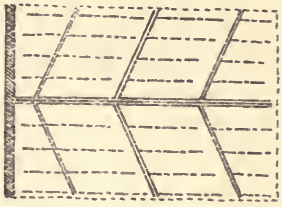

Fig. 76.-Plan for draining land.
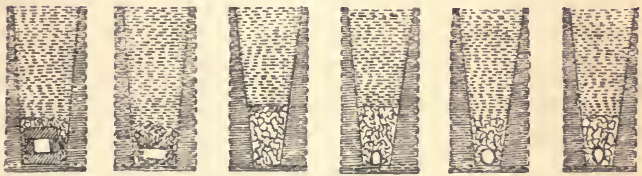

FIG. 77. FIG. 78. FIG. 79. FIG. 80. FIG. 81. FIG. 82.

yearly. How it is people cannot see that it would pay them better, and serve the purpose equally as well, to fill these in with rubbish, surely defies comprehension. Brick and stone drains are probably very useful, but they are very expensive, and require much time and labour to put down. Their utility and cost are not then proportionate. Rubble drains are often found to be useful, and are commendable chiefly on the score of less expense; and certain 


\section{How to manage a Garden}

it is that they are infinitely better than no drains at all. If, for some reason, pipes cannot be used, then make rubble drains by filling in the trenches (to a thickness of six inches in the case of tributaries, but one foot or more in the case of mains) with broken bricks, crocks, and stones, and any other hard material. Some turf should be put immediately over this to prevent the soil filtering down, and so blocking them up. The horse-shoe tiles are not now often used. A flat tile is placed beneath and the "horse shoe" over it. The best form of drain pipe is shown in Fig. 82, where instead of being perfectly circular in shape its curve is sharper in the lower part, so that there is less opportunity for sediment settling in the bottom. The depth at which these drains should be put is from two to three feet, according to the nature of the soil; and the distance apart may be from ten to thirty feet. It being a principle that water will always find its own level, and as it will also follow the line of least resistance, it will certainly find its way to the drains, when, if the drains are properly constructed, it will be merely a matter of gravitation to take it from the land. Having then set down the drain pipes so that they are barely touching, it will be necessary to put over them some material which will stop the small soil from getting into, and thereby stopping the drains. Brick rubble, furze, turf, or some such matter, may well be used for this purpose.

\section{Need of Plentiful Water-Supply.}

Although drainage is in many cases absolutely necessary, it is nevertheless a fact that water is not always in sufficient 


\section{Drainage and Water-Supply}

quantity during dry weather to supply the needs of the crops, hence we have to discover ways and means of meeting this demand. Whether in the vegetable or flower garden, and no matter what may be the crops grown and the character of the soil, it will be admitted by all possessing experience in the matter that artificial watering, if not absolutely necessary for the life of the plants, greatly increases the quantity and quality of their produce. It will also be found that where there is a plentiful supply of water the productiveness of the land is increased, for many plants can then be grown which will not do well without artificial supplies of water. In reference to the flower garden and the lawn, it is obvious that when dry weather sets in the man with a good supply of water has a long start over the one without; for whereas in the one case growth is practically stopped, in the other the plants continue to grow with renewed vigour, and the lawn instead of looking brown will be clothed with a rich green.

\section{Means of Obtaining Water.}

There are a multitude of people who are ready to admit that it certainly would be much better if they had a regular supply of water properly distributed about their land, but when it is suggested that they should at once set about to get the matter seen to, their principles suddenly change because it is recognised that the pocket will be affected. At once they have doubts whether after all they would ever get their money back. I have not time now to argue the question, but I am convinced, and no man conversant with the subject will deny, that, if profit only is looked to, then 


\section{How to manage a Garden}

there is every reason why the work should be taken in hand at once. There is much that might be done in this direction without going to any great expense, and this has been already hinted at in a former chapter. The water from houses, sheds, greenhouses, frames, \&c., is too often considered too trifling a matter to merit attention, although by the expenditure of nothing but labour much use may be made of this water, and if not altogether sufficient for the needs of the plants will at least go a long way towards meeting the demand. For the purpose of getting a watersupply in this way it is of course necessary that there be a fall from the buildings from which it is obtained to the garden. Given this, a large tub should be placed beneath each water pipe to catch the water from the roof. At the top should be affixed a pipe which will take off the overflow. Now it matters little how the water is taken to the garden, provided it gets there, the method of distribution being primarily governed by means and other prevailing circumstances. For ease and effectiveness either galvanised pipes or ordinary drain pipes will suit admirably; but where expense bars their use, and in the case of short distances, the water may well be conveyed by forming a trench and making a kind of water-course of rough stones. The manner of distribution around a kitchen garden is shown in Fig. 3, page 30 , and need not be again mentioned. As, however, in the case of a garden of considerable size this method of water-supply is very primitive, and not to be considered at all equal to the necessities, we must discuss other means. Of course if water can be obtained from a higher point by gravitation, the matter is greatly simplified. Unfortunately for the owner such a position for a holding cannot always be 


\section{Drainage and Water-Supply}

chosen, so that water must by some power be forced to a high point, and distributed therefrom by gravitation, or wells may be dug and pumps put in. This latter method is probably the cheaper, but it entails more labour in working, and it is but reasonable and according to experience to suppose that the plants will suffer from this ineffectiveness. I do not wish to disparage the efforts of those who have decided on this method of providing a sufficiency of water, but I do say that a system which entails so much labour has little chance of becoming used to the extent which would be required to increase the natural productiveness of the soil. Therefore I strongly favour a system which we might call automatic, as it is obtained rather by the regulation of mechanical than the expenditure of human labour. For throwing water up to a sufficient height we may put in rams worked by water or by wind power. The former is not always convenient, but the latter is free for the harnessing, and if a sufficiently large store tank is provided, there will be no need to fear shortage during a spell of mild unwindy weather. Into all the intricacies of the workings of these apparatus we need not enter, for they can be discussed to advantage with the engineer who is to be called in. Some curious person anxious to find difficulties may think that the questions of drainage and water-supply clash with one another. "Why," it may be asked, "take water from the land and then by much labour and great cost put it on again? Surely this double barrelled contrivance is merely waste?" To understand thoroughly this question we must be fully aware of the needs of plants under culture. Plants require a right supply of moisture not at certain periods of the year only but all during their growth. In 


\section{How to manage a Garden}

undrained land the supply is too great during the larger part of the year, and this, besides rendering the soil cold and unsuitable for the plants, retards the work of bringing the plant food into an available form, and necessarily takes up space which could with advantage to the plant be occupied by air. It is conceivable that during a drought, the cultivation of the surface being good, the plants would not suffer so much from want of moisture as in a loose soil. But it is certainly not, by any canon of cultural economy, advisable to sacrifice good growth during three-quarters of the year in the hope that the starved weaklings may receive a transitory help during the remaining part. Moreover, practice clearly teaches us the truth of this principle-let the plants never have too much water; always give them enough.

\section{Distribution in the Flower Garden.}

It would probably offend the fastidiousness of some of our puff-powder and perfume guests, if we allow barrels of water to be seen in the flower garden. In view of this whimsical notion it is better to hide such things or to transform them into fountains, \&c. The water may of course be so arranged that there exist several places in the lawn or in the paths where hydrants may be affixed and a length of hose-piping attached, and the water thus brought to all parts. 


\section{CHAPTER XV}

\section{HOW TO BRING LAND UNDER TILTH}

\section{Scope of this Chapter.}

To attempt to tell in a chapter, very much limited, how to bring land under tilth is rather a daring venture. The subject is in itself so expansive, and has so many divisions, each of which could be advantageously, but then not exhaustively, made to form a volume equal to this, that it requires great powers of compression to be able to handle the subject at all. The object here is not so much to give in detail the various operations needed to effect good cultivation, but rather to point out the mode of procedure in converting unbroken land into a garden, which will from its commencement show favourable results. Having relieved myself of this prelude, I turn to practical matters.

\section{Spade v. Plough.}

Many would advise that the land intended to be converted into a vegetable garden should be ploughed. Others would certainly have it dug with a spade. With this latter sentiment I entirely agree. The plough is a wonderful contrivance, notwithstanding its antiquity, but in its present form it certainly does not equal in 


\section{How to manage a Garden}

thoroughness and in practical results the hard and honest work of a good spade. It seldom goes deeper than nine inches, whilst a good workman with a suitable spade will dig quite one foot, and the difference of three inches in root-room throughout a plot is going to have considerable influence on the cropping. In the case of ploughed land there is not the opportunity of breaking up the soil which exists in the case of spade tillage. The chief objection-in fact the only one that carries weight-against the spade is that it costs more. Again we see that a man's principles are usually founded on his pocket. It was, I believe, Carlyle who said that "not one man in a thousand has the slightest turn for thinking." Men will content themselves with scratching the surface of a subject just as they will but tickle the upper part of the soil. It may be harder work to dig deeply with a spade, it will certainly entail greater cost, but it will also produce the biggest dividend. As we expect our income to be greater when we spend more capital, so must our produce increase as we cultivate more soil. Those who have had the advantage of seeing corn grown on land that has previously been used as a garden, and on ordinary farm land will find the difference very conspicuously in favour of the garden which has during former years been deeply dug.

\section{Trenching.}

I have before mentioned that there is really no such thing as unfertile land. As long as the soil is still, that is to say, not blown away as in sand-storms, the cultiva- 


\section{How to bring Land under Tilth}

tion by man will quickly bring it to a state of productiveness. Certainly the soils which are in England supposed to be unfertile have really within them a large store of plant food, and it only needs thorough and intelligent cultivation to render this food available for the plants. A good beginning is perhaps half the battle. It must be presumed that the land we have now to deal with was formerly under grass, probably an old pasture which has not been broken within the memory of any living man. If the grass is very high it should be roughly cut over with the scythe, to facilitate

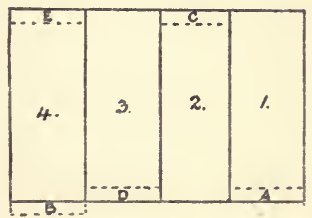

FIG. 83.-A plan for digging ground.

the work. The grass nay be collected up and burnt, or put into a heap to rot. In either case its ultimate destiny should be the land from which it was taken. It will now be necessary to divide the piece into suitable rectangular pieces. If in the vegetable garden this will have been done to some extent by the paths. Fig. 83 shows a square plot of land divided into four equal rectangular pieces. These are marked out clearly with the aid of the line, and by cutting a nick along it. On the first piece, a strip three feet wide is marked off as shown at A, and the top spit of that piece is 


\section{How to manage a Garden}

taken out and wheeled to B for filling in the last trench. Plot No. I will be dug first. The trench taken out from Plot 2 at $\mathrm{C}$ will be used for completing the Plot 1 . Plot 2 will be completed by taking a trench from Plot 3, and in like manner with Plot 3 and 4 . This system saves carting the soil the whole length of the plot.

It will be well, however, to enter somewhat further into details. The first trench, three feet wide and one foot deep, has been taken out. The soil beneath is covered with some good, half-decayed manure and leaves, and thoroughly turned over. This soil especially should be well broken. This completed, we skim off the turf from another strip two feet wide, and lay it grass side downward over the newly dug portion. The second two feet of soil is then dug over on to the first, keeping it uniformly level at the top, and well breaking the soil underneath. Manure is again dug into the exposed surface of the second strip, and so on throughout the plot. In order to have the work well done, it is essential that the width be properly marked out with a line and the soil stirred to a uniform depth. By trenching thus we, so to speak, increase the acreage of land, not by enlarging the superficial area, but by doubling the depth, and making more rooting space for the plants. It will be observed that under the system of trenching here advocated there is practically no danger. The position of the layers of soil is not reversed. Bad, sour soil is not brought to the top, but is well loosened and manured in order to free it from a surcharge of moisture, and render it capable, not only of admitting the roots of plants, but likewise of affording nourishment to them. By adopting this 


\section{How to bring Land under Tilth}

course of treatment if possible every year, but certainly every two years, the lower layer of soil will become sufficiently ameliorated to be brought little by little to the surface; and by a constant repetition of the work the whole two feet of soil will become of a uniformly good character. This is often called bastard, mock trenching, or double digging.

There is also what is termed trenching proper, which cannot be so unguardedly commended, but which will be briefly described. The land, as in the previous case, is divided into plots, and these in turn subdivided into strips two feet wide. The first trench, three feet wide and two feet deep, is then taken out and wheeled away. The second strip, two feet wide, is dug on to the newly-opened trench in such a way that what was formerly the surface soil is buried, and the second spit is brought to the top. Now it will seldom be found that the lower layer of soil is in a condition fit for plant culture, and it will take several years for it to become so. Thus we bury the better class of soil and operate upon the worse, which is obviously not an economic process.

\section{Digging.}

Digging as compared with trenching is but a half-hearted mode of cultivation, but on that account it must not be despised, but rather be more encouraged. Having had the . advantage of seeing the work of digging done in many and widely separated parts of England, I must give the verdict that the proper way to dig is known to: or at any rate practised by, only a few. A famous gardener used to say that 


\section{How to manage a Garden}

if he were to be compelled to judge a man's qualification for a gardener by one act alone, he would hand him a spade, meaning thereby that a man who could dig thoroughly and intelligently was sufficiently imbued with a knowledge of the elementary principles of horticulture that there was little fear of his making fatal errors in other directions. This idea will be thoroughly endorsed by all who have had sufficient scope for observation. As generally understood digging means the turning over and working of the first spit of soil, so as to bring it into a fit state to receive and provide for the necessaries of plant life. We must understand clearly that soil is not only a medium in which to grow plants, and to afford them sufficient anchorage to support their superterrene portion, but it also possesses within it, and is in fact made up of, plant food, which has, by the right quantity of air, moisture, and warmth, to be brought into a state available for the plant. When we recognise that without air, water, and warmth in the soil, in a word, without cultivation, the plant cannot thrive, we may perhaps be led to understand more clearly the why and wherefore of cultivation.

There are a few rules relating to digging which might here be laid down. A good clean spade is necessary and should be not less than ten inches in depth. Drive the spade into the ground almost vertically and well up to or even beyond the hilt. By sloping the spade we necessarily lessen the depth of digging. Do not take too much at each spit. Turn it well over and take especial care to break up that portion of the soil beneath, which cannot come under the pulverising influence of frost. This is too often neglected. Keep a 


\section{How to bring Land under Tilth}

good wide trench. Not only does this enable the soil to be thoroughly turned and broken, but it also affords facilities for burying manure, rubbish, \&c. Keep the ground level and work along the plot one spit at a time-not with three or four, as is often done, for by this means the difficulty of keeping the ground level is greatly increased, and there is no saving in time. The best way to learn to dig properly is to watch an adept spadesman at the work. Digging is said to be one of the best physical exercises possible if not indulged in too much, and especially if the position of the hands on the spade can be frequently reversed. Never dig ground when it is very wet, or when frozen or covered with snow. The best season at which to dig most soils, but especially those of a very retentive character, is during the autumn; so that the winter rains may the more readily drain away, and the rough lumps be broken up by successive frosts. In such cases it will need also to be turned over with a fork immediately before planting. With light soils this course is not needed. If the soil be of such a nature that it can be well turned over with a fork, then by all means use that tool in preference to a spade, for it is certainly lighter work, and those who consider this a lazy plea may be justly termed ignorant of true economy, which militates equally against a useless expense of energy as of coin.

\section{Disposal of Rubbish.}

It is a self-evident truth that everything has come from the land and everything will return to it. It is 


\section{How to manage a Garden}

also equally certain that all vegetable and animal matter can be safely and advantageously returned to the land in the form of manure. The only condition laid down is that matter is not returned which will bring with it the danger of a large crop of very undesirable weeds. In view of this the principle must be laid down and strictly adhered to, that all weeds which increase largely by their roots or underground stems, such as couch grass, colt's foot, "old man's beard," nettles, docks, \&c., should either be burnt or staked in a heap to rot. The ordeal of fire is at once the quickest and safest. With the exception of these weeds and those of a like nature, all vegetable refuse should be returned to the land. Now, in forming a new garden there is afforded an excellent opportunity of disposing of much of such matter with great advantage to the soil. In speaking of mock trenching or double digging it was advised that manure be incorporated with the lower layer of soil. This manure could well be dispensed with if a sufficiency of vegetable refuse, weeds, decaying vegetables, \&c., were at hand to take its place. To those who object to this method of economy on the ground that the garden would be full of weeds, I would reply that it must be within their own knowledge that seeds will not germinate at a depth of eighteen to twenty-four inches below the surface. That the disposal of rubbish in this way is economical may be amply proved by the fact that many gardens receive no other form of manure, and yet yield rich crops year after year. It will be readily agreed that such a system can only be carried out under thorough cultivation, for it is essential that the rubbish 


\section{How to bring Land under Tilth}

be well buried so as not to interfere with the ordinary cropping. Such rubbish of a hard nature, as hedge trimmings, prunings, cabbage stumps, \&c., had better be burnt, for they would take too long to decay in the soil and might be prejudicial to the plants. 


\section{CHAPTER XVI}

\section{RAISING STOCK BY PROPAGATION}

\section{Seed.}

IT will be well for us to briefly consider the separate methods by which plants are reproduced, in order that we may learn therefrom how far they may be useful in furnishing, and to what extent they may replace the costly method of buying, in which there is always great risk of a beginner not getting value for his money, and in some cases indulging in bargains where worthless stuff is sold at a low price which is however far above the actual value. If for no other reason, I should advise the amateur to grow most of his own stuff in order to afford him an additional interest, and to imprint his own personality as it were on every feature of his garden. The work of another, no matter how excellent it may be, cannot be viewed with the same impartial admiration which would apply to the work of one's own hands, formed after one's own design. The garden may take longer to evolve after this manner, but that surely is not a matter of very great importance.

Let us, however, turn to the subject of reproduction by seed. This will either have been bought or home saved, presumably from the best sources. The vitality of seeds can be seriously impaired by careless storing. 


\section{Raising Stock by Propagation}

For the safe storing of seed conditions are required directly opposed to those necessary for their germination. Hence we require a cool dry atmosphere removed from sun and light, and of course beyond the reach of vermin. If these conditions are afforded to seeds which have been gathered when ripe, there is little fear of their vitality being in any way impaired. Seeds require for germination moisture, warmth, a fine tilth and shade from sunshine. If these are available, and good seed is sown at the right time, all will be well.

Seed may be sown broadcast or in drills. Which should be done is chiefly a matter of circumstance. Sowing in drills certainly looks neater when there is a large area, but for a few seeds such as is sufficient to provide a cottager with lettuce or cabbage, it may quite as well be sown broadcast. More important than the manner of sowing is the preparation of the soil ; for it is absolutely necessary if seed is to germinate, that a fine tilth be obtained. This means breaking the soil so small that pieces larger than a marble are an exception. In light soil this desideratum is very soon obtained, but not so easily in the case of a heavy clay soil. Here the soil having been dug over in the autumn and left during the winter, has been broken up to a great extent, but not sufficiently. It will be necessary to fork it over perhaps two or three times, and beat it, tread it, and rake it, repeatedly. If the digging has been left till the spring the work will be doubled, for if wet when dug a dry March wind will soon make the soil as hard as bricks and almost superhuman effort must be expended if it is to be brought into a sufficiently fine state. 


\section{How to manage a Garden}

It is rather difficult to say how deep seed should be sown, for it varies so greatly in size. It has been said, and it is a fairly safe practice, that seed should be buried to a depth equal to three or four times its thickness. A word of advice is also needed on the subject of thick or thin sowing. Most catalogues will advise thick sowing, but we can hardly accept their statements and argument as being impartial, for obviously, the thicker the seeds are sown, the greater the quantity needed, and the greater in consequence the seedsman's custom. It is quite possible to err also in the other direction and leave many gaps, or to suffer great loss from the attacks of slugs, \&c. If seed is sown thickly it must be thinned quickly. Now, here lies a mischief. It may not be possible to perform the work for a few days, so that the seedlings quickly become overcrowded and suffer from it. If thin sowing had happened, the need for thinning would have been less imperative, and when thinned, the plants having grown to a decent size would not suffer from the check so much as if they were but a few days old. I certainly advise thin sowing, but let it not be carried to extremes. Slugs and other enemies must be warred against.

For sowing seed broadcast, beds four feet wide and six feet long should be made up, and let there be paths or alleys twelve or eighteen inches wide between them. There need not be any elaborate work about these, such as we used to see some years ago. As regards the distance apart at which drills should be made, a more difficult question confronts us, and must really be decided only by a knowledge of the class of seeds to be used. It is safe, 


\section{Raising Stock by Propagation}

however, to say that drills should never be less than six inches apart, and the minimum could with advantage be increased to one foot. The danger lies in leaving them in these drills too long, and thereby causing overcrowding. Now the thinner the seed is sown, and the wider apart are the drills, the greater the length of time which they may be left there before transplanting. Consequently, having gained greater strength, they can bear the check of transplanting without injury.

A few words may be added as to seed sowing under glass. Here the warmth to be obtained outside is not considered sufficient, or a sufficiently fine tilth cannot be obtained. We require under glass the same conditions for germination, but there is this advantage, that another condition can be enforced which could not be obtained outside-keeping the surroundings close. Seed under glass is sown in boxes, pans, or pots. In either case the details are the same. Allow plenty of drainage by the use of clean crocks. Over the crocks put some moss or leaves to prevent the fine soil from filtering down among, and blocking up, the drainage. Almost any fine soil will do, but for preference get loam, leaf-soil, and sand, in equal proportions, and pass through a half- or a quarter-inch sieve, according to the size of the seed. This should be pressed down firmly, especially around the sides of the pot, pan, or box. It should be in a moist state at the time, or be watered the day before the seed is sown; sprinkle the seed over the top, and then some soil on these, just sufficient to cover them. Press the soil again very slightly, cover with a sheet of glass, put paper over this, and stand in a house or frame having the needful temperature. In 


\section{How to manage a Garden}

most cases there will be no further watering needed until germination has commenced. At this stage the glass should be taken off, and the seedlings gradually exposed to full light. It will be necessary to take many precautions against birds, slugs, vermin, \&c.

\section{Cuttings.}

Another method of reproduction which is found of great use to the gardener, and which may be employed for the increase of a large majority of plants, is by means of cuttings. Cuttings are pieces taken off a plant and put into soil for the purpose of emitting roots. When the nature of growth admits of cuttings being taken, it is very rare for them not to emit roots, if the right conditions are afforded them. The proper way to take a cutting is to cut it from the parent plant, immediately below a leaf-joint, but not so close that the leaf will fall off. In most cases the lower leaves should be cut off. Only when it is especially desirable that the lower leaves of a plant should be retained will it be necessary to infringe this rule. The cut should be straight, not slanting. Some cuttings are to be taken from well-ripened, and others from young, wood. In most cases it is better to have fairly plump wood, as distinguished from sappy growth, which is more likely to damp instead of striking. The size of a cutting is another thing for which no hard and fast rule can be laid down. If we say that there should usually be left five or six leaves, or buds, there is little fear of going far astray. Personally, I prefer short cuttings, as there is then practically an entirely new plant to work upon. 


\section{Raising Stock by Propagation}

Cuttings require for striking somewhat the same conditions as seeds need for germinating, viz., a sufficiency of heat and moisture. For this purpose an open, sandy soil is essential. If any reader is doubtful of this essential let him experiment for himself by preparing two cuttings, equal in every way, and insert one in clay, the other in sandy soil, and watch the result. It is doubtful whether the cutting in clay will root at all, but certain it is the other will do so far more quickly. The conclusion arrived at is that there is too much moisture in the clay. It is likewise too cold, and the air cannot reach the base of the cutting. It is not in all cases essential that the cutting has attached to it a growing shoot. Cuttings of currants, for example, may be made by cutting off pieces about six inches in length, even though two or even three cuttings be taken from the same branch. The part buried should be sufficient to keep them erect, and to prevent their being blown over. If a large number of cuttings, such as of roses, currants, \&c., are to be put in, a trench may be cut out as depicted in Fig. 84, and, after sprinkling sand along, the cuttings should be placed against the line, and the soil thrown back and well firmed around the cutting. In other cases a dibber is used. This may be formed of any sound stick of sufficient size, but instead of being brought to a sharp point, as is usually done, it should be blunt; in fact, its bluntness should bear some relation to that at the base of the cutting, so that the cutting rests always on the bottom of the hole. Each cutting should be firmed individually, so that when gently pulled by a leaf it will not readily leave the soil. In some species of plants it is necessary to take off a heel of the old wood, as it is found 


\section{How to manage a Garden}

thereby to strike more readily. It will be found more convenient to put the cuttings in lines, or where there are only a few they may be put in bunches, and bell glasses placed over. Frames will be found very useful for cuttings.

\section{Buds and Leaves.}

Another method of propagation is by buds and leaves. These are not applied so extensively as propagation by cuttings, but still have their uses. When it is especially desired to increase the stock of a particular plant-let us take a currant tree for example-every bud may be propa-

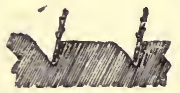

FIG. 84 .

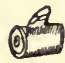

FIG. 85 .

A trench for cuttings. A bud cutting.

gated if cut off as shown in the accompanying illustration (Fig. 85). This method of propagation is invariably used with the vine. There is also a process known as budding, which will be familiar to all rose growers, by which we take a living bud off one tree and insert it within the bark of another, and thus obtain a new variety. It is hardly necessary to mention the process here as it can be gleaned from all works on the subject, and is yearly figured in the horticultural periodicals. Suffice it to give a few general remarks. Cut out the bud at a time when the bark parts freely from the wood; see that the bud is left whole and entire; do not cut out the bud until you are ready to insert 


\section{Raising Stock by Propagation}

it in the stock; tie moderately tight with wool or matting, but in such a way as not to bruise the shoot; do not cut off the upper part of the shoot until the bud is found to have "taken"; loosen the matting or wool when it appears to be too tight. Propagation by means of leaves is by no means common with outside plants, but is very effective with many indoor ones. We might take the instance of many begonias, of gloxinias, gesneras, saintpaulias, \&c., which are often increased by mature leaves being nipped off and inserted in sandy soil.

\section{Layering.}

Many plants also submit to this form of increase. Among them we may notice carnations, strawberries, \&c. These two differ somewhat in their manner. It is found that carnations root more readily and afford better results when the cuttings are not wholly detached from the old plant, but are cut half-way through and then split some way up and inserted in sandy soil. The method of layering in a strawberry differs, for here a runner is thrown out, and after covering some space, culminates in a small plant which only needs contact with moist soil to cause it to emit roots. This is done when we set round a strawberry plant several pots of suitable soil, and press the embryo plant into them, keeping it in place by means of a stone, or peg, or similar device. A great number of plants can be increased in this way, and surely it is cheaper to work up our own stock than to provide others with a large dividend for the purpose of so doing. 


\section{How to manage a Garden}

\section{Division.}

There is yet another form of increase of stock which merits a few words, and that is division. There is no need for any lengthy survey of the benefits accruing from this form of reproduction, nor will many remarks be needed to show how it is done. Sometimes the plant is taken and torn asunder, in other cases it is cut up with a spade or a knife. There are many classes of plants which lend themselves to this treatment, and whether they prefer to be cut or torn asunder must be learnt from the venerable school of practice. There are also other methods of propagation and increase which need not be detailed here. 


\section{CHAPTER XVII \\ PURCHASING STOCK}

\section{A Few Dangers.}

WHEN a person who knows nothing about the matter goes a-marketing he is always likely, no matter what his purchases may be, to return home poorer than he went. This could be proved by a great many people, who would rather not speak on the subject. Accepting the statement as being in most cases fairly accurate, we must draw the moral that unless a person is qualified to so judge of the quality of stuff that he can arrive at its approximate value, he had better leave purchasing alone, or take with him some one who can perform this useful office. It often happens, though perhaps not more so in gardening than in other callings, that a person attends a sale for the express purpose of picking up something cheap. Now, at a casual glance before the sale, it is difficult for an amateur to appraise the value of what he intends to bid for, and certain it is that he will not see it at greater disadvantage when being disposed of by the auctioneer. Hence a person is very likely to buy what might to all outward and casual appearances seem a healthy plant, and at the same time be introducing to his own stock some of the most destructive and noxious insect and fungoid pests. This, of course, is a danger to be sedulously avoided; for the 


\section{How to manage a Garden}

extermination of these pests often requires a large expenditure in time, money, and plant energy. Even if already you are troubled with the same undesirable foes, there is surely no reason why you should increase the stock. This is one of the chief dangers of what we might term jumble sales. Only too often we find that sales include a variety of stuff which could not be disposed of in the orthodox way; which is the remains of a large stock from which the best has been scrupulously selected. True, the price is low, but a worthless plant is dear at any price. I do not wish to urge readers to keep away from sales altogether, but I certainly advise them to buy cautiously, and if they know nothing as to the value of a plant, to take some one with them who does.

In buying stuff from established seedsmen there is much less fear of being "done," for it may be said with pride that by far the large majority of our horticultural firms carry on their business in an irreproachable manner. They usually try to give every satisfaction to their customers, for they are fully aware that their own interest is indissolubly bound up therein. Nor is the price paid for things always a safe criterion of value. By paying a large price it often happens that we are really paying for a careful method of selection, and the additional cost cannot then be reasonably begrudged. A low price is not always a criterion of cheapness, nor is a high price always one of quality. The best school in this case is perhaps the old one of experience. 


\section{Purchasing Stock}

\section{Useful Friendships.}

Another useful way of working up a stock is to cultivate the acquaintance of professional gardeners, and men of a kindred spirit, by which means many plants, cuttings, \&c., may be obtained which would otherwise be thrown away. Only those acquainted with the workings of a large establishment can understand the amount of stuff wasted, which would prove a real boon to amateur growers. For an instance may be quoted strawberry plants. Yearly many hundreds of these are forced in pots, and when the fruit has been plucked are thrown away. Now in spite of what people who have never tried the experiment may say as to its futility, I am prepared to state from experience that if these plants have not been submitted to very hard forcing, they will, on being planted out, and well cared for, provide very useful material for fruit, or for increasing by means of runners. In many cases they could be had for the asking, although there are undoubtedly some morally constructed men with iron bound consciences who consider it their duty to consign these valuable masses of plant life to oblivion rather than help a fellow-man in his striving after gardening pleasure. These, however, are in the minority. May their number continue to decrease.

Apart from the advantages in kind which are likely to accrue from an acquaintance with professional gardeners, there is also much to be learnt from them as to practical culture, and also how to work up a stock in the shortest possible time from a given number of plants, cuttings, \&c., where to go for the best plants, bulbs, seeds, trees, \&c., and much other information which is not by any means to be despised. 


\section{How to manage a Garden}

\section{Exchange.}

There is also another aspect to be considered. It often happens that an amateur gardener propagates more of a particular class of plants than is requisite for his own needs. He may likewise be anxious to obtain more of some plant which another amateur possesses. Here we find a demand and a supply both of which can be mutually brought together. In fact there is every reason to urge that a kind of society should be formed for the facilitating of mutual exchange. It might even extend its limits so far as to give advice in the matter of purchase, or take over the work of purchasing goods and distributing them to the members according to their requirements. Such a co-operative society is, I believe, really required amongst all lovers of gardening, by which means they could get better stuff, get it cheaper, and be benefiting their fellow-man, to say nothing of the gratuitous imparting of advice and experience which must inevitably accompany the system. Will our many "Mutual Improvement Societies" take this matter up and try to provide amateur enthusiasts with plants, \&c., at a reasonable rate before they teach them how such plants are to be grown. A little more public spirit and a march with the times need to be infused into our local societies before they can make rapid headway. This criticism, be it understood, is meant in a most friendly way, and it is hoped that some results may accrue therefrom. It is indicative of a large amount of energy and enthusiasm that we have so many local societies, and it only needs that the energy and enthusiasm should be directed into the right channels to make them still more successful and more useful. 


\section{CHAPTER XVIII \\ PLANTING AND BEDDING}

\section{Too Deep Planting.}

As with a child, so with a plant; it is of great importance that we should give it a fair start in life, and if afterwards things go wrong-as they often will do-we can gaze on the scene with a calmness of conscience. Notwithstanding that the right method of planting has been taught over and over again by description, by figures, and by practical lessons, the hard and stubborn fact remains that few plants are planted as they should be. And mark! the fault is not confined to one particular class of trees, nor to one class of people, but it extends right along the line, whether it be fruit-tree, timber-tree, shrub, flower, or pot plant. The greatest fault committed has reference to the depth at which the trees should be planted. The idea would seem to be that it is necessary to get the roots not only out of sight, but away from the reach of air, and sufficiently low down to supply anchorage to the top, and thereby prevent it from toppling over. If this is really the impression it is an erroneous one. The roots of a tree have need of air as well as the branches, though not to the same extent. Without the presence of a sufficiency of air in the soil no change can take place in the constituents of the soil which would in any way be favourable to the plant. It is an essential 


\section{How to manage a Garden}

in converting the plant food already in the soil into a state available for the plant. As to anchorage, we cannot reasonably expect a tree to sustain itself immediately on replanting, any more than we can expect a lad to provide for his own support in his first situation. It is not only advisable, but really essential that a tree should be staked after planting. Its efforts then are not to sustain itself against the wind, so much as to drive out roots in search of food for its further growth. To plant too deeply we defeat the ends we have in view by thrusting the roots into a cold subsoil, far from the warming influence of the sun and the decomposing influence of the air, so that they cannot throw out roots for support and sustenance.

In buying fruit or other trees from a nursery there can be readily discerned on the stock what is known as the "earth line," formed by the juncture of the above and below-ground portions of the stock. It is a safe practice to let this still remain the earth line; that is, to plant so that the surface is level with the earth line. It must be seen that if too deep planting is censurable, the opposite fault of planting too shallow is still more so, for here the roots, if not immediately on the surface, are not sufficiently below to free them from excessive heat and light. As to supporting itself in such a case, no tree will ever do it.

\section{Preparation for Planting.}

For the better illustration of what follows it will be presumed that the subject to be planted is a fruit-tree. Let it be announced at first that the best time for planting these, and in fact most trees, is during the dull season of the year, 


\section{Planting and Bedding}

when there is no outward and active growth. From October to March the period may extend. Of course the earlier it is got in the better chance it has to become suited to the surroundings, and to prepare itself for making renewed effort on reawakening. Let it also be accepted as a selfevident truth that it is bad practice to plant a tree when the soil is very wet, or very dry, or frozen, or covered with snow. With these exceptions you may plant any time during the period mentioned. Ordinary cultivation, it must be admitted, does not extend to the depth required for fruit planting. It is safe to say that seldom is the soil disturbed below nine inches in depth. This, of course, is contrary to the doctrine laid down in this and other books, but it is nevertheless only too true. It is evident that a tree cannot be planted with any hope of success in such shallowness. To sustain itself properly a fruit-tree must have not less than eighteen inches of good soil to grow in, and preferably it should be increased to two feet or even two-and-ahalf feet. If the ground is to be given up entirely to fruit, and it is possible to put on the labour, the whole plot should be thoroughly trenched. It often happens, however, that fruit-trees are to be planted in an orchard. In this case we cannot well trench the whole of the ground, so that when the stations for the trees are found, a circular area is dug out to a depth of quite two-and-a-half feet, and filled in with good soil. A strip of land, as shown in Fig. 86, might be cultivated which, when possible, is better than having merely the hole dug out. This illustration, together with the other (Fig. 87), will serve to show how the positions of the trees may be marked out.

The great objection to digging out holes in which to I 5 I 


\section{How to manage a Garden}

plant trees and leaving the other part uncultivated is, that the water is very likely to drain into these spaces much to the detriment of the tree. This argues strongly in favour of good tillage throughout the piece, but it is certainly better to provide a good start for them thus than to plant in bad soil. In the work of planting itself, all the roots, after having been trimmed as required, should

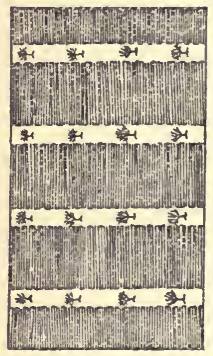

Fig. 86.

Trees grown in cultivated land in orchard.

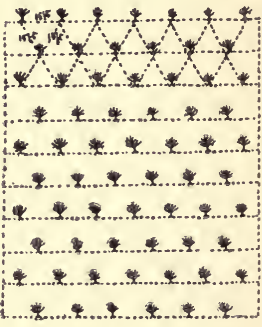

Fig. 87.

Method of planting trees.

be spread out at their respective levels, and have some good soil put about them. More attention should be paid to the smaller roots than to the larger ones, for it is from these former that the chief work of sustenance is to be expected. The soil should be made firm around all of them, and the stem of the plant kept upright. When duly filled in, make secure with cords or stakes, and if needed, water well. 


\section{Planting and Bedding}

\section{Bedding.}

We now arrive at a very interesting phase of gardening, which unfortunately cannot be treated at the length it deserves. A few generalities may, however, be noted. The making of beds and borders and their arrangement in the garden having been already dealt with in writing and figure, it remains for us to point out some of the methods of arranging the plants in these beds in order to give the most pleasing effect for the greatest possible length of time and at the least expense in money and labour. It might be truly stated that bedding of almost any kind is rather an expensive luxury, whether the stuff be bought in or be grown. In speaking of bedding now, it is intended to include all kinds - spring bedding, summer bedding, bulb bedding, annuals, perennials, carpet bedding, ribbon borders, massing and grouping, and in fact all cases where flowering and foliage plants are grown in beds and borders for effect.

\section{Carpet Bedding.}

Of all the various forms of bedding, this is probably the most expensive of all; for it is essential that small dwarf plants be used, and obviously these cannot be planted so widely apart as plants which cover a larger area. Here we have an increase not only in the number of plants required, but in the time it takes to plant them. A couple of plans are appended (Figs. 88, 89), wherein are given some ideas of the arrangement of design in carpet bedding. In private places this form of bedding 


\section{How to manage a Garden}

finds but few adherents. Not only is it considered too expensive, but men's tastes have risen of late years. They look to Nature for their inspirations, for they recognise that it is the beauty of the plants themselves which ought to take the first place of admiration and not their arrangement, which is of course wholly and entirely the work of

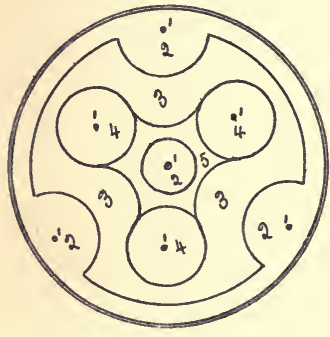

FIG. 88.

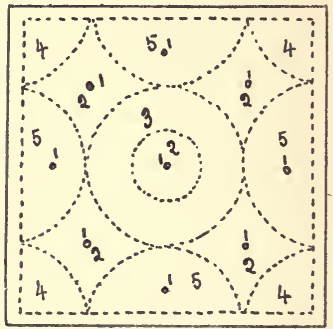

FIG. 89.

Plans of carpet bedding.
r. Dot plants.
3. Mesembryanthemum.
2. Antenaria.
4. Yellow Alternanthera.

5. Red Alternanthera.

man. In our public parks we often see some pleasing examples of this form of bedding. This may be accounted for, not by the fact that those responsible for the bedding are behindhand in their ideas, but rather that the people are not yet ready for the transition, and as every park superintendent knows, he must cater for the tastes of the multitude, not for his own. 


\section{Planting and Bedding}

\section{Summer Bedding.}

As used here we understand by summer bedding that which is chiefly represented by lobelias, geraniums, \&c. This likewise is going largely out of fashion. Gardeners generally are rather glad of this, for it takes quite eight or nine months to propagate and prepare the plants and

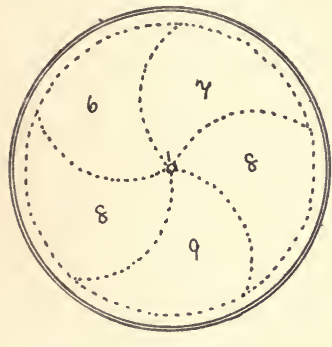

FIG. 90.

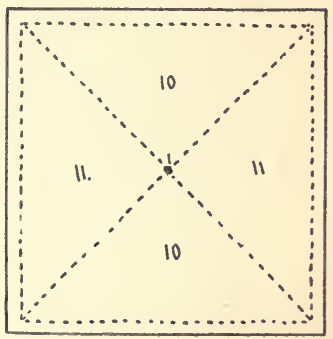

FIG. 91.

Plans of summer bedding.

I. Dot plants.

6. Verbena red.

7. Verbena white.
8. Verbena pink.

9. Verbena purple.

ro. Geranium bronze.

Ir. Geranium white.

bed them out for the display during the few remaining months. In bedding with these plants as with all others, it is necessary to know the characters of the plants, so that they may be set at such a distance apart as to well fill the bed when they have grown to their fullest extent. Each plant must have sufficient room to develop itself, and display itself to advantage, but no 


\section{How to manage a Garden}

more. A couple of examples of this manner of bedding are also given (Figs. 90, 91). Spring bedding is not so popular as it might be. It is a great pity that when the summer bedding has been completed, the beds should be left naked until the following summer, when they could be filled during the spring months by so many beautiful plants and bulbs, which could be got

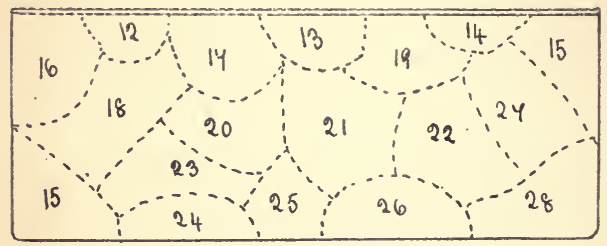

FIG. 92.-Plan of grouping.

12. Delphiniums.

13. Sweet peas.

r4. Hollyhocks.

x5. Violas.

16. Phlox Drummondi.

I7. Montbretias.

r8. Pentstemons.

r. Lobelia Cardinalis.
20. Poppies.

21. Gypsophylla elegans.

22. Antirrhinum.

23. Calceolaria.

24. Verbena red.

25. Nasturtium.

26. Salvia, blue.

27. Stocks.

28. Godetia.

off in time to make room for the summer occupants. It would seem to be even more desirable that there should be a wealth of bloom in the early spring, when flowers of whatever kind are more appreciated owing to their rarity, than in the summer months when so many are with us. I should certainly advise readers to pay more attention to this class of bedding. 


\section{Planting and Bedding}

\section{Massing and Grouping.}

Of late years a new informal and highly interesting style of bedding has arisen. It is worked on no formal geometric plan, but each class of plants is bedded in a mass or group by itself, and in its own colour, so that even if the plants themselves are not handsome specimens the effect on the whole is pleasing. An example plan is given to convey the idea (Fig. 92). There is a large range of choice in colours, in height, and in general habits, and every one who has a sufficient breadth of ground to justify him in undertaking this bedding should be able to find something to suit his tastes. The plants of course should not be disposed in groups promiscuously. There should be order; and due regard must be had to the colour, the height, the habit, and the time of flowering. Both annuals and perennials are suited for the purpose, and may be arranged in beds or borders. Seldom could we find a prettier picture than a broad border well furnished in this style. 


\section{CHAPTER XIX \\ SUPPLY OF TOOLS, ETC.}

\section{Necessity of Good Tools.}

I AM well aware of the fact that I cannot do adequate justice to the title subjects of the various chapters in the space at command, but I hope to touch on the more important items, and to engender a craving for more knowledge, which may be secured by speculating in works devoted especially to certain departments, according to the tastes and natural inclinations of the reader. Dispensing with further prelude, I proceed.

That tools are required is axiomatic; that good tools are also necessary will also be generally admitted. This being so, I would urge on all those who seriously intend taking up gardening for a hobby, or for the praiseworthy purpose of providing themselves and families with a wholesome supply of fruit and vegetables, to see to it that the machinery, so to speak, is in proper working order. The old saying has it that a bad workman always quarrels with his tools. This is not to be disputed; but it is likewise true that a good workman and a bad tool cannot long exist together. Try to dig ground with a healthy intention but a rusty spade; the goodness of the intention will quickly disappear, and you will be peril- 


\section{Supply of Tools, etc.}

ously near giving way to anger. The moral is obvious. Makeshift tools are seldom satisfactory. Perhaps possessing a fund of ingenuity we make tools for ourselves. We pride ourselves on their value, their strength, their everlastingness-qualities which we find very soon disappear. It is generally safer and cheaper to buy good tools direct from the manufacturer, and be sure that they are what they are said to be. These remarks apply throughout, whether for scythes, mowers, spades, forks, barrows, baskets, or knives. In all cases pay a fair price for a good implement and avoid the middleman, where the cost is greater or the quality less.

There is need, I think, for a remark also on the proper keeping of tools, by which they last much longer than under careless treatment. If a tool is put away dirty, it will surely not last long. If a lawn-mower is not often oiled and cleaned it will very soon become inefficient. It is dictated by common-sense as well as by economy that tools should always be well cleaned after use, that they should be well oiled, and be put away in order in a dry place.

\section{Supply of Manure.}

It is most important that there should be abundance of manure available to be put on the land. Whether this manure be of an animal or vegetable origin matters little, so that sufficient can be found by some means to repair the fertility of the soil. Now there is much talk about fertility, but few people understand what it really 


\section{How to manage a Garden}

is. Perhaps I can enlighten them. Fertility has a different meaning for different crops. A land which would produce excellent wheat might fail to produce potatoes in like proportion. For a land to be really fertile, it must possess a sufficiency of decayed animal and vegetable matter in the soil, and the agents necessary to cause that to be worked into a form suitable to be received by the plant. A manure heap contains plenty of plant food, but usually the agents necessary to make it available are absent, or present in too great a number. In a previous paragraph mention has been made of the disposal of rubbish by working it, as far as possible, back into the land. Of the value of this process I am convinced. Whatever is brought out of the land by the power of growth, and is not required for use should be returned again, unless it is likely to be injurious by causing greater growth of weed. Apart from the manurial value of this matter, it also solves for many of us an economic question, for if not disposed of in this way there would necessarily occur a large accumulation which would have to be carted away at some expense. Therefore I recommend to all and sundry, whether they have plenty of animal manure or whether they have not, to use all vegetable refuse.

\section{Animal Manure.}

The availability of animal manure will depend largely on the resources of the holding. If pigs, poultry, \&c., are kept, there will probably be sufficient. To those 160 


\section{Supply of Tools, etc.}

unacquainted with country life it would seem that there must be ample means of getting good manure at a reasonable cost, but such is not the case. Most farmers use their own manure on their land. Some are even bound by their leases to do so. In the towns, hotel owners and those who have stables are often glad for some one to take their manure away; hence it may be had for the carting. The difficulty of obtaining animal manure-a difficulty which will probably increase as the motor becomes more fashionable-suggests three things: Firstly, it emphasises the importance of using green manure ; secondly, it urges a man to keep live-stock; and thirdly, it shows the great use of making a study of artificial manures. If I might add one more point involved, I would say that the three before-mentioned must necessarily be coexistent with thorough cultivation.

\section{Artificial Manure.}

I feel it absolutely necessary to point out that practice teaches us that there is much to be got from artificials, but that they cannot wholly take the place of animal manures. The two should, as far as is compatible with the requirements of the plants, be used together, but neither the one nor the other will be of much use if the ground be not thoroughly tilled. In purchasing artificials, avoid buying in quântity and keeping them about, unless you are sure that the value will not deteriorate. Refrain also from mixing different manures together too long before use, for chemical changes may take place I6x 


\section{How to manage a Garden}

which might nullify their effect, or render them harmful. In a word, rely solely on well-proved experiments of others, until you obtain sufficient knowledge and sufficient practice to work on your own lines. Experiment is one of the chief roads to knowledge, but in view of the risk involved it should be traversed cautiously. 


\section{CHAPTER XX \\ ROTATION OF CROPS}

\section{The Need for Rotation.}

Rotation is spoken less of now than it used to be, but it has nevertheless its value, and is not to be ignored. It is a fallacy to say that the same crop cannot occupy land profitably for several years in succession. Innumerable instances can be pointed out where this does occur, as in the case of a great number of cottage gardens, where potatoes are grown on the same ground year after year. Let it be clearly understood that I do not advocate this course. I do not consider it wise to continually draw one kind of food only from the soil, for there must of necessity be other plant food which must waste or get into a state which will render the soil sour. Although it is not impossible to continually crop a land with the same subject, it is unwise to do so for too long a time. In fact it can only be done successfully when good tillage obtains. Good tillage is the great corrective of sourness, and in proportion as a soil is well tilled so is the possibility of its becoming sour decreased. Hence we infer that good cultivation lessens the need for rotation, though it certainly does not do away with it altogether. The fallacy has been in placing too much reliance on the cultural value of rotation, whereas its economic value should commend it to practitioners of the twentieth century. 


\section{How to manage a Garden}

\section{Its Economic Value.}

Rotation combined, as previously pointed out, with good tillage has this effect, that there may be a saving in the amount of manure. If $I$ grow celery for one year on a plot of well-cultivated land, that celery takes from the land as much available plant food as it can absorb, consistent with its nature. If I desire to grow celery again, and yet again, it is obvious that the same kind of plant food will in time become insufficient, whilst at the same time there might be sufficient for an excellent onion crop; hence by changing the crops we use up all varieties of plant food, and give very little opportunity for it to go to waste. It must furthermore be admitted that the more we take from the soil the better, provided always we put back an equivalent amount. It is foolish to suppose that we injure the land by taking large crops off it. Only when we neglect to put back manure, or put it back in inordinate quantities, does injury occur.

It may be laid down as a guide for those who are anxious to work their garden according to a really healthy rotation, that plants having the same nature and habit, or which, it is safe to presume, take from the land a similar kind of food, should not follow each other. Thus carrots, parsnips, and beet, although requiring different food, yet are so alike in general characteristics that it is safe to presume that much plant food in common will be required by all three. 


\section{CHAPTER XXI \\ THE ERADICATION OF WEEDS}

\section{Hoeing.}

AfTer the weather, there is no subject on which the gardener can wax more indignant than on the subject of weeds. How they come there he cannot tell. That question, of course, does not concern him, except in as much as it reflects on his past relations with the soil. Ofttimes a weedy land denotes an indifferent husbandman. Again it gives a sign of latent fertility; a land which would not grow weeds has little chance of producing anything more valuable. Before, however, entering on the question of how to get rid of weeds, I would like to suggest that their number might be considerably diminished if timely measures of prevention were taken. Of course, if weeds are allowed to flower and seed before they are pulled up, how will it ever be possible to have a clean garden? Likewise, if deep-rooting weeds are simply chopped off, their number will grow rather than lessen. Weeds, of course, mean plants in the wrong place. Notwithstanding its great utility, horseradish is to some growers a very troublesome weed. One of the chief methods of dealing with weeds is by hoeing, but it may here be remarked that this is not the only gain derived from hoeing: it loosens the soil, enabling it to receive more moisture, and to retain I 65 


\section{How to manage a Garden}

more, and should be frequently practised. Whenever the amateur feels a desire for gardening, and knows not what to do-if this could ever happen-let him take a hoe. It will always do good to stir the soil during favourable weather, and more especially during the summer months. This alone should keep down the weeds, and tend to invigorate the crop.

There are two sorts of hoes : the draw, and the thrust, or dutch hoe. Both are useful in their different spheres. The dutch hoe is especially useful for light soils and where the weeds are of a shallow-rooting nature. It is also useful for cleaning and turning over walks, although for ridding walks of weeds there can be nothing better than the use of a good weed-killer. Where this is not possible, use salt, which certainly saves labour, though not to so large an extent as does a really good weed-killer. A hoe, be it a dutch or a draw hoe, will quickly wear out if used on a gravel path. A heavy soil is better worked with a draw hoe, as a little experience will show. It will be noted that a heavy soil cannot be brought to so fine a tilth as a lighter soil, and must therefore require a hoe with a deeper blade. There are also triangular hoes, but they are not so often seen as the two just mentioned. As long as it is possible to get among the crops without damaging them, hoeing should be periodically practised whether there be weeds to skim off or not. Get well below the weeds so that they may be got up by the roots and not simply cut off by the tops, as is too often done with weeds of a troublesome nature. 


\section{The Eradication of Weeds}

\section{Troublesome Weeds.}

Among the most troublesome of weeds are couch-grass, colt's-foot, nettles, docks, and "old man's beard." For a garden infested liberally with all or any of these, there is absolutely no cure but deep cultivation and hand picking. It must be continued not throughout one year only but for several years together. Of course the best time for cleaning ground is when it is being dug over. There is certainly this advantage in having ground thus infested, for if there is a thorough determination to get rid of the evil there must of necessity be deep digging and thorough breaking up of the soil. A basket or barrow should be kept at hand, and even the smallest piece should be pulled out, as it will surely grow. To make thoroughly sure that these weeds do not get returned to the land, it is better to burn them straight away, or bury deeply in a hole. To throw them into the common rubbish-heap, from which they will eventually return to the garden, is labour in vain. Other weeds may be dug in the ground. In hot dry weather it will be necessary simply to hoe the ground and leave the weeds on the surface, where they will wither from the fierce rays of the sun. In other cases they should be raked up and put into a trench prepared for the purpose. When this trench has been filled with weeds, cover it over with the soil previously taken out, and take out another trench to be filled likewise. A friend of mine-a practical cultivator of some fifty years' experience-makes it a practice each autumn to take out a trench, eighteen inches deep, on the piece on which he intends to plant his runner beans. The bottom of the trench is then dug up. All the weeds and rubbish which accumu- 


\section{How to manage a Garden}

late for the next five or six months are spread out in this trench. As the time of planting approaches the trench is filled in, and probably some well-decayed manure incorporated with the soil. Of course the planting and other details of culture have to be attended to properly; but it is chiefly owing to the deep cultivation, and to the right use of the weeds as green manure, that the crop has invariably proved to be a first class one. 


\section{CHAPTER XXII \\ PROTECTION FOR THE CROPS}

\section{What it Means.}

I MEAN the protection of the crops from that large gang of enemies, extending from a bullock to a bug, and including therein all animal and fungoid pests.

\section{Animals and Birds.}

The title of this chapter might well be made the title of a large volume, for if treated fully it would include a large area of knowledge. It is hoped here to be able to trace out the general methods of protection from attacks of all kinds, without specifying the means of dealing separately with each individual pest.

As previously mentioned, the intruder may be anything from a bull to a bug, and I intend in these few paragraphs to show how we may lessen the mischief done. For domestic animals of the larger type it is easy to see that they can be kept out only by a sufficiency of protective fencing. This has been previously alluded to. The smaller domestic animals, such as cats and dogs, are often very troublesome. In many cases it is possible to teach them better manners; but when they do not belong to the owner of the garden r69 


\section{How to manage a Garden}

protective measures must be applied. Dogs learn not to interfere if frequently driven off, but cats are not so intelligent. The smell of chloride of lime is said to be disliked by them, and should be put in places where they play their pranks. If it can be found out where they enter the garden a very simple device will deter them. Procure a large, thick piece of cardboard, and pierce it with sharp tin tacks. Place it with the points uppermost at the entry and cover with a thin piece of cardboard or brown paper, so that when the cat treads on it the points of the tacks will enter its feet. To add to the deception some sand or soil should be scattered over. It is safe to say that the cat or cats will soon leave the garden severely alone or find other entrances, where they can be treated in like manner. To keep out fowls it will be necessary to have wire netting, although it may often be remarked that fowls do not enter a garden when it is fully open to them. Much depends on the way they are managed. If a sharp, business-like terrier has been kept to drive the fowls from the garden whenever they intrude, it is probable that caution in entering is handed down through generations as a species of legacy. The trouble is trebly increased where pea fowls are kept, for these will not confine themselves to a little healthy scratching, but must needs be pecking and biting at vegetables, flowers, and fruit. I never yet met a gardener knowing anything of the matter who could see anything to admire in a peacock. Perhaps this is prejudice, but it is certainly backed up by knowledge.

Among the smaller feathered tribe we have many 


\section{Protection for the Crops}

friends and likewise many enemies. Which class is the greater is difficult to say. Certain it is that birds prevent an overstock of injurious insects, but they will not confine themselves to a meat diet. They are all such strivers towards vegetarianism. This is where they become our enemies. We should endeavour to find out what birds are friends to us throughout, and spare them always, but spare the others only when they are serviceable, and ward them off or destroy them when they begin to be troublesome. It has often been asked whether it would not be better to have the garden thoroughly protected from birds by netting in the whole of the garden. Apart from the great expense, it would be found that much time, labour, and material would have to be expended to keep down insect pests, which could be better used in increasing the standard of cultivation. It is certainly a good plan to keep birds from the plants or the fruit when they would do more evil than good, but this is only during a few months of the year, and it is only fair to allow them free ingress when they are able to benefit the crop. There are numberless methods of making scarecrows to frighten birds from a large area. In the case of seed beds nets should be stretched tightly across at a distance of quite one foot from the soil and tightly pegged down. Breakages in the net may be repaired with string. In netting fruit such as strawberries it is better to stretch the material over the fruit at a height of five feet, so that there is no occasion to take it off at each picking. 


\section{How to manage a Garden}

\section{Trapping Rats and Mice.}

Among smaller animals we have usually to contend with rats, mice, and moles. The latter are in themselves harmless creatures, but they have a disagreeable habit of earthing up the soil, and may thus do considerable damage to a seed bed or make a lawn extremely unsightly. The method of ridding a garden is to place traps in their runs at a point where they cannot easily burrow beneath them such as where the run crosses a path or piece of hard ground. Gloves should be worn when setting the trap, as the moles are said to have a very keen sense of smell, and to be somewhat suspicious. Rats and mice have few if any good qualities, and should be ruthlessly destroyed. A good cat and a sharp terrier dog will do away with these to a great extent; but in places where there are abundant facilities for them to lay the foundations of a colony, numerous traps and hangs must be provided. There are so many forms of traps for mice, all of which are useful, that it is impossible to single out any particular form for special mention. Those may be said to be the best which kill the vermin at once, and thus render escape through the weakness of the trap, or through negligence an impossible occurrence. The main thing of course is to catch the mice, and measures will not be wanting to bring about their annihilation. The ordinary spring gin is probably the best for rats. It is certainly preferable to a wire cage, unless a readjusting one is obtained, by which the trap is automatically set again on the entrance of each victim. The hang or snare if properly set is a valuable means of catching them. A snare is made of easy running wire in the same 


\section{Protection for the Crops}

way as for rabbits. This is tied on to a pliable stick, one end of which is stuck firmly in the ground, and the other is attached to a peg in the ground, so that when the rat is caught and commences to struggle it will disengage the stick from its fastening to the peg, and the stick will fly up and have the rat slung up, in such a way as to prevent it from biting the wire to free itself. Rats may often be got out of their holes by ferreting, or by pouring water down. To effectually stop rat holes break up a piece of glass and stuff the hole and its surroundings with it, mixed with earth, clay, or mud. Cats and dogs are, however, the natural enemies of rats and mice, and will seldom flourish well together. Poison is not to be recommended owing to the possibility of accidents.

\section{Slugs and Snails.}

Common earthworms are not mentioned as pests, for they do little or no damage. A lawn may certainly be rendered unsightly by their castings, but the remedy is merely to run the brush over them. If they become too numerous, the best thing is to water the lawn with weak lime water which will bring most of the worms to the surface, so that they may be swept off. In a heavy land it is rather advantageous to have worms, as they assist in draining, and in their own small way in cultivating, the soil. We can certainly afford to leave these harmless beings whilst we prepare the sinews of war for the ruthless and uncompromising attack on slugs and snails. The appetite of these pests is enormous, but this is not their worst characteristic. If some enterprising person would train 


\section{How to manage a Garden}

slugs and snails in such a way that when once they had started on a plant they would confine the whole of their destructive attention thereto, before attacking another, he would earn the praise of every gardener. By long experience it has been found that the only real and thoroughly effective method of exterminating slugs is by catching them individually. In the evening of a showery day many hundreds can be caught making speedily with vicious intent toward some prized plant. Those who dislike the touch of a slug should wear gloves to pick them up and drop them into the pot of lime. Lime and soot will deter slugs and snails to a great extent, but will not keep them off altogether. Sharp coal ashes and wood ashes also act as a deterrent, but should be accompanied by hand picking. In addition we should go to the bottom of the trouble by finding out where the slugs have their abode and driving them therefrom. It may be that there is a large mass or growth, a hedge or something similar, close at hand which harbours them. Plenty of quicklime or soot should be scattered about in such places so that the pests may be killed or be forced to come out into the broad light of day. The more thorough the cultivation the less pests there will be, and the better will the crops withstand them.

\section{Insect Pests.}

Among insects we have a whole collection of enemies. It is quite an important business with them, so much so that they seem to have mapped out for themselves specialities. Thus we have the celery fly, the onion fly, the turnip flea, the peach curl, the Eucharis mite. 


\section{Protection for the Crops}

Throughout the whole range of horticulture we meet these undesirables, and if let go unchecked there will soon be little of useful produce in the garden. The best way to deal with these pests, as well as with fungoid diseases, is to find out their habits and characteristics, and treat them with some obnoxious application which will not do harm to the crops. I would advise all readers to send an unstamped letter to the Secretary, Board of Agriculture, 4 Whitehall Place, London, asking for leaflets dealing with insect pests and fungoid diseases having connection with the garden. These will be willingly supplied gratis. 


\section{CHAPTER XXIII}

T RAINING, PRUNING, Eтc.

\section{Forms of Training.}

My wish here is to give the general principle governing these important operations. Though applied more especially to fruit-trees, they are intended also to have reference to plants and trees in other departments. Among fruit-trees there are many different forms of training. We might mention the bush, the standard, the pyramid, the espalier, the cordon; the horizontal, the fanshaped and the upright. (See Figs. 93-100.)

\section{Shaping a Tree.}

The necessity of giving some sort of shape to a tree must be apparent to all who have had occasion to observe the different mode of growth between a wild fruit-tree and a cultivated one. If allowed to run wild at the start, the result will be that much growth will be made, and little or no fruit. It must be recognised that the aim of a tree is not to produce large fruit for human consumption, but rather to form a protective covering for the seed wherewith to reproduce its kind. This is in nature found to be not incompatible with a quantity of growth. For our own use we require much fruit, and only enough 


\section{Training, Pruning, etc.}

growth to assist in producing it. Hence it is evident that the tree must be restricted in one direction in order to increase the production of the other. The object in confining a tree to some definite shape is twofold. There is, first of all, the restriction of growth to add to the fruitfulness, and secondly, a symmetry of form to enable the tree

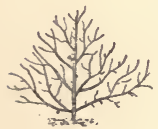

FIG. 93.

Bush-shaped.

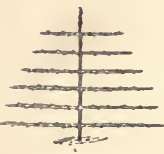

FIG. 97.

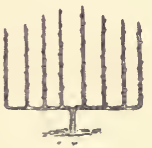

FIG. 98.

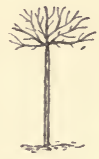

FIG. 94.

A Standard.

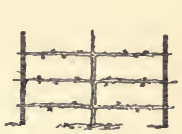

FIG. 95.

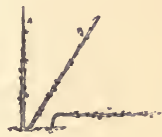

FIG. 96.

An Espalier. A-Upright.

B-Oblique.

C--Horizontal Cordon.

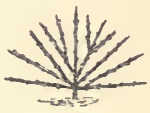

FIG. 99.

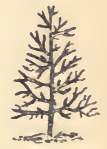

Fig. 100.

Horizontal trained. Upright trained. Fan-shaped. Pyramids.

to benefit fully from light and air, and to enable the cultivator to get to all parts of a tree without doing damage to any.

If a tree is to be made into a proper shape it must be taken in hand when young. Any attempt to alter the course of a tree when it has experienced many summers 


\section{How to manage a Garden}

is a fruitless fight against nature, and will only result in partial success and a great check to the tree. The question of pruning cannot be well separated from that of training, the two being necessarily embodied in the same process. It being understood that the bud is, so to speak, but an embryo shoot, attention must at the commencement be paid to these. Two figures (Figs. IOI-IO2) are given. The first is a young tree before it has known the knife. The second is the same tree a year older. We have thus cut to encourage three shoots, one of which will act as the lead, and the other as two side branches for forming

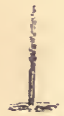

Fig. IоI.

Young tree after grafting.

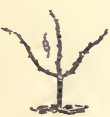

FIG. I02.

The same a year later.

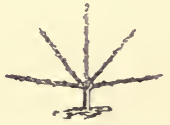

Fig. 103.

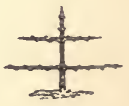

FIG. I04.

As fan-shaped. As a horizontal.

into a horizontal or fan-shaped tree. Two other figures (Figs. 103-104) are given to show the next stage of development in either the horizontal or the fan-shaped. Espaliers are horizontally trained trees which are trained to a wire fence instead of to a wall. Cordons may be upright, horizontal, or oblique. The fan-shaped is used greatly for peaches, nectarines, apricots, plums, and cherries, as they do not easily admit of other forms owing to the necessity of continually working in new wood. During the formation of a tree it is necessary to keep restraining the shoots, so that greater sturdiness, which is 


\section{Training, Pruning, etc.}

consequent on slow growth, may be obtained. If owing to the frequent restraint the tree breaks into unusual vigour, as young trees will often do, the best remedy is to lift them and perhaps curtail their roots. Those who want good trees which will be fruitful for a long period must certainly be patient and wait for them. At present there is no other way.

\section{The Pruning Question.}

It is intelligence rather than skill which is required for pruning. We have to study the nature of a tree to find out how it fruits and try to divert much of the energy of the tree in that direction and remove superfluous growth.

Apples and pears may be pruned in much the same way. The old wood is left, as it is from this that the spurs spring. New growth, except where required for extending the tree, or filling vacancies, should be cut back to six or eight buds in July or August, and then when the leaves have left and the sap is still, cut hard back to one or two eyes. Peaches require plenty of young wood to be worked in, at the same time getting rid of old fruitless portions. The disbudding and summer pruning consists in cutting back to one leaf all laterals and sublaterals, and those shoots which it is clearly seen will not be required. Apricots produce spurs, and these should be left, as well as much of the young wood worked in. With cherries it may be said that so long as there is plenty of room in the tree do not trouble them with a knife. If pruned, spur back the side shoots to three or four buds. Plum trees are very apt to become gross growers, and should on indi- 


\section{How to manage a Garden}

cation of this be lifted and root-pruned. This will greatly facilitate the work of branch pruning. Spurs should be encouraged and sufficient young wood worked in to fill out the space and keep the tree rejuvenated.

\section{Small Fruits.}

By small fruits we mean gooseberries, currants, raspberries, blackberries, and loganberries. There is less knowledge required in handling these, notwithstanding that many gardeners hold that it requires much art to prune and shape a gooseberry bush. A well-shaped gooseberry bush should be as symmetrical as circumstances will allow. It should have a clear three inches of naked stem above the soil ; its branches should be sufficiently far from the ground to prevent the weight of fruit dragging them to the soil; and there should be a possibility of getting the hand easily to all parts of the tree. To bring about this condition in an old tree is a most difficult matter, but with a clear start from the cutting it is fairly easy. The fruit is borne on the previous year's growth, and the aim is to preserve as much of this as can be reasonably borne, and that without unduly extending the tree. In old neglected bushes it will be noticed there is a lot of old barren wood with a few inches of young growth at the ends. This is what we do not want. We want the young wood springing from near the base and thus get a greater quantity of fruit from a given area. All growths tending to the inside of the tree should be cut out, as well as those which cross each other. Unless the tree has a great tendency to spread it is better not to cut back the growths that are to be I 80 


\section{Training, Pruning, etc.}

retained. Red currants should have the annual growth cut back to one or two eyes except where it is required to fill out or extend the tree. Black currants should have as much young wood as possible left, provided there is room for it. Young growths from the base should be encouraged to take the place of those which are older. Suckers should also be encouraged. Raspberries throw up fresh canes each year. The old ones should be cut out, and the best of the young ones trained in at a distance of not less than six inches apart. They may be cut off at a height of about five feet. Loganberries are treated in a similar manner, although these may be let go to a height of eight or ten feet, or trained over an arch. The value of this fruit is not yet fully seen. Blackberries romp away gladly in good, rich, cultivated soil, and yield abundantly. Thinning out is the principal part of their pruning; for they should not be greatly restrained.

\section{Hedge Trimming.}

Frequently hedges are cut with a hook, but the work is never so neatly done as with shears. Whether in the hedges in the garden, or in the pleasure ground, use the shears in all cases except with laurels or large-leaved subjects. These should be cut back with a knife, otherwise the leaves will be slashed about in a most hideous manner. The great thing in a hedge is to get it well clothed at the bottom. If a hedge be found which is well filled out at the top but naked below, it is very certain to have been neglected in its youth. Most persons are so anxious to get a high hedge that they do not see the need 


\section{How to manage a Garden}

of laying a good foundation on which to build. To be kept in good condition, hedges which display a tendency to break into growth quickly should be clipped twice a year. To allow them to grow rankly and then cut them hard in is to make the hedge an eyesore. 


\section{CHAPTER XXIV}

\section{CARE OF A GREENHOUSE}

\section{Potting.}

AMONG the many operations connected with the management of a greenhouse this is probably the most important; for how can a plant get any assistance from the other favourable conditions, such as suitable temperature, and careful watering, if its roots are caged and cabined up in a worthless soil, or so adjusted in a good soil that it requires several months' energy to get them into a feeble way of providing for the plant's sustenance? In indoor plant culture there is this great advantage-that we can to a very large extent choose our own soil, which cannot be done outside. Even if the basis is not a good one, its harmful effect may be greatly reduced by the addition of leaf soil, peat, lime rubble and numerous other useful ingredients. I hope those who are of opinion that any one can pot a plant successfully will have occasion to change their hasty opinion before they have completed the perusal of this chapter. The best soil that can be procured for potting purposes is the first three or four inches of an old pasture. Here there is most likely to be plenty of good fibrous roots, which keep the soil well open, and are the chief test of a good potting soil. 


\section{How to manage a Garden}

\section{Stacking the Turfs.}

The best time to cut the turfs is during the early autumn, before the land has become sodden by wet weather. The best size for stacking purposes is two feet by one foot. The depth of course depends on the amount of fibre, but should not be less than two inches nor more than four. A dry spot with a firm bottom should be chosen for stacking, and the turfs should be put grass side downwards, so that vegetation may be stifled more quickly. The length and breadth of the stack matters little, but the height should never exceed six feet. The chief reasons for stacking are, that the vegetation is stifled, the soil is more likely to be freed from insect pests, and there is not the trouble of cutting fresh turf every few days. To aid in keeping the turf from becoming too dry, and to further enrich it, well-decayed manure may be spread over each layer of turfs during the process of building, or leaf soil may be used for the same purpose. An occasional sprinkling of lime or soot will also assist in destroying many insect pests. As the stack approaches completion, it should be roofed in by gradually narrowing the sides, so as to form two spans, and eventually completing it by a row of turfs. When the time for cutting arrives, which should be in the spring, let the turf be chopped straight down, commencing on the northern side, so that the exposed surface will not quickly become dry. 


\section{Care of a Greenhouse}

\section{Composts.}

Before treating of the general make-up of a compost, a few words might be expended on the materials of which it is composed. Turf has already been mentioned. The next in importance is leaf soil. The best leaf soil is formed from oak and beech leaves; that from elms, sycamores, chestnuts, \&c., being far inferior. Usually, however, the grower has to have a mixture. As far as possible, all sticks should be omitted. The leaves are then set up in a heap and frequently turned over to prevent fermentation. They are hardly likely to be sufficiently decayed for use until the following year, by which time they should be capable of being passed through a halfinch riddle. Leaf soil is greatly valued on account of its quality of retaining moisture, in addition to being a plant food. Peat is usually bought of two qualities - the orchid, and the common. The latter is more generally used. Though not in itself largely endowed with plant food, it can retain food which is applied, and by reason of its opening nature is greatly in demand where the turf is lacking in fibre. It should be broken up into pieces as large as a plum, and well incorporated in the soil, the dust resulting being thrown about on the ground. Charcoal and wood-ashes may be classed together as resulting from the same process. They are of a hot, burning nature, and must not be too liberally applied. They are a valuable addition to a soil wanting substance, and to plants whose soil will not be changed for some considerable time. Ashes resulting from the burning of rubbish are also spoken of as wood-ashes and are very valuable. Before 185 


\section{How to manage a Garden}

use they should be passed through a half-inch sieve, and should be stored always in a dry place. A little charcoal may be put in every soil as it has a tendency to preserve its sweetness. Let it be crushed fine for the purpose. Mortar rubble is very useful in a compost. It is chiefly used for the purpose of keeping the soil well opened, and, like the leaf soil, should previously be passed through a half-inch sieve. If the fine dust is not required, the sifted portion may afterwards be submitted to a quarter-inch sieve, and what will not pass through the sieve retained for potting purposes. Sand is also used for keeping the soil porous, and figures more prominently in soil for seeds, cuttings, or young plants. If cow manure is added to a compost, it is very evident that it cannot be used in a raw state, but must be allowed to become dry, and then broken up. The same applies to sheep manure. Horse manure should rarely be used fresh. For potting purposes it is quite as well that the horse manure be first used for the cultivation of mushrooms, and when the crop has been taken off and the heat of the manure spent, let it then be used for potting. The best compost for general purposes is made up of two parts loam, one part leaf soil, and one-tenth part coarse sand. If the turf and leaf soil are good, this compost will grow almost anything.

\section{How to Pot a Plant.}

It may be mentioned that pots should be well washed before use if the plants are to do well. Then comes the business of crocking. A large potsherd should be obtained 186 


\section{Care of a Greenhouse}

nearly as large as the bottom of the pot, and put in with the hollow side downwards. A few more smaller pieces should be put around, and finally a handful of finely broken crocks. Over the crocks should be placed moss, leaves, or rough turf to prevent the soil from choking the drainage. A little more soil is then put in. The plant should be knocked out of its former pot and the crocks extracted. It will then be put into the newly prepared pot, and soil worked well around it by means of the hands or the ramming stick. Enough room should be left for water, the distance between the surface and the rim of the pot being never less than half an inch. A few rules for potting may be appended. See that plenty of drainage is provided according to the character of the plant. Do not give too large a shift; that is, do not let there be too great a difference between the old pot and the new one. Let the plant stand upright in the centre of the pot, and let the ball of soil be covered by quite an inch of the new compost. Do not ram the soil too hard, but yet make it firm. The question of firmness varies with each class of plants.

\section{Watering.}

A paragraph must surely be allowed to give a few hints on this important subject, an ignorance of which often causes much annoyance, and ofttimes failure. It is well-nigh impossible to lay down any definite rules for watering, for no matter how explicit and how numerous, they will surely be subject to many exceptions. The quantity of water given varies greatly according to the character of the plant, and the special circumstances under 


\section{How to manage a Garden}

which it is grown. A plant in a hothouse will require more water than one in a cool house. A plant whose roots have well filled their pot will require more than one just potted. More water will be needed in hot, dry, than in dull, weather; and more in summer than in winter. Do not give water to a plant until you are certain it is required. If you are doubtful, it is safer to refrain from watering. There are several methods of discovering whether a plant is in need of water. If it wilts, or flags; if its leaves are unduly soft and flabby; if, when lifted, it is found to be very light; if the soil looks and feels dusty; if it gives forth a decidedly hollow sound when the pot is sharply rapped. When a plant has been allowed to become unduly dry, the best remedy is to stand it for some time in a bucket of water. Use water which is approximately of the same temperature as the house. If there is a tank within the house there will be no difficulty in this matter. During the summer months, watering should be done chiefly in the afternoon, and in the morning during the winter. Soft water is decidedly superior to hard.

\section{Shading.}

Although the sun's rays do much good to all plants, it is nevertheless certain that there are many plants which cannot withstand its full glare. These, of course, have to be shaded during the hottest part of the day. With this necessity arises a difficulty. The material used for shading should not be too thick. Something in the nature of canvas is what is required. This, it will be seen, breaks the fierceness of the sun's rays but does not greatly I 88 


\section{Care of a Greenhouse}

diminish the light. If it is a greenhouse which requires shading, the best method is to put on a blind which can be rolled up and down at will; and the best form of blind is undoubtedly that formed of laths, and which is known as the lath-roller blinds. They may be found more expensive at first but they last much longer, are less troublesome, and therefore in the long-run much cheaper. Frames are best shaded by "tiffany" or canvas rolled on a stick. Another method of shading is to use a mixture known as summer-clouding painted evenly over the glass. A permanent shading of this sort is not at all to be recommended where moveable material can be employed. Shade only when really necessary : overshading is harmful.

\section{Ventilation.}

A greenhouse needs airing in order to allow the plants therein their due quantity of fresh air, and is quite as necessary with plants as with animals. The only difficulty arising is the regulation of it so as to suit the occupants of the house. Where a house is set apart especially for the culture of one kind of plants, such as carnations, ferns, begonias, vines, \&c., it is not so difficult to ventilate for their benefit, as when there is a whole mass of miscellaneous matter requiring different attention. Here as in other phases of gardening it is well-nigh impossible to lay down rules which can be considered absolute. A few may be mentioned. Ventilate sparingly on foggy days and during wet, cold weather. During hot weather give full air. Do not allow the wind to blow straight in on the plants. Do not open the top ventilators when very windy. Commence 


\section{How to manage a Garden}

to ventilate as soon as the sun strikes the house in the morning; and close the lights as the sun wanes, to bottle up the heat. When dull and sunny periods alternate quickly, work the ventilators so as to alter the temperature of the house as little as possible. During winter allow just a chink of air to remain on always at the top of the house. Do not open the ventilators of a house which is already too cold. These few rules will perhaps help to simplify the matter, although the best principle in this as in all other departments of gardening is to observe and practise.

For fuller information on the care of a greenhouse, see the author's work on "Greenhouses, How to Make and Manage Them," published by Messrs. C. A. Pearson, Ltd. Price is. net. 


\section{CHAPTER XXV \\ A GARDEN CALENDAR}

\section{January.}

Dig vacant ground. Protect from frost all plants needing it. Wheel manure on ground during hard frost. Burn weeds and rubbish. Make up hotbeds. Make mushroom bed. Plant potatoes, peas, and beans in pots. Force asparagus in pits and hotbeds and keep up supply of forced rhubarb and seakale. Sow tomatoes, cucumbers, and melons for early work. Sow seed of cabbages and cauliflowers in boxes. Look over potatoes and other store roots. Plant trees in favourable weather. Prune pyramid and other trees. Tie or nail up wall trees and espaliers. Prune and train peach trees. Put by scions of apples, pears, \&c., for grafting. Hoe among crops and clean between them. Sow onions in boxes in gentle heat. Water plants during the morning. Clean vines. Wash plant houses inside and out. Start first batch of gloxinias. Sow primulas in pan. Bring some pot strawberries inside. Put in cuttings of chrysanthemums. Fumigate to keep down green fly.

\section{February.}

Roll lawn after showers. Keep up succession of forcing plants such as bulbs, azaleas, spireas, \&c. See that seed 


\section{How to manage a Garden}

potatoes are kept exposed and yet free from frost. Start vines to fruit in July and August. Top-dress vine border and water it well. Sow mustard and cress weekly. Wash pots, pans, boxes, and baskets. Prune gooseberries and currants. Keep flowering-house fairly dry. Take cuttings of summer flowering plants. Keep plenty of water near hot pipes. Sponge all inside plants with soapy water if troubled with mealy bug and scale. Tie up raspberry canes and loganberries. Pot amaryllis. Sow Brussels sprouts in boxes and carrots in frames. Put pot roses inside. Start bulbs of caladiums and the yellow calla. Sow early celery, lettuce, and parsley. Plant shallots. Pot up plants that are rootbound or give them liquid manure. Prepare a cold frame with ash bottom for chrysanthemums. Put in cuttings of geraniums.

\section{March.}

Give more air to greenhouses, pits, and frames. Pot up stove plants in good open compost. Pot up also chrysanthemums and tomatoes as they need it. Sow seed of peas, spinach, lettuce, savoys, turnips, radishes, celery, celeriac, \&c. Plant asparagus in rows four feet apart and two-and-a-half feet between plants. Graft trees. Get soil broken down ready for sowing and planting. Make a trench ready for sweet peas and also for runner beans. Syringe peach trees and vines twice daily. Damp floors of glass houses. Make new plantations of seakale and rhubarb. Plant potatoes and artichokes (Jerusalem and Chinese). Pull or dig up old cabbage stumps, \&c. Put in cuttings of coleus, winter carnations, begonias, \&c. 


\section{A Garden Calendar}

Dig over herbaceous border. Put dahlia root in warm house to obtain cuttings. Pot up eucharis. Disbud peach trees inside. Plant cauliflowers sown early.

\section{April.}

Plant potatoes. Cover peach trees flowering. Shift chrysanthemums into six-inch pots. Divide and pot up old stools of chrysanthemums. Put spireas and other forcing stuff outside. Keep vinery drier during flowering. Give asparagus a dressing of salt. Sow onions, also plant out from boxes. Pot up calanthes. Sow seed of savoys, broccoli, curly greens, also marrows, stocks, and asters. Prick out celery in frame. Prepare trenches for celery if land is vacant. Make up mushroom bed. Prick off seedling plants of inside stuff and sow more seed. Pot on primulas, cyclamen, and all rooted cuttings, also begonias, gloxinias, gesneras, \&c. Thin fruit of pot strawberries. Do not syringe them but water with liquid manure. Plant cucumbers in house. Shade all seedlings and tender plants. Allow crotons and foliage plants plenty of light. Keep hoe going in garden. Clean herbaceous borders. Prune roses. Clip ivy on walls. Trim grass edgings.

\section{May.}

Sow seed of beet, also of cinerarias, calceolarias, and primulas. Take cuttings of euphorbias and poinsettias. Pot up tuberoses and plunge in heat. Thin grapes. Water vines and give some artificial manure. Do not syringe vines again. Plant runner beans. Sow beet. Mow lawns. 


\section{How to manage a Garden}

Harden off stuff to be planted out. Prepare cold frames for many inside plants. Plant Brussels sprouts. Hoe and weed among all plants. Earth up potatoes. Stake peas. Thin peaches and nectarines. Plant out forced strawberries, also such forced stuff as spireas, arums, azaleas, \&c. Plant tomatoes and marrows at end of month. Stake border and malmaison carnations. Thin flower buds on latter, also on roses. Syringe for mildew and green fly. Keep all houses regularly damped. Shade flowers from sun to keep them longer. Give ample air. Prepare soil for final potting of chrysanthemums. Stop sublaterals on vines and peaches to one leaf. Prepare beds for summer bedding. Water all plants needing it during hot weather. Look out for slugs and insect pests, and use preventive measures.

\section{June.}

Put straw beneath strawberries to keep fruit clean. Bed out all summer plants. Put stakes to runner beans. Plant celery, leeks, and winter greens. Pot chrysanthemums, and stand outside in rows. Put nets over fruittrees. Support broad beans with cord. Pinch tops when first pods are formed. Tie in growths of peaches and nectarines. Sow more cinerarias, and prick and pot off others. Put primulas, tree carnations, cyclamen, geraniums, \&c., in cold frames. Layer malmaison carnations in frames. Plant dahlias. Pot on all plants requiring it. Put leaves of gloxinias in sandy soil to root. Mulch many plants to save watering. Look over inside plants twice a day. Give vines plenty of air. Let not the foliage 


\section{A Garden Calendar}

become scorched. Keep border well damped to ward off red spider. Use weed-killer on walks. Tie in main shoots of wall fruit.

\section{July.}

Mulch peach border. Give artificial manure to vines, and cut out bad berries. Sponge plants to keep down mealy bug and scale, and fumigate regularly for thrip and green fly. Put tub beneath spouting of house to catch all water. Sow cabbage for spring use. Clean herbaceous border and stake all plants that need it. Layer strawberries in pots for forcing and for new plantations. Prepare ground for new plantations. Tie up raspberry canes loosely. Leave off syringing peaches when they commence to colour. Keep seed pods pulled off sweet peas and rhododendrons. Summer prune apples and pears by cutting growth back to four or five buds. Clip hedges with shears, except laurels, where the knife should be used. Dig up early potatoes, choosing best for seed. Dry off gloxinias which have finished flowering. Keep celery well watered. Sow more spinach. Keep side shoots pinched from tomatoes. Make up mushroom bed. Bud roses. Peg down many bedding plants. Stake dahlias. Mow lawns every week. Look well after chrysanthemums. Tie shoots to stakes or wire fence.

\section{August.}

Layer carnations. Pot up strawberries in six-inch pots, and plant others out two feet apart. Keep cyclamen well 


\section{How to manage a Garden}

ventilated, shaded, and syringed. Earth up celery slightly. See that boiler and heating apparatus are in good repair. Take cuttings of hydrangeas, and strike in a cool house. Pot up palms and other stuff which is root-bound. Clean all green slime off pots. Sow onions. Pinch off all buds from winter flowering plants for quite another month. Continue to propagate poinsettias, and keep rooted ones well cared for. Pot up arum lilies, and stand for a few days in shade. Commence to propagate bedding stuff. Put the boxes when finished in cold frames. Take cuttings of violas. Put in cuttings of roses and many other hard-wooded subjects. Cut off dead rose-blooms. Pot up roman hyacinths, and plunge in ashes. Remove dead flowers from all plants. Sow more cabbage seed. Stop tomatoes when four feet high. Thin out shoots of raspberries. Keep vinery dry during ripening of berries Sow seeds of cyclamen.

\section{September.}

Gather apples carefully. Cut turf and stack for potting in the spring. Put a layer of manure alternately with turf. Pull up onions, and store when ripened. Water chrysanthemums well, giving them manure water two or three times a week. Prepare houses for putting plants inside in case of frost. Close pits and frames earlier in the afternoon. Gather green fruit from tomatoes, and put on shelf in sunny spot. Allow primulas, cyclamen, tree carnations, and geraniums to develop their buds. Dig up potatoes when ripe. Store in a cool dry place, and cover with straw. Take cuttings of calceolarias, and dibble in frame. 


\section{A Garden Calendar}

Pot tulips and hyacinths, and plunge in ashes. Commence to pot up spireas and other forcing stuff. Plunge pot strawberries in ashes or soil. Take shading off houses. See that all valves, air-traps, \&c., on heating apparatus work well. Plant wallflowers. Buy in a stock of fuel when prices rule low.

\section{October.}

Make gravel walks, or repair those already made. Cut out new flower beds, and make other needful arrangements. Get up old plants of bedding stuff to provide cuttings in spring. Pot on carnations. Get chrysanthemums and other tender plants housed. Plant tulips and hyacinths and other bulbs for spring flowering. Cut down asparagus and clean the beds. Syringe less frequently. Plant out border carnations if sufficiently rooted. Fill window boxes with laurels, hollies, bulbs, \&c. Wash bulbs, such as amaryllis and eucharis, which are infested with bug. Plant fruit and other trees. Gather up leaves and put in a heap to form leaf-soil. Plant out spring cabbages. Trench and replant herbaceous borders. Dig and trench heavy ground. Get up dahlias and store in cool, dry place. Plant daffodils in grass, also crocuses. Store carrots, beet, and celeriac in sand. Leave parsnips in ground till required, digging up only sufficient to last during frost.

\section{November.}

Pot up cuttings rooted in greenhouse. Put gas-lime on land badly infested with insect pests, or with the 


\section{How to manage a Garden}

cabbage club-root. Discontinue mowing. Clean machine, take to pieces and store. Plant raspberries and currants. Commence forcing seakale and rhubarb. Lift and prune fruit-trees that have grown vigorously. Prune vines and peaches. During mild weather prune and nail wall trees. Pot on bulbs in variety. If vines are to be propagated from eyes in the spring, heel in some of the cuttings. Cover up frames, \&c., during frost. See that the fire burns well throughout the night. Dig ground round orchard trees. Earth up celery and protect during frost. Point garden walls where fruit is to be trained. Put a frame over Christmas roses to get them along early, and keep them clean. Put ashes or soil round wooden frames, the better to keep out frost. Commence taking cuttings of chrysanthemums. Select sturdy pieces from the base.

\section{December.}

Dust sulphur among chrysanthemums to prevent mildew. Give them plenty of room. Remove all bad petals. Look over all root vegetables and remove decayed ones; also with apples and pears. Pot up little ferns. Clean vine rods when pruning is completed. Wash greenhouses, and whitewash walls of sheds. Make labels, stakes, \&c., during bad weather. Plant box for edging walks. Dig among shrubs. Plant shrubs and hedges. Prepare seed list. Look over account of year's work and note failures and successes. Prune raspberries and loganberries. Scrape moss off orchard trees. Put some pot strawberries in cold house to prepare for forcing. Mix soil some few days before it is required in order that it 198 


\section{A Garden Calendar}

may become warm. Water frames in morning. Cut down chrysanthemums as they go out of flower. Put old plants in frame and induce cuttings to spring up. Strike chrysanthemum cuttings with as little heat as possible. 



\section{N D E X}

A

Animal manure, 160

- pests, 169

Apples, 80

Apple trees, to prune, 179

Apricots, 80

- to prune, 179

Artichokes, 39

Artificial manure, 16I

Ashes, use of wood, 185

Asparagus, 46

Aspect, 18

Asphalt for walks, 89

B

Beans, $4^{6}$

Bedding, 153

Beds, shape of, 99

Beetroot, 39

Bird pests, 169

Black currants, to prune, $18 \mathrm{I}$

Blackberries, to prune, $18 \mathrm{I}$

Boards for edging, 33

Boiler for a greenhouse, II 5

Borders, 55

Boundary, the question of, 2 I

Box edging, 32

- renewing, 52

Broccoli, 4I

Brussels sprouts, 42

Buds and leaves, 142
C

Cabbages, 42

Calendar, a gardener's, I9I

Carpet bedding, 153

Carrots, 39

Cauliflowers, 43

Celery and celeriac, 44

Charcoal for potting, 185

Cherries, 82

Chinese artichokes, 39

Cleaning a lawn, 96

Coast, proximity to the, 15

Cold frames, 117

Composts, 185

Concrete for walks, 89

Cordons, 177

Cottager's fruit garden, 75

Cucumbers, 44

Curly kale, 43

Currants, 82

Cuttings, 140

D

Daisies in a lawn, 97

Design in the flower garden, 49

Digging, 131

_ value of, 18

Distances between trees, 79

Division, 144

Draining, methods of, 120

Drives, 70 


\section{Index}

E

Edging of paths, the, 32

Endive, 44

Environment, 13

Espalier, an, 177

\section{F}

Fan-shaped trees, 178

Fences, wooden, 24

Flower beds, size of, 53

_- garden, formation of, 49

Flowering plants, list of, 62

Flowers in the vegetable garden, $3^{6}$

\section{G}

Gooseberries, 82

\section{as hedges, 26}

Gooseberry bushes, to prune, 180 Grapes, 82

Greenhouse, heating a, $\mathrm{II}_{5}$

- construction of $a, \mathrm{rr}_{2}$

- value of $a$, rro

\section{$\mathrm{H}$}

Heating a greenhouse, $\mathrm{x} / 5$

Hedge trimming, $18 \mathrm{x}$

Hedges as shelter, 19

Hip-roofed greenhouse, I I I

Hoeing, 165

Hollow walls, 22

Holly bedge, the, I9

Hot-water pipes, Ir6

Insect pests, 174
$\mathrm{J}$

Jerusalem artichokes, 39

L

Land under tilth, to bring, 127

Lawn, to make a, $9 \mathrm{r}$

Layering, $x 43$

Leaf soil, $x 85$

Lean-to greenhouse, III

Leeks, 40

Lettuce, 44

"Lining" a frame, 118

List of flowering plants, 62

Locality, II

Loganberries, to prune, I8I

M

Manure, difficulty of obtaining, 15 the supply of, 159

Marrows, 47

Massing and grouping, $x_{57}$

Mice, trapping, 172

Mint, 46

Mortar rubble for potting, 186

Moss in a lawn, 97

Mowing and rolling a lawn, 95 machine, care of, 95

Mushrooms, 97

Mustard and cress, 45

$\mathrm{N}$

Nectarines, 80

O

Onions, 40 


\section{Index}

$\mathbf{P}$

Parsley, 46

Parsnips, 40

Path, qualities of $a, 83$

Paths, 70

- arrangement of, 28

the edging of, 32 upkeep of, 90

Peaches, 80 to prune, 179

Pears, 80

Pear trees, to prune, 179

Peas, 47

Peat for potting, 185

Pergolas, 58

Pests, garden, 169

Pillars and pergolas, 57

Planting and bedding, 149

Plant, when to, 150

Pleasure garden, the, 66

Plums, 80

Pot a plant, how to, 186

Potatoes, $4 \mathrm{I}$

Potsherds and crocks, I 86

Potting, 183

Privet hedge, the, 19

Protection for crops, 169

Pruning, 176

- question, the, 179

— small fruits, 180

Pyramids, 177

R

Radishes, 45

Railings, wooden, 24

Raspberries, 82

- to prune, 181

Rats, trapping, 172

Red currants, to prune, 180

Rhubarb, 48

Rock garden, a, 72
Rockery, a, 103

Root crops, 39

Rose garden, $5^{8}$

Rotation of crops, $16_{3}$

Rubbish, disposal of, 133

\section{S}

Savoys, 43

Seakale, $4^{8}$

Seed, 136

Shading, on, 188

Shaping a tree, 176

Shelter, 18

Shrubs, arrangement of, 68

Site, choosing the, II

Slugs and snails, 173

Soil, the, 16

Sowing, on, $13^{8}$

Spade $v$. plough, 127

Span-roofed greenhouse, III

Spinach, $4^{8}$

Sprouting broccoli, 42

Staging for a greenbouse, II 4

Standard trees, 177

Stock, on purchasing, 145

Stones for edging, 33

Strawberries, 82

Summer bedding, 155

\section{$\mathrm{T}$}

Tenant's rights, 20

Thyme, 46

Tiles for edging, 33

Tomatoes, 45

Tools, on, $15^{8}$

Training, pruning, 176

Trapping rats and mice, $\mathbf{1 7 2}$

Trees as shelter, 19

- position of, 34

Trenching, 128 


\section{Index}

Troublesome weeds, 167 Turf for edging, 34

_ for potting, 184

Turnips, $4 \mathrm{I}$

\section{V}

Variety of fruit, 77

Vegetable garden, the, 21

Ventilation, on, 189
W

Walk, composition of a, 84 construction of $\mathrm{a}, 87$

Walks, 70

Wall gardens, 108

Walls, on building, 22

Water supply, the, $16,37,122$

Watering, on, 187

Weeds, eradication of, 165 in a lawn, 97

THE END

Printed by Ballantyne, Hanson \& Co.

Edinburgh \& London 
SPECIAL NOTICE.

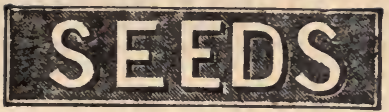

IF YOU WANT

\section{REALLY COOD SEEDS AND BULBS}

AT MODERATE PRICES,

SEND TO

\section{MR. ROBERT SYDENHAM,}

TENBY STREET, BIRMINGHAM,

No one will serve you better.

\section{HIS UNIQUE LISTS}

Are acknowledged by all to be the Best, Cheapest, and mont Reliable ever published. They contain only the Best

\section{VEGETABLES, FLOWERS, AND BULBS WORTH GROWING.}

Belog the Selections of the Largent Seed Growere, Market Gardener, and the most oelebrated Profensional Gardeners and $\Delta$ mateurs in the Kingdom.

They also contain very useful cultural instructiona.

Mr. 8YDENHAM'8 Bulbs and 8eeds were represented and gained FIrst Prizes at London, Birmingham. Nowcastle-on-Tyne, Shrewsbury, Edinburgh, Hanley, Taunton, Cardiff, Wolverhampton, and many other Exhibitions all over the KIngdom, for the last twelve years.

\section{SWEET PEAS A SPECIALITY.}

No flowers give so much out bloom at so Jitlle cost and trouble if treated an instruction sent with each Collection. His Sweet Peas have gained more Prizes than those from any two or three firms put together.

12 nseful varleties, 50 seeds of each, 18. 6d.; 12 good varietles, 50 seeds of eaoh, 13. 9d.; or the Two Collectiona for 2s. 6d.; a Third Collection of the 12 best varieties for Exhibition, 2s. 6d.; or the Three Collectlons, 4s. $6 \mathrm{~d}$, pret free, with a Packet of each of the four best striped varieties and 100 seeds of Countese Spenoer Giant Seedling, free of charge ;

Generally sold at much higher prlces.

THE BE8T TOMATOES, ad. per packet of 200 seeds.

THE BE8T OUCUMBER8, 6d. per packet of 10 seeds.

THE BEST ONIONS, "AILSA CRAIQ" and "EXCELSIOR,"

6d. per packet of about 3000 seeds.

ALL OTHER BEEDS EQUALLY CHEAP AND GOOD.

FULL LISTS POST FREE ON APPLICATION. 
For Amateur Gardeners

\section{Small Gardens}

AND HOW TO MAKE

\section{THE MOST OF THEM}

\section{BY VIOLET PURTON BIDDLE}

Cloth, price is. Post free, Is. $2 d$.

This handbook teems with useful information and contains numberless wrinkles of the utmost importance to the would-be Gardener. The directions are clear and lucid, with a due regard to the pocket and want of experience of the amateur Horticulturist.

SOMe of the 18 Chapters are :-

ChAP. XI.-THE INS AND OUTS OF GARDENING.

Planting-Watering - "Puddling "- ShelterCatalogue defects-A time for everything, etc.

Chap. XII.-THE PROFITABLE PORTION.

Fruit-Best kinds for small gardens-Size minus flavour-Vegetables-Herbs.

Сная. XIV.-WINDOW BOXES.

How to make them-Suitable soil-Window plants for different aspects, etc.

Chap. XV.-TABLE DECORATION.

Graceful arrangement-Thick-skinned stemsPreserving and resuscitating flowers - Colour schemes-Table of flowers in season.

CHAP.XVII.-THE MANAGEMENT OF ROOM PLANTS.

Best kinds for "roughing it"-The proper way of watering them, etc.

Chap. XVIII.-VARIOUS HINTS.

Artificial manures - Labelling - Cutting off dead flowers-Buying plants, etc.

GARDENING CALENDAR, giving the times for planting, bedding and watering the various plants.

\section{$* *$}

At all Booksellers, or of the

Book Publisher, 17, Henrietta Street, W.C. 
Keynes'

Keynes'

Dahlias

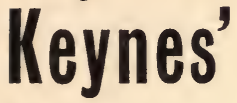

Fruit

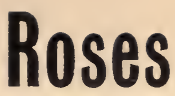

Vines

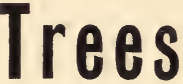

100,000 grown every year. Raised in a soil peculiarly adapted for it, and not overfed to produce exhibition blooms, these often thrive where others fail. See Catalogue.

A very large proportion of the varieties now grown were raised in these Nurseries. See Catalogue.

Our great speciality for fifty years. Grown most carefully they invariably produce satisfactory results. See Catalogue.

Trees from our stony loam produce fruit, not wood only. A grand collection to choose from. See Catalogue.

\section{KEYNES, WILLIAMS \& CO. The Nurseries, SALISBURY}

\section{Established 1740}

\section{Greenhouses}

How to Make and Manage Them

By WILLIAM F. ROWLES

Author of "How to Make and Manage a Garden"

Crown 8vo. Cloth. With many Illustrations

\section{Price 1s.}

The Contents include full information on-

House Construction-The Heating Question-Working up a Stock-Propagation-Pots and Potting-Soils and Manures-Watering-Ventilation-Shading-Tying and Staking-Syringing-Training - Pinching and Pruning-Arranging-Cleanliness-Forcing-Tools and Accessories - Utilising Space-Specialisation-Selection and Improvement-Suitable Plants, \&c.

At all Booksellers, or past free for 1s. 2d. from the Publishers, C. Arthur Pearson, Lid., Henrietta Street, W.C. 


\section{Roses}

\section{and How to}

\section{Grow Them}

By Violet P. Biddle,

Author of

"Small Gardens and How to Make the Most of Them."

With a Chapter by Horace J. Wright.

Crown 8vo.

Price 1s., Post Free 1s. 2 d.

To those of the public who are interested in Roses we would heartily recommend this book, which is written by an authority on the subject.

\section{SOME}

OF THE NUMEROUS CHAPTERS ARE:

Introductory Hints-Preparing Beds and Borders-Select Garden Roses-Planting Out -Climate and the Rose-Pruning-Budding -Climbing Roses-Pillar Roses-Rose Hedges -Roses for Shady Places-Roses for Towns -Rose Pergolas-Late Roses-Carpets for Roses-Rose Enemies-Roses as Cut Flowers -Some Useful Hints-Roses for Exhibition -New Roses Introduced since 1896.

Address: Publisher, 17, Henrietta Street, W.C. 


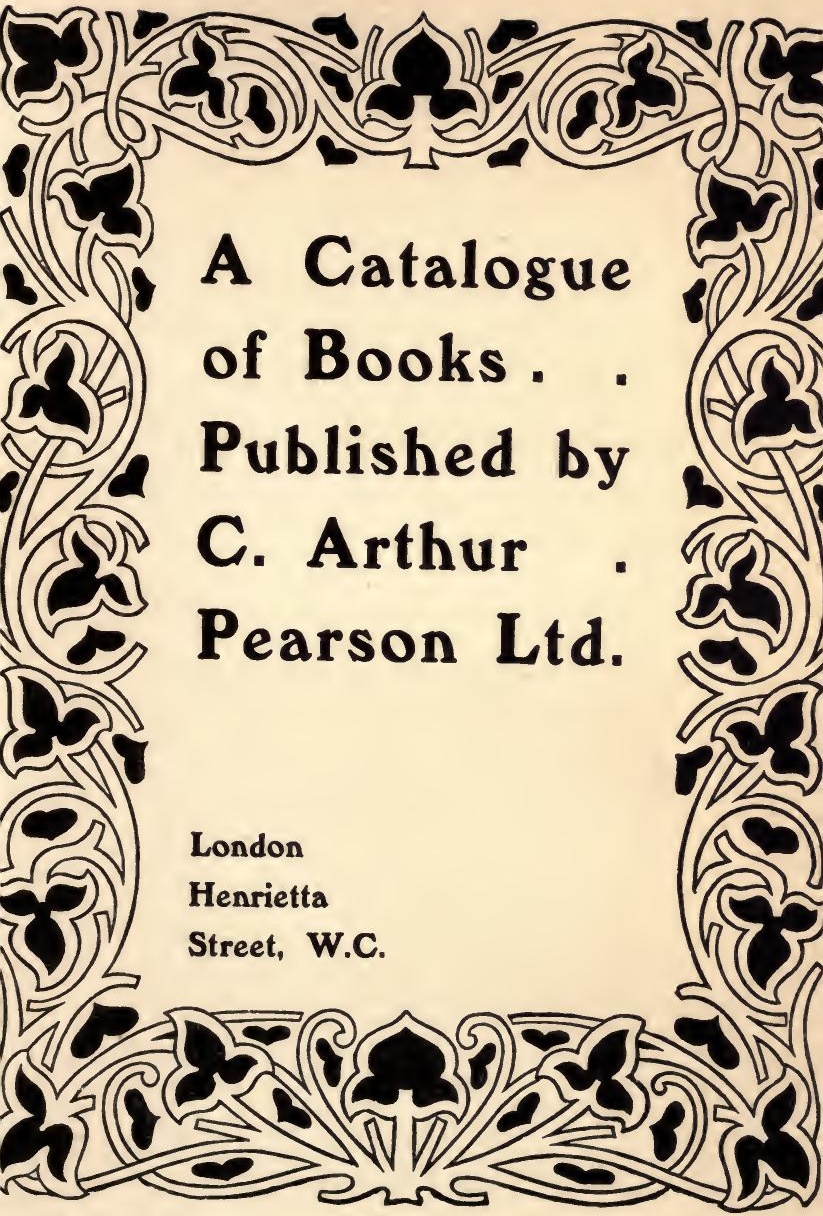

OCTOBER, 1904. 



\section{JBooks [Publíshed by}

\section{ARTHUR PEARSON, LTD.}

ADE, George

Fables in Slang. With 26 Illustrations. $16 \mathrm{mo}$, gilt top. Price 2s. 6d. net.

More Fables in Slang. Uniform with the above. Price 2s. 6d. net.

ALDERSON, Bernard Andrew Carnegie: From Telegraph Boy to Millionaire. With 4 Illustrations. Crown 8 vo. Price 2s. $6 d$.

ALLEN, Grant

The Incidental Bishop. Extra crown 8vo, cloth, flat back. Price $2 s$.

ANDREWS, Harry.

Training for Athletics. Crown 8vo, cloth. Price rs.

ARCHER, F. M.

The Dog in Health and Disease. With I2 Illustrations by S. T. DADD. Crown 8vo, cloth. Price Is.

AUSTIN, H. H.

Among Swamps and Giants in Equatorial Africa. Demy 8vo. With 32 Full-page Illustrations and 2 Maps. Price 15 s. net.

BARR, Amelia E.

Bernicia. Crown 8vo, cloth. Price 2s.

The Preacher's Daughter. Crown 8vo, cloth. Price 2s.

BEAVAN, Arthur $\mathrm{H}$.

Crowning the King. An Account of the Coronation of English Kings and Queens. Crown 8vo. Price 2s. $6 d$.

BENNET'T, Arnold

How to Become an Author. Crown 8vo, buckram. Price $5^{s}$.

BENSON, J. K.

Book of Indoor Games. Square cr. 8vo, cloth. Fully Illustrated. Price $5^{5}$. 


\section{ARTHUR PEARSON'S CATALOGUE}

BERREY, Robert P. Boy's Book of Bravery. With 8 Illustrations. Extra crown 8vo, cloth. Price $5^{s}$.

BIDDLE, Violet

Small Gardens, and How to Make the Most of Them. Crown 8vo, cloth. Price Is.

Roses, and How to Grow Them. Crown 8vo, cloth. Price Is.

BOОTHBY, Guy

The Woman of Death. Illustrated. Crown 8vo, cloth. Price 5 s.

BULLEN, Frank T.

A Sack of Shakings. Essays from the Spectator, \&c.

Extra crown 8vo, buckram, gilt top. Price 6 s.

BULLIVANT, Cecil $\mathrm{H}$.

The Drawing-Room Entertainer. A practical guide to the Art of Amateur and Semi-professional Entertaining, with instruction in Ventriloquism, Conjuring, Vocal and Instrumental Mimicry, \&c. Crown 8vo, cloth. Price Is.

BUNYAN, John

The Pilgrim's Progress. Illustrated by the Brothers Rhead. With Preface by the Rev. H. R. Haweis, M.A. Demy 4to, cloth. Price 7 s. $6 d$.

See also Illustrated Scarlet Library, page 8.

BURROW, Francis Russell

Alexander in the Ark. Square crown 8vo, cloth. Illustrated. Price $5^{\text {s. }}$

BUTE, John, late Marquess of The Alleged Haunting of $\mathrm{B}-$ House. Edited by the late John, Marquess of BuTE, and Miss A. GOODRICH-Freer. Crown 8vo, cloth. Price $2 s$.

CADETT, Herbert

Boys' Book of Battles. With Illustrations. Extra crown 8vo, cloth. Price $5^{s}$.

CAMERON, Mrs. Lovett

A Loyal Lover. Cr. 8vo, cloth, flat back. Price $2 s$. 


\section{ARTHUR PEARSON'S CATALOGUE}

CLARK, C. E.

The Mistakes We Make. Fcap. 8vo, cloth. Second edition. Price Is. $6 d$.

CONSULT THE ORACLE, or How to Read the Future

By Gabriel Nostradamus. Crown 8vo, cloth. Price Is.

CUPID'S PUPILS : From Courtship to Honeymoon

Being the Recollections of a Parish Clerk. Crown 8vo, cloth. Price $3 s .6 d$.

DEVEREUX, G. R. M.

Etiquette for Men. A Book of Modern Manners and Customs. Crown 8vo, cloth. Price Is.

Etiquette for Women. A Book of Modern Modes and Manners. Crown 8vo, cloth. Price Is.

The Etiquette of Engagement and Marriage. Crown 8vo, cloth. Price Is.

The Lover's Guide to Courtship and Marriage. Crown 8vo, cloth. Price Is.

EAST, W. G.

Rowing and Sculling. Crown 8vo, cloth. Price Is. EVERY WOMAN HER OWN DOCTOR.

A Medical Dictionary in Plain English showing Causes, Prevention, and Cure of all Maladies and Accidents to which Women and Children are liable. Crown 8vo, cloth. Price 2s. $6 d$.

FARROW, George Edward

Uniform Edition. Extra Crown 8vo, cloth gilt, gilt edges. Price 5 s. per volume.

The Wallypug of Why. Illustrated by HARRY Furniss and Dorothy Furniss.

The Missing Prince. Illustrated by HaRRY Furniss and DOROTHY FURNISS.

The Wallypug in London. Illustrated by ALAN WRIGHT.

Adventures in Wallypugland. Illustrated by AlAN WRIGHT. 


\section{ARTHUR PEARSON'S CATALOGUE}

FARROW, George Edward (continued)

The Little Panjandrum's Dodo. Illustrated by Alan Wright.

The Mandarin's Kite. Illustrated by Alar WRIGHT.

Baker Minor and the Dragon. Illustrated by ALAN WRIGHT.

The New Panjandrum. Illustrated by ALAN WRIGHT.

In Search of the Wallypug. Illustrated by ALAN WRIGHT.

Professor Philanderpan. Illustrated by ALAN WRIGHT.

The Wallypug in Fogland. Illustrated by ALAN WRIGHT.

FERMOR, M. G. P.

Home Pets, Furred and Feathered. With 8 Illustrations. Crown 8vo, cloth. Price 2s. $6 \mathrm{~d}$.

FINNEMORE, John

The Story of a Scout. Crown 8vo, cloth. Price 5 s. FOLEY, Charles

The Marquis of Valrose. Translated by ALYs Hallard. Crown 8vo, cloth. Price 3s. $6 d$.

FOLI, Prof. P. R. S.

Handwriting as an Index to Character. A Popular Guide to Graphology. Fully Illustrated. Cloth. Price Is.

Fortune Telling by Cards. Crown 8vo, cloth. Price Is.

FRYERS, Austin

The Pauper Millionaire. Crown 8vo, cloth.

Price 3 s. 6d.

The Devil and the Inventor. Crown 8vo, cloth. Price 3s. $6 d$.

\section{FUN ON THE BILLIARD TABLE}

A Collection of Amusing Tricks and Games for Amateurs. By "StANCLIFFE." Illustrated with Photographs. Crown 8vo, cloth. Price 2s. 6d. 
GALLICHAN, W. M. (Geoffrey Mortimer)

Angling in Rivers, Lakes, and Sea. Crown 8vo, cloth. Illustrated. Price Is.

GARDNER, George

Rabbit Keeping for Pleasure and Profit. Crown 8vo, cloth. Illustrated. Price Is.

GARNETT, J. H.

Wood Carving: A Practical Handbook for the Home Student. With numerous Illustrations and Designs. Crown 8vo, cloth. Price Is.

GIBERNE, Agnes

The Mighty Deep and What We know of It. With Io Illustrations. Extra crown 8vo, cloth. Price $5^{5}$.

GLYDE, John

The Life of Edward Fitzgerald. With Introduction by EDWARD CLODD. With Photogravure Portrait. Crown 8vo, buckram. Price $7 \mathrm{s.} 6 \mathrm{~d}$.

GOLSWORTHY, Arnold

The New Master. With numerous Illustrations by Tom Browne. Third Edition. Extra crown 8vo, cloth. Price 3 s. $6 d$.

Hands in the Darkness. Crown 8vo, cloth. Price 3 s. $6 d$.

GRAHAM, Winifred

When the Birds Begin to Sing. Illustrated. Imperial I6mo, cloth. Price $3 s .6 d$.

GRIFFITH, George

Men Who Have Made the Empire : From William of Normandy to Cecil Rhodes of Rhodesia. With 8 Illustrations by STANLEY L. Wood. New and Revised Edition. Extra crown 8 vo, cloth. Price 5 s.

GROSER, Horace G.

Lord Kitchener. With Illustrations. Extra crown 8vo, cloth. Price 2s. 6 d.

GUIDE BOOKS.

See Pearson's Gossipy Guides, page I3. 


\section{ARTHUR PEARSON'S CATALOGUE}

HODGSON, Lady

The Siege of Kumassi. Profusely Illustrated. Demy 8vo, cloth. Price 2 Is.

HOLBEIN, Montague A.

Swimming. Crown 8vo, cloth. Illustrated. Price Is.

HOLLAND, Clive

How to Take and Fake Photographs. With 8 Illustrations. Crown 8vo, cloth. Price Is.

HORSLEY, Rev. J. W.

Prisons and Prisoners. Crown 8vo, cloth. Price 3s. $6 d$.

\section{HOW SHALL I WORD IT?}

A Complete Letter Writer for Ladies and Gentlemen.

Crown 8vo, cloth. Price Is.

HUME, Fergus

Lady Jezebel. Cr. 8vo, cloth, flat back. Price $2 s$.

HYNE, C. J. Cutcliffe

Adventures of Captain Kettle.

Further Adventures of Captain Kettle.

The Little Red Captain. An Early Adventure of Captain Kettle.

Captain Kettle, K.C.B. The Latest Adventures of Captain Kettle.

Each volume illustrated by Stanley $L$. Wood. In uniform cloth covers. Price 6s. each.

ILLUSTRATED SCARLET LIBRARY (THE)

With 8 Original Illustrations. Antique laid paper.

Extra crown 8vo. Price 2s. each.

The Pilgrim's Progress. By John Bunyan. Illustrated by $\mathrm{H}$. M. BRock.

The Wide, Wide World. By Elizabeth Wetherell. Illustrated by Fred Pegram.

Uncle Tom's Cabin. By Beecher Stowe. Illustrated by LouIs BETTS.

Ben Hur. By General Lew Wallace. Illustrated by H. M. Brock. 


\section{ARTHUR PEARSON'S CATALOGUE}

ILLUSTRATED SCARLET LIBRARY (THE)Continued-

Westward Ho! By Chas. Kingsley. Illustrated by H. M. Brock.

John Halifax. By Mrs. CraIk. Illustrated by H. M. BROCK.

Robinson Crusoe. By Daniel Defoe. Illustrated by H. M. Brock.

Little Women and Good Wives. By Louisa M. Alcotr. Illustrated by H. M. Brock.

The Swiss Family Robinson. Illustrated by H. M. Brock.

Grimms' Fairy Tales. A New Translation by N. J. Davidson. Illustrated by Lancelot Speed.

The History of Henry Esmond. By W. M. THACKERAY. Illustrated by H. M. Brock.

Other volumes to follow.

IN THE DAYS OF MY YOUTH.

Chapters of Autobiography selected from M.A.P. With Introduction by T. P. O'Consor. A Popular Edition in Picture Covers. Price Is.

"ISOBEL" HANDBOOKS (THE)

Small crown 8vo, cloth. Price Is. each.

(I) Dainty Dishes for Slender Incomes.

(2) Household Hints.

(3) Plain Needlework.

(4) A Healthy Home, and How to Attain it. By Dr. ANDREW WILSON.

(5) Our Foods and Drinks. By Dr. Andrew Wilson.

(6) Breakfast and Supper Dishes. By C. HeRMANN SENN.

(7) The Art of Beauty. By a Toilet Specialist.

(8) Infectious Diseases, and How to Prevent Them. By Dr. ANdrew Wilson.

(9) Little French Dinners. By Eveleen de Rivaz. (IO) Home Nursing. By Sister GRACE. 


\section{ARTHUR PEARSON'S CATALOGUE}

"ISOBEL" HANDBOOKS (THE)-Continued.

(II) What to Do in Emergencies. By Dr. ANDREW WILSON.

(12) Things a Woman Wants to Know. Including an Illustrated Chapter on the Folding of Serviettes.

(13) Little Economies and How to Practice Them. By Mrs. Waldemar Leverton.

JACOBS, W. W.

The Skipper's Wooing, and The Brown Man's

Servant. Crown 8vo, cloth. Price 3 s. $6 d$.

JESSOP, G. L.

Cricket, with Contributions by K. S. Ranjitsinhu,

C. B. Fry, C. L. Townsend, G. Brann, \&c.

Crown 8vo, cloth. Price is.

JONES, J. L.

Association Football. Crown 8vo, cloth. Price Is.

LAMB, W.

How and What to Dance. Crown 8vo, cloth. Price Is.

LANDER, Harry.

Lucky Bargee. Crown 8vo, cloth. Price 3 s. $6 \mathrm{~d}$.

LEE, Albert

The Key of the Holy House. Large crown 8vo, cloth. Price 6s.

LENEY, L., M.D.

The Mother's Guide to the Management of Children in Sickness and Health. Crown 8vo, cloth. Price 3 s. $6 \mathrm{~d}$.

Indigestion : and How to Cure it. Crown 8vo, cloth. Price is.

LEVERTON, Mrs. Waldemar Small Homes and How to Furnish Them. With I6 Illustrations. Price Is.

Little Entertainments, and How to Manage Them. Crown 8vo, cloth. Price is.

See also "Isobel Handbooks," No. I3.

LOVER'S DICTIONARY, THE

Crown 8vo, cloth. Price 2s. $6 d$. 


\section{ARTHUR PEARSON'S CATALOGUE}

MARKS, Montague

The Home Arts Self-Teacher. With hundreds of Illustrations, Models, and Practical Designs. Crown 4to, cloth. Price $7 s$. 6 d. net.

Home Arts and Crafts. Modelling, Wood Carving, Fret Sawing, Pyrogravure, Leather Decoration, Metal Work, Taxidermy, \&c., \&c. Crown 4to, cloth. Price $3 s$. $6 d$. net.

MATHERS, Helen

Cinders. Second Edition. Ex. crown 8vo, cloth. $6 s$. Becky. Extra crown 8vo, cloth. Price 6s.

MAYDON, J. G.

French's Cavalry Campaign. Cr. 8vo, cloth. 3 s. $6 d$.

McNEILL, Capt. Malcolm, D.S.O.

In Pursuit of the Mad Mullah. Service and Sport in the Somali Proctectorate. Extra crown 8vo. r6 Illustrations and Map. Price 6s.

MOORE, F. Frankfort

The Conscience of Coralie. With 8 Illustrations by F. H. Townsend. Large cr. 8vo, cloth. Price $6 s$ Nell Gwyn, Comedian. Fourth Edition. With 8 full-page Illustrations. Crown 8vo, cloth. Price $6 s$.

MORICH, Stanton

Thou Shalt Not- Crown 8vo, cloth. Price 3s. $6 d$.

NEIL, C. Lang

Amateur Theatricals. Crown 8vo, cloth. Price 3s. $6 d$. net.

The Modern Conjurer and Drawing-room Entertainer. With a Preface by Prof. Chas. Bertram. With over 500 Illustrations. Demy 8 vo, cloth. Price 6 s. After-Dinner Sleights. In stiff paper cover. With many Illustrations. Extra crown 8vo. Price Is. Modern Card Manipulation. In stiff paper cover. With many Illustrations. Extra crown 8vo. Price Is.

Modern Physical Culture. With Diagrams Illustrating all the best systems of Physical Development. Crown 8vo, cloth. Price Is. 


\section{ARTHUR PEARSON'S CATALOGUE}

NEWTON, Professor A. J.

Boxing. Including a Chapter on Singlestick.

With Illustrations. Crown 8vo, cloth. Price Is.

\section{NURSERY WALL CARD}

For Accidents and Emergencies. Edited by a VIsITING Physician of one of the London Hospitals. Printed in Red and Black on a Card for hanging on the Wall. Price Is.

O'DELL, Stackpool E.

Heads, and How to Read Them. A Popular Guide to Phrenology. Crown 8vo, cloth. Price Is.

OPPER, F.

Our Antediluvian Ancestors. With 50 Illustrations. Demy 4 to, cloth gilt. Price 7 s. $6 d$. net.

ORCZY, Baroness

The Emperor's Candlesticks. Crown 8vo, cloth. Price 3s. $6 d$.

PALLANDER, Edwin

The Log of an Island Wanderer. With $3^{2}$ Illustrations. Extra crown 8vo, cloth. Price $6 s$.

PEARSON, Mrs. A. Cyril

The Acrostic Dictionary. New and Enlarged Edition. Containing over 40,000 references. Crown 8vo, cloth. Price 3 s. $6 \mathrm{~d}$.

\section{PEARSON'S DREAM BOOK}

Giving the Interpretation of Dreams by Magic Cyphers, by the Square of Fate, by a Table of Dreams according to Days, \&c. By Prof. P. R. S. Foli. Cloth, crown 8vo. Price Is.

\section{PEARSON'S FORTUNE TELLER}

Giving Divination by Cards, Astrology, Crystal Gazing, Palmistry, Rings, Divining Rod, Clairvoyance, \&c. By Prof. P. R. S. Foli. Cloth, crown 8vo. Price Is. 


\section{ARTHUR PEARSON'S CATALOGUE}

\section{PEARSON'S GOSSIPY GUIDES}

With New Maps, and the latest information for all travellers, arranged Alphabetically, and with beautiful Illustrations from photographs specially taken for this Series. Foolscap 8vo, cloth. Price Is.

Bournemouth and District (including the New Forest). By Clive Holland.

Swanage and District. Paper wrapper. Price $6 d$. Glasgow and the Clyde.

North Cornwall.

Ilfracombe and District.

South Devon.

Great Yarmouth, Lowestoft, and Cromer.

The English Lakes.

Weymouth and District.

The Thames from Source to Sea.

London and Environs.

Oban and Western Highlands.

Paris and Environs.

Edinburgh and District.

\section{PEARSON'S HOME MANAGEMENT}

Edited by "ISOBEL," of Home Notes. In One Volume. Demy 8vo, cloth, containing I2 Beautifully Produced Coloured Illustrations, 64 Full-page Halftone Illustrations, and numerous Cuts in the text. Price ros. 6d. Also in Half Rexine Morocco, Roxburgh Style, cloth sides, gilt top. Price I 2 .

\section{PEARSON'S RECITERS}

The Humorous Reciter. Crown 8vo, cloth. Price 2s. $6 d$.

The New Reciter and Reader. In Three Parts : Humorous, Descriptive, and Pathetic. Crown 8vo, cloth. Price 2s. $6 d$.

The Irish Reciter and Reader. Crown 8vo, cloth. Price 2s. 6d. 
C. ARTHUR PEARSON'S CATALOGUE

\section{PEARSON'S RECITERS-(Continued).}

The Scottish Reciter and Reader. Crown 8vo, cloth. Price 2s. $6 d$.

Boys' and Girls' Reciter. Crown 8vo, cloth. Price Is.

\section{PEMBERTON, Max}

The Phantom Army. Extra crown 8vo, cloth.

Price 3s. 6d.

Queen of the Jesters. With 8 Illustrations by Harold Piffard. Crown 8vo, cloth. Price 3s. $6 \mathrm{~d}$.

PEMBERTON, T. Edgar

Ellen Terry and Her Sisters. An Authorised Biography. Illustrated. Demy 8vo, cloth. Price I6s. Life of Bret Harte. With I6 Illustrations. Demy 8vo. Price 16 s.

PERKS, Lily

Life's Counterpoint. Extra crown 8vo, cloth. Price 6s.

\section{PETERS, Dr. Carl}

The Eldorado of the Ancients. Describing the Discovery of King Solomon's Mines in the Land of Ophir. With Ioo Illustrations and 2 Maps, and Photogravure Portrait of Author. Price 2is. net.

\section{PRACTICE STROKES AT BILLIARDS}

For Tables of all Sizes. Examples from the actual match play of Roberts, Dawson, Stevenson, Mitchell, Spiller, Peall, and other leading Professional Players, with their methods of scoring therefrom. With rio Diagrams illustrating the various strokes. Crown 8vo, cloth. Price Is.

\section{PRAGA, Mrs.}

Dinners of the Day. By A Careful Cook (Mrs. Praga). Crown 8vo, cloth. Price 2s. $6 d$.

How to Keep House on $£ 200$ a Year. Crown 8vo, cloth, Price $2 s .6 d$. 


\section{ARTHUR PEARSON'S CATALOGUE}

PRIVATE LIFE OF THE KING, THE * By One of His Majesty's Servants. With numerous Illustrations. Extra crown 8vo, cloth. Price 5s.

PRIVATE LIFE OF QUEEN VICTORIA, THE By One of Her Majesty's Servants. With Portrait and numerous Illustrations. New and Enlarged Edition. Crown 8vo, cloth. Price 2s. $6 d$.

QUANTOCK, Andrew

Tandra. Crown 8vo, cloth. Price $3 s .6 d$.

RAHILLY, Jerome J. (Vice-Captain London Irish). Rugby Football. Crown 8vo, cloth. Price Is.

RALPH, Julian

Towards Pretoria : A Record of the War Between Briton and Boer. With Map. Extra crown 8vo, cloth. Price 6s.

At Pretoria: The Capture of the Boer Capitals and the Hoisting of the Flag at Pretoria. Extra crown 8vo, cloth. Price 6s.

War's Brighter Side. The History and Principal Contents of The Friend, with contributions by RuDYARD KIPLING and others. With I5 Illustrations. Extra crown 8vo. Price 6s.

RATTRAY, Margaret

Sweetmeat Making at Home. With Coloured Frontispiece and numerous Illustrations. Crown 8vo. Price 2s. $6 d$.

Cold Meat and How to Disguise It. Crown 8vo, cloth. Price Is.

RECITERS

See under PEARSON, pages I3 and I4.

RENÉ, E.

Hands, and How to Read Them. A Popular Guide to Palmistry. Illustrated. Crown 8vo, cloth. Price Is.

RIDDELL, Mrs. J. H. Alaric Spenceley. Crown 8vo, cloth. Price 2s. $6 d$. The Senior Partner. Crown 8vo, cloth. Price 2s. $6 d$. A Struggle for Fame. Crown 8vo, cloth. Price 2s.6d. 


\section{ARTHUR PEARSON'S CATALOGUE}

\section{RIDGE, W. Pett}

Mord Em'ly. Crown 8vo, cloth. Price 3s. $6 d$.

Three Women and Mr. Frank Cardwell.

Crown $8 v 0$, cloth, flat back. Price $2 s$.

RITCHIE, M. J. G., and WALTER HARRISON Table Tennis, and How to Play It. With the Rules, \&c. A Handbook to Ping-Pong. With 7 Illustrations. Cloth. Price Is.

\section{ROBERTS, John}

Modern Billiards. By JoHn RoBerTs, and others. With 92 I Diagrams, including complete set of diagrams of some famous breaks. Demy 8vo, cloth. Price 6s.

SCHOOLING, J. H.

A Woman's Chance of Marriage. Demy ramo, stiff boards. Price Is.

SCOTT-GATTY, A. S.

Domestic Ditties. With Words and Music by A. S. ScotT-GatTy, and profusely Illustrated by A. J. S. Scott-Gatty. Crown 4to. Price $2 s .6 d$.

SCOTT, G. Firth

From Franklin to Nansen. Tales of Arctic Adventure retold by G. FIRTH ScotT. With numerous Illustrations. Extra crown 8vo, cloth, gilt. Price 3 s. $6 d$. SCOTT, Sir W.

Woodstock. Abridged Edition for Children. Eight coloured Illustrations. Cloth, gilt. Price 2s. $6 d$.

SHERARD, R. H.

The Iron Cross. Crown 8vo, cloth. Price 3 s. $6 \mathrm{~d}$.

SMITH, G. Barnett

Heroes of the Nineteenth Century.

Vol. I.-Wellington, Garibaldi, Gordon, Grant.

Vol. II.-Nelson, Roberts, Sir Charles Napier, Livingstone.

Vol. III.-Gladstone, Bismarck, Havelock, and Lincoln.

With Portraits and other Illustrations. Large crown 8vo. Price 5s. each. 


\section{SPEECHES FOR ALL OCCASIONS}

By an OxFord M.A. Crown 8vo, cloth. Price is.

\section{THINGS EVERY ONE WANTS TO KNOW}

A Manual of General Information on all Subjects. 4I6 pp. Crown 8vo, cloth gilt. Price $2 s .6 \mathrm{~d}$.

THOUSAND (One) CURIOUS THINGS WORTH KNOWING

A carefully indexed selection from the "Questions Worth Answering" page of Pearson's Weekly. Demy I $2 \mathrm{mo}$, cloth. Price Is.

\section{VAUGHAN, Alexander}

The Mystery of the 'Medea.' Crown 8vo, cloth. Price 3 s. $6 d$.

VAUGHAN, Lieut.-Col. H. B.

St. George and the Chinese Dragon. An account of the Relief of the Pekin Legations. With a Portrait of and Illustrations by the Author. Crown 8vo, cloth. Price 3 s. $6 d$.

VOGEL, H. B.

My Dear Sir! Crown 8 vo, cloth. Price 3 s. $6 d$.

WARDEN, Florence

Beatrice Froyle's Crime. Extra crown 8vo, cloth. Price 6s.

WESTCOTT, Edward Noyes

David Harum. Crown 8vo, cloth. Price 6s.

David Harum. Illustrated. Cloth. Price $7 s .6 d$.

The Teller. Crown 8vo, cloth. Price 3s. 6d. net.

WHITE, Mary

Basket Making at Home. With 12 full page and numerous Illustrations in the Text. Crown $8 \mathrm{vo}$, cloth. Price 2s. 6d.

White, Percy

A Millionaire's Daughter. Crown 8vo, cloth, flat back. Price $2 s$. 


\section{ARTHUR PEARSON'S CATALOGUE}

WILliamS, Archibald

The Romance of Modern Invention. Illustrated.

Crown 8vo, cloth, gilt edges. Price $5^{s}$.

The Romance of Modern Engineering. Illustrated. Crown 8vo, cloth, gilt edges. Price $5^{s}$.

The Romance of Modern Locomotion. With 25 Illustrations. Extra crown 8vo, cloth, gilt edges. Price 5 s.

WILSON, Andrew

* *

See "Isobel" Handbooks (4), (5), (8), (I I), pages 9 and $\mathrm{\text {Io. }}$

WILSON, F. E.

Poultry Keeping, and How to Make it Pay. Crown 8vo, cloth. Price Is.

\section{Pearson's}

Bound in

Sixpenny Editions of $\begin{gathered}\text { an artistic } \\ \text { yellow }\end{gathered}$

Famous Novels

Are the Best.

List on Application. 


\section{Books in this Catalogue arranged}

\section{in Order of Price.}

21s. NETT.

PAGE

Eldorado of the Ancients .. 14

21 s.

Siege of Kumassl .. $\quad$.. 8

165.

Bret Harte, Life of $\quad$. 14

Ellen Terry .. $\quad \ldots \quad \ldots \quad 14$

15s. NETT.

Among Sxamps and Giants

10s. 6d.

Home Management.. . .. 13

7s. 6d. NETT.

Home Arts Self Teacher .. 11

Our Antediluxian Ancestors 12

\section{7s. 6d.}

Dayld Harum (Illustrated

Edition) .. $\quad$.. $\quad \ldots 17$

Fitzgerald's Life $\quad . . \quad \ldots \quad 7$

Pilgrim's Progress .. . . 4 6s.

PAGE

Adrentures of Captain

$\begin{array}{lllll}\text { Kettle } & \text {.. } & \text {.. } & \text {.. } & 8\end{array}$

At Pretoria .. $\quad \ldots \quad \ldots 15$

Beatrice Froyle's Crime .. 17

Becky .. .. .. $\quad$.. 11

Captain Kettle, K.C.B. .. 8

$\begin{array}{lllll}\text { Cinders } & \text {.. } & \text {.. } & \text {.. } & 11\end{array}$

Consclence of Coralie .. 11

Dayid Harum .. .. 17

Further Ady. of Capt. Kettle 8

In Pursuit of Mad Mullah.. 11

Key of the Holy House .. 10

Life's Counterpoint.. . . 14

Little Red Captain .. $\quad$.. 8

Log of an Island Wanderer 12

Modern Billiards .. $\quad$.. 16

Modern Conjurer .. .. 11

Nell Gywn, Comedian .. 11

Sack of Shakings $\quad$. $\quad$.. $\quad 4$

Towards Pretoria .. .. 15

War's Brighter Side $\quad$. 15 


\section{ARTHUR PEARSON'S CATALOGUE}

\section{5s.}

Adventures in Wallypugland

Alexander in the $\mathbf{A r k} \quad$.. $\quad 4$

Baker Minor and the

Dragon .. $\quad . . \quad$.. 6

Book of Indoor Games ... 3

Boy's Book of Battles .. 4

Boy's Book of Bravery ... 4

Heroes of the 19th Century

(3 vols.) .. $\quad . . \quad \ldots 16$

How to Become an Author 3

In Search of the Wallypug

Little Panjandrum's Dodo 6

Mandarin's Kite .. .. 6

Men Who Haye Made the

Empire .. $\quad . . \quad$.. 7

Mighty Deep.. $\quad$.. $\quad$.. 7

Mrissing Prince $\quad . . \quad$.. 5

Nex Panjandrum .. $\quad$.. 6

Private Life of the King .. 15

Professor Philanderpan .. 6

Romance of Modern Inven-

tion $\quad . . \quad$.. $\quad$.. 18

Romance of Modern Engineering .. $\quad . . \quad$.. 18

Romance of Modern Locomotion .. $\quad . . \quad$.. 18

Story of a Scout $\ldots$..

Wallypug of Why .. .. 5

Wallypug in Fogland .. 6

Wallypug in London $\quad$.. 5

Toman of Death .. .. 4 3s, 6d, NETT.

PAgE

Amateur Theatricals ... 11

Home Arts and Crafts ... 11

Teller, The $\ldots \quad$.. $\quad$.. 17

\section{3s. 6d.}

Acrostic Dictionary $\quad$.. 12

Cupid's Pupils $\quad$.. $\quad$.. 5

Dexil and the Inventor .. 6

Emperor's Candlesticks .. 12

French's Cavalry Campaign 11

From Franklin to Nansen 16

Hands in the Darkness .. 7

Iron Cross $\quad \ldots \quad \ldots \quad \ldots \quad \ldots 16$

Lecky Bargee $\quad$. $\quad$.. 10

Marquis of Yalrose.. .. 6

Mord Em'y .. $\quad$.. $\quad$.. 16

Mother's Guide, The .. 10

My Dear Sir ! $\quad . . \quad \ldots \quad 17$

Mystery of the 'Medea'.. 17

New Master .. $\quad$.

Pauper Millionaire .. $\quad$.. 6

Phantom Army $\quad$. $\quad \ldots 14$

Prisons and Prisoners .. 8

Queen of the Jesters .. 14

St. George and the Chinese

Dragon .. $\quad$.. $\quad \ldots 17$

Skipper's Wooing .. .. 10

$\begin{array}{lllll}\text { Tandra } & \ldots & \ldots & \ldots & 15\end{array}$

Thou Shalt Not- $\quad$.. 11

When Birds Begin to Sing 7

2s. 6d, NETr.

Fables in Slang $\quad \ldots \quad \ldots \quad 3$

More Fables in Slang .. 3 


\section{ARTHUR PEARSON'S CATALOGUE}

2s. 6d.

Alaric Spenceley .. $\quad$. 15

Andrew Carnegie .. $\quad$.. 3

Basket Making $\quad$.. $\quad$.. 17

Crowning the King.. .. 3

Dinners of the Day .. 14

Domestic Ditties .. $\quad$.. 16

Exery Woman her own

Doctor .. $\quad$.. $\quad \ldots \quad 5$

Fun on the Billiard Table 6

Home Pets .. .. $\quad$.. 6

How to Keep House on $£ 200$

$\begin{array}{lllll}\text { a Year } & \text {.. } & \text {.. } & \text {.. } & 14\end{array}$

Humorous Reciter .. .. 13

Irish Reciter .. $\quad . . \quad \ldots 13$

Lord Kitchener $\quad$. $\quad$.. 7

Loxers' Dictionary .. $\quad$.. 10

Pearson's New Reciter .. 13

Priyate Life of Queen Yic-

toria $\quad . . \quad \ldots \quad \ldots 15$

Scottish Reciter $\quad \ldots \quad \ldots \quad 14$

Senior Partner $\quad$.. $\quad$.. 15

Struggle for Fame .. .. 15

Sweetmeat Making.. .. 15

Things Eyery One Wants to

Know $\quad$.. $\quad$.. $\quad$.. 17

Woodstock $\quad . \quad \ldots \quad \ldots \quad \ldots 16$

\section{2s.}

Alleged Haunting of B--

$\begin{array}{lllll}\text { House } & \ldots & \ldots & \ldots & 4\end{array}$

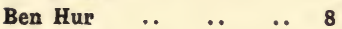

$\begin{array}{lllll}\text { Bernicia } & \text {.. } & \text {.. } & \text {.. } & 3\end{array}$

Grimms' Fairy Tales _. 9

History of Henry Esmond 9 2s. (continued).

PAGE

Incidental Bishop .. $\quad$. 3

John Halifax.. $\quad \ldots \quad \ldots 9$

Lady Jezebel.. $\quad$. $\quad$.. 8

Little Women $\quad$. $\quad$. 99

Loyal Loyer .. $\quad$. $\quad \ldots \quad$ \&

Millionaire's Daughter .. 17

Pilgrim's Progress .. . . 8

Preacher's Daughter .. 3

Robinson Crusoe $\quad$. $\quad \ldots \quad$.. 9

Swiss Family Robinson .. 9

Three Women and Mr.

Frank Cardwell _. 16

Uncle Tom's Cabin .. .. 8

Westward Ho! ..

Wide, Wide World .. .. 8

\section{1s. 6d.}

Mistakes We Make.. .. 5

1 s.

After Dinner Sleights $\quad$. 11

Angling

Art of Beauty $\quad$.. $\quad$.. 9

Association Football $\quad$. 10

Boxing.. $\quad . . \quad \ldots \quad \quad \ldots 12$

Boys' and Girls' Reciter .. 14

Breakfast and Supper Dishes 9

$\begin{array}{lllll}\text { Cold Meat } & \text {. } & \text {.. } & \text {.. } & 15\end{array}$

Consult the Oracle.. $\quad$.. 5

$\begin{array}{lllll}\text { Cricket.. } & \text {.. } & \text {.. } & \text {.. } & 10\end{array}$

Dainty Dishes $\quad \ldots \quad$.. 9

Dog (The) .. $\quad \ldots \quad$.. 3

Drawing-Room Entertainer

Dream Book .. .. .. 12 


\section{ARTHUR PEARSON'S CATALOGUE}

1s. (continued).

PAGE

Etiquette of Engagement and Marriage .. $\quad$.. 5

Etiquette for Men .. .. 5

Etiquette for Women .. 5

Fortune Teller $\quad$.. $\quad$.. 12

Fortune Telling by Cards .. 6

Hands, and How to Read

Them .. .. $\quad$.. 15

Handwriting .. $\quad$.. $\quad$.. 6

Heads, and How to Read

Them .. $\quad$.. $\quad$.. 12

Healthy Home $\quad$. $\quad$.. 9

Home Nursing $\quad$. $\quad$.. 9

Household Hints .. $\quad$. 9

How and What to Dance.. 10

How Shall I Word It? .. 8

How to Take and Fake

Photographs $\quad$.. $\quad$.. 8

In the Days of My Youth .. 9

Indigestion $\quad . \quad \quad \ldots \quad \ldots 10$

Infectious Diseases.. . . 9

Little Economies .. $\quad$.. 10

Little Entertainments .. 10

Little French Dinners $\quad$. 9

Loyers' Guide 1s. (continued).

PAG E

Modern Card Manipulation 11

Modern Physical Culture.. 11

Nursery Wall Card.. .. 12

Our Foods and Drinks .. 9

Pearson's Gossipy Guides.. 13

Plain Needlework .. . . 9

Poultry-Keeping $\quad$.. $\quad$.. 18

Practice Strokes at Billiards 14

Rabbit Keeping $\quad$. $\quad$.. 7

Rosesand How to Grow Them 4

$\begin{array}{lllll}\text { Rowing } & \text {. } & \text {. } & \text {. } & 5\end{array}$

Rugby Football $\quad$. $\quad$.. 15

Small Gardens $\quad$. $\quad$. $\quad 4$

Small Homes.. $\quad$.. $\quad$.. 10

Speeches for all Occasions.. 17

$\begin{array}{lllll}\text { Swimming } \quad \ldots & \text {. } & \text {. } & 8\end{array}$

Table Tennis.. $\quad$.. $\quad$.. 16

Things a Woman Wants to

Knoy .. $\quad$.. $\quad$.. 10

Thousand Curious Things .. 17

Training for Athletics .. 3

What to Do in Emergencies 10

Woman's Chance of Mar-

$\begin{array}{lllll}\text { riage } & . & \ldots & \ldots & 16\end{array}$

Wood Carxing $\quad$. $\quad$.. 7 


\section{N D E X}

Acrostic Dictionary, 12

Adventures in Wallypugland, 5

Adventures of Captain Kettle, 8

After-Dinner Sleights, II

Alaric Spenceley, I5

Alexander in the Ark, 4

Alleged Haunting of B

Amateur Theatricals, II

Among Swamps and Giants, 3

Angling, 7

Art of Beauty, The, 9

Association Football, Io

At Pretoria, I5

Baker Minor and the Dragon, 6

Basket Making, I7

Beatrice Froyle's Crime, I7

Becky, I I

Ben Hur, 8

Bernicia, 3

Book of Indoor Games, 3

Boxing, 12

Boys' and Girls' Reciter, I4

Boys' Book of Battles, 4 " " Bravery, 4

Breakfast and Supper Dishes, 9

Captain Kettle, K.C.B., 8

Carnegie, Andrew, 3

Cinders, II

Cold Meat, I5

Conscience of Coralie, The, II

Consult the Oracle, 5

Cricket, ro

Crowning the King, 3

Cupid's Pupils: From Courtship to Honeymoon, 5

Dainty Dishes for Slender Incomes, 9

David Harum, I7

Devil and the Inventor, The, 6

Dinners of the Day, 14

Dog, The, 3

Domestic Ditties, 16

Drawing-Room Entertainer, 4

Dream Book, 12

Eldorado of the Ancients, I4

Emperor's Candlesticks, The, 12

Etiquette for Men, 5

Etiquette for Women, 5
Etiquette of Engagement and Marriage, 5

Every Woman her own Doctor, 5

Fables in Slang, 3

Fitzgerald, Life of Edward, 7

Fortune Teller, I2

Fortune Telling by Cards, 6

French's Cavalry Campaign, 11

From Franklin to Nansen, I6

Fun on the Billiard Table, 6

Further Adventures of Captain Kettle, 8

Gossipy Guides, I 3

Grimms' Fairy Tales, 9

Hands, and How to Read Them, 15

Hands in the Darkness, 7

Handwriting, 6

Harte, Bret, Life of, I4

Heads, and How to Read Them, 12

Healthy Home, A, 9

Heroes of the Nineteenth Century, 16

History of Henry Esmond, 9

Home Arts and Crafts, II

Home Arts Self-Teacher, II

Home Management, I3

Home Nursing, 9

Home Pets, 6

Household Hints, 9

How and What to Dance, ro

How Shall I Word It ? 8

How to Become an Author, 3

How to Keep House on $f_{2} 200$ a Year?

14

How to take Photographs, 8

Humorous Reciter, I3

Illustrated Scarlet Library, 8, 9

Incidental Bishop, The, 3

Indigestion, Io

Infectious Diseases, 9

In Pursuit of the Mad Mullah, II

In Search of the Wallypug, 6

In the Days of My Youth, 9

Irish Reciter, 13

Iron Cross, The, 16

Isobel Handbooks, 9, 10

John Halifax, 9 


\section{INDEX}

Key of the Holy House, The, 10

Kitchener, Lord, 7

Lady Jezebel, 8

Life's Counterpoint, I4

Little Economies, Io

Little Entertainments, Io

Little French Dinners, 9

Little Panjandrum's Dodo, 6

Little Red Captain, 8 .

Little Women, 9

Log of an.Island Wanderer, 12

Lovers' Guide, 5

Lovers' Dictionary, Io

Loyal Lover, A, 4

Lucky Bargee, 10

Mandarin's Kite, 6

Marquis of Valrose, The, 6

Men Who Have Made the Empire, 7

Mighty Deep, 7

Millionaire's Daughter, A, I7

Missing Prince, 5

Mistakes We Make, The, 5

Modern Billiards, I6

Modern Card Manipulation, II

Modern Conjurer, II

Modern Physical Culture, II

Mother's Guide, Io

Mord Em'ly, 16

More Fables in Slang, 3

My Dear Sir, 17

Mystery of the "Medea," The, I7

Nell Gwyn, Comedian, II

New Master, 7

New Panjandrum, 6

New Reciter, 13

Nursery Wall Card, I2

Our Antediluvian Ancestors, 12

Our Foods and Drinks, 9

Pauper Millionaire, The, 6

Phantom Army, The, I4

Pilgrim's Progress, The, 4, 8

Plain Needlework, 9

Poultry Keeping, I 8

Practice Strokes at Billiards, 14

Preacher's Daughter, 3

Prisons and Prisoners, 8

Private Life of the King, I5

- Private Life of Queen Victoria, The,
Professor Philanderpan, 6

Queen of the Jesters, I4

Rabbit Keeping, 7

Robinson Crusoe, 9

Romance of Modern Engineering, 18

Romance of Modern Invention, 18

Romance of Modern Locomotion, 18

Roses and How to Grow Them, 4

Rowing and Sculling, 5

Rugby Football, I5

Sack of Shakings, 4

St. George and the Chinese Dragon, I7

Scottish Reciter, I4

Senior Partner, 15

Siege of Kumassi, 8

Skipper's Wooing, ro

Small Gardens, 4

Small Homes, Io

Speeches for all Occasions, I7

Story of a Scout, The, 6

Struggle for Fame, I5

Sweetmeat Making, I5

Swimming, 8

Swiss Family Robinson, 9

Table Tennis, I6

Tandra, 15

Teller, The, 17

Terry, Ellen, and Her Sisters, 14

Things a Woman Wants to Know, ro

Things Every One Wants to Know, I7

Thousand Curious Things, 17

Thou Shalt Not-, I I

Three Women and Mr. Frank Cardwell, 16

Towards Pretoria, 15

Training for Athletics, 3

Uncle Tom's Cabin, 8

Wallypug in Fogland, 6

Wallypug in London, 5

Wallypug of Why, 5

War's Brighter Side, 15

Westward Ho, 9

What to do in Emergencies, ro

When the Birds Begin to Sing, 7

Wide, Wide World, 8

Woman of Death, The, 4

Woman's Chance of Marriage, A, 16

Wood Carving, 7

Woodstock, I6

UNWIN BROTHERS, LIMTED, THE GRESHAMI PRESS, WOKING AND LONDON 


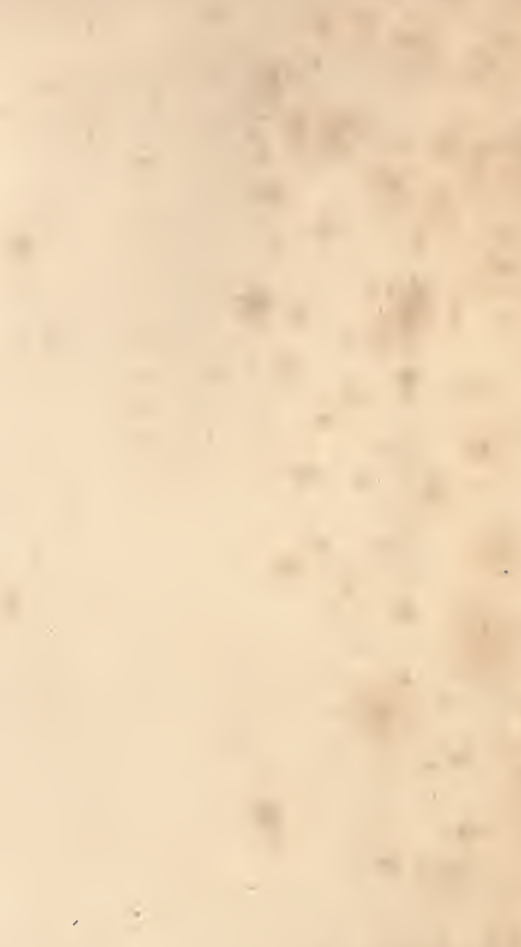


Thin horty" 


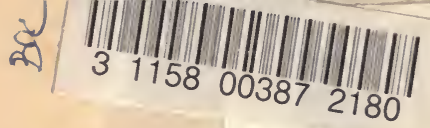

n! .

,

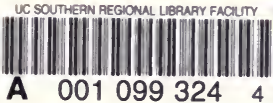


